\title{
Opportunities for Open Automated Demand Response in Wastewater Treatment Facilities in California - Phase II Report. San Luis Rey Wastewater Treatment Plant Case Study
}

Lisa Thompson, Alex Lekov, Aimee McKane, Mary Ann Piette Lawrence Berkeley National Laboratory 


\section{Acknowledgements}

This work described in this report was coordinated by the Demand Response Research Center and funded by the California Energy Commission (CEC), Public Interest Energy Research (PIER) Program, under Work for Others Contract No. 500-03-026 and by the U.S. Department of Energy under Contract No. DE-AC02-05CH11231.

The authors wish to thank Jim Filanc (Southern Contracting), Rudy Guzman (San Luis Rey Wastewater Treatment Plant), Anish Gautam and Chris Scruton (California Energy Commission), and Stephen Fok (PG\&E).

\section{DISCLAIMER}

This document was prepared as an account of work sponsored by the United States Government. While this document is believed to contain correct information, neither the United States Government nor any agency thereof, nor The Regents of the University of California, nor any of their employees, makes any warranty, express or implied, or assumes any legal responsibility for the accuracy, completeness, or usefulness of any information, apparatus, product, or process disclosed, or represents that its use would not infringe privately owned rights. Reference herein to any specific commercial product, process, or service by its trade name, trademark, manufacturer, or otherwise, does not necessarily constitute or imply its endorsement, recommendation, or favoring by the United States Government or any agency thereof, or The Regents of the University of California. The views and opinions of authors expressed herein do not necessarily state or reflect those of the United States Government or any agency thereof or The Regents of the University of California. 


\section{TABLE OF CONTENTS}

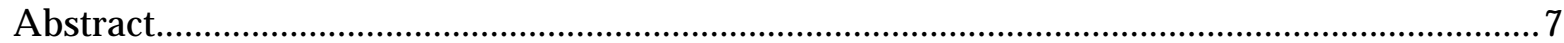

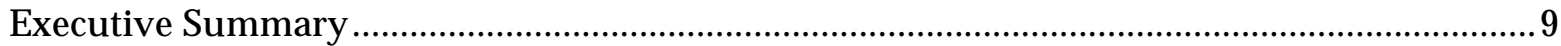

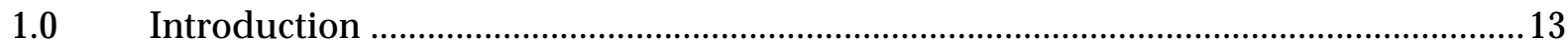

2.0 San Luis Rey Wastewater Treatment Plant ............................................................17

2.1. San Luis Rey Wastewater Treatment Plant Description .......................................17

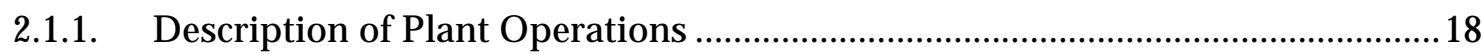

2.1.2. Wastewater Treatment Process........................................................................... 18

2.2. San Luis Rey Effluent Regulations ........................................................................2

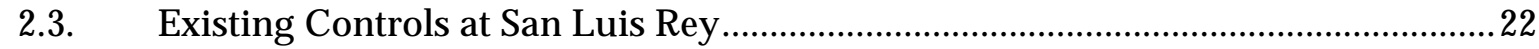

2.4. Load Management at the San Luis Rey Facility ...................................................23

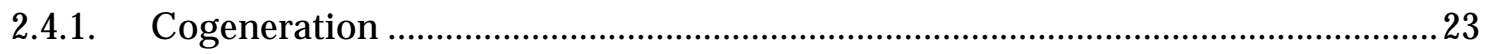

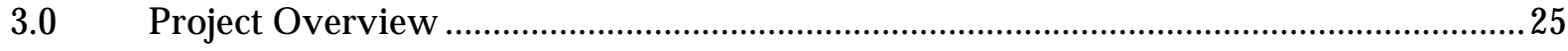

3.1. Key Equipment at San Luis Rey Wastewater Treatment Plant .............................25

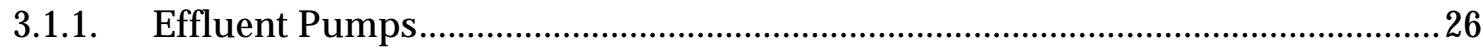

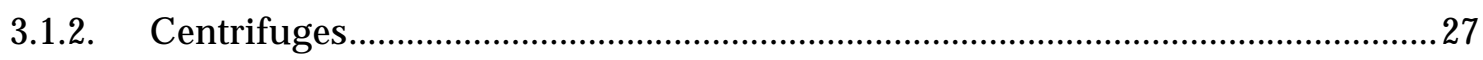

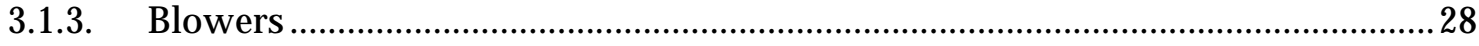

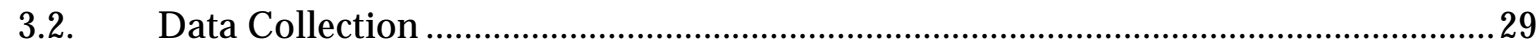

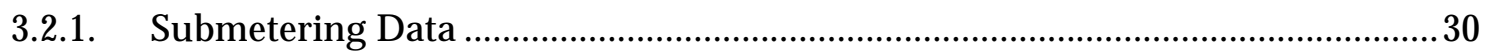

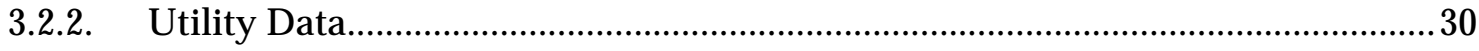

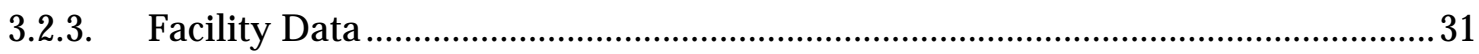

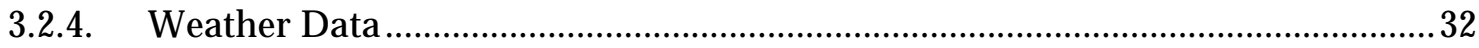

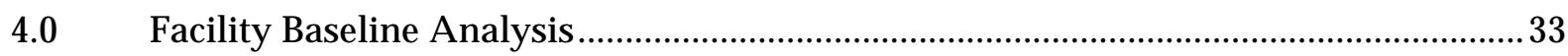

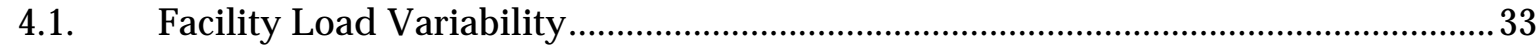

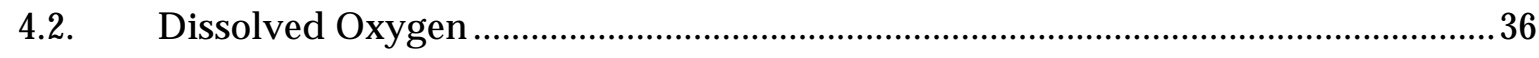

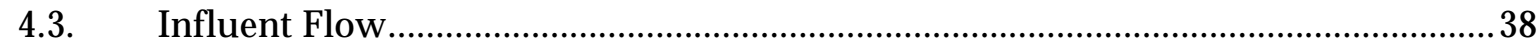

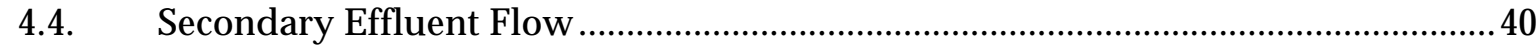

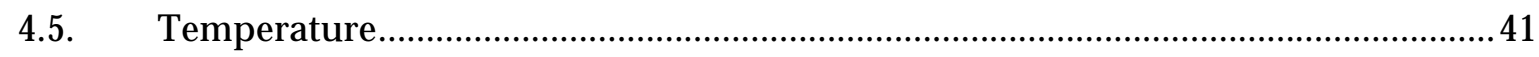

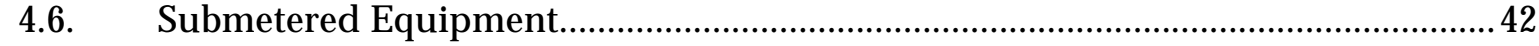

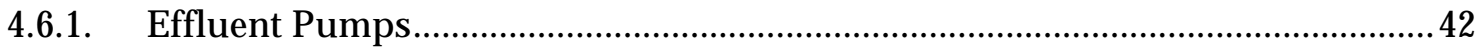

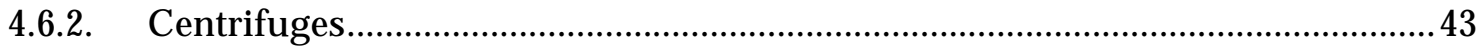

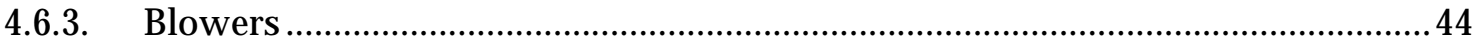

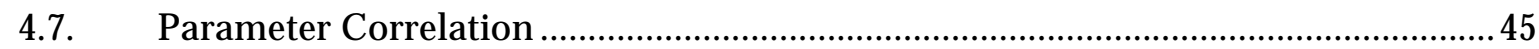

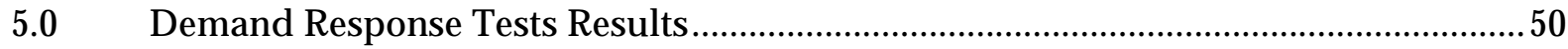

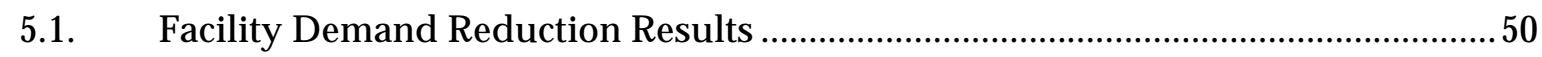

5.2. Equipment Demand Reduction Results..............................................................50

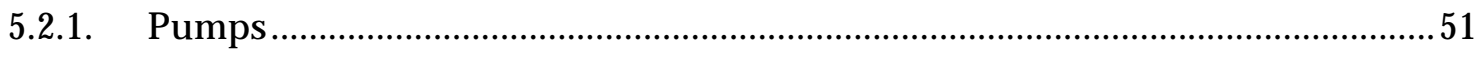

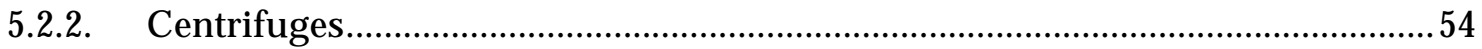

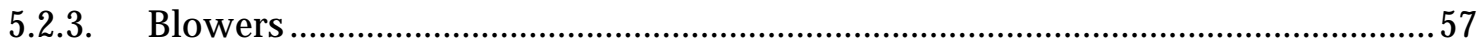


5.3. Discussion of Demand Response Tests.................................................................59

5.3.1. Facility Response to Demand Response Tests on Blowers ...............................59

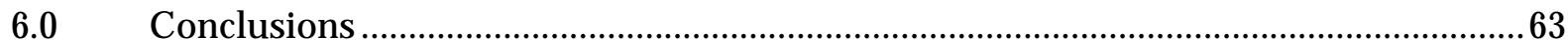

6.1. Demand Response Findings at the San Luis Rey Facility .....................................63

6.2. Limitations in Wastewater Treatment Facilities ..................................................63

6.3. Potential for Demand Response in Wastewater Treatment Facilities ....................64

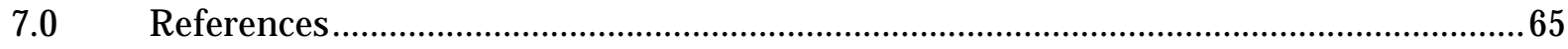

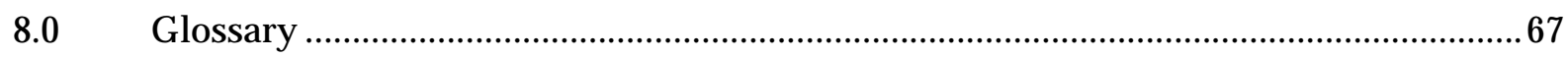

\section{List of Tables}

Table 1. San Luis Rey Effluent Regulations Based on Secondary Treatment ............... 21

Table 2. San Luis Rey Wastewater Treatment Plant Equipment Controls ................... 23

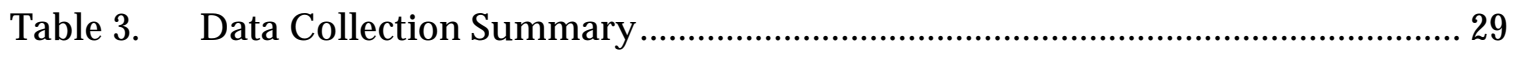

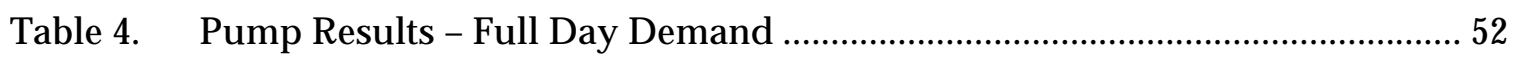

Table 5. Pump Results - Peak Period Demand …......................................................... 52

Table 6. Centrifuge Results - Full Day Demand, Weekday Tests ................................ 55

Table 7. Centrifuge Results - Peak Period Demand, Weekday Tests ............................ 55

Table 8. Centrifuge Results - Full Day Demand, Weekend Tests ................................ 56

Table 9. Blower Results - Full Day Demand.................................................................. 58

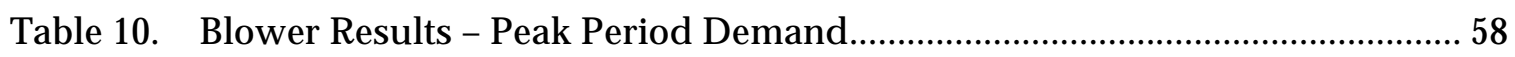

\section{List of Figures}

Figure 1. San Luis Rey Wastewater Treatment Plant ................................................... 18

Figure 2. San Luis Rey Technology Diagram .............................................................. 19

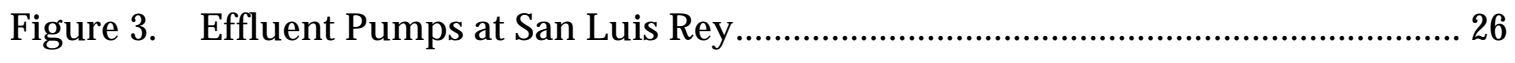

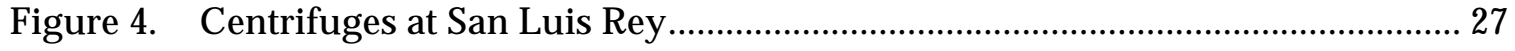

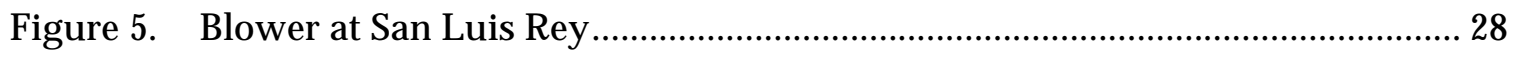

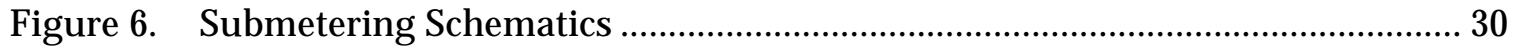

Figure 7. Placement of Dissolved Oxygen Sensors at San Luis Rey ............................. 31

Figure 8. 2009 San Luis Rey Facility Load Variability by Hour, No Cogeneration ........ 33

Figure 9. 2010 San Luis Rey Facility Load Variability by Hour (January-May), With Cogeneration. 
Figure 10. San Luis Rey Facility Load Variability by Hour - Summer 2009 (No Cogeneration) 35

Figure 11. San Luis Rey Facility Load Variability by Hour - Winter 2009 (No Cogeneration) 35

Figure 12. Daily Dissolved Oxygen Measurements - November 2009 ....................... 36

Figure 13. Daily Dissolved Oxygen Measurements - August 2009 …......................... 37

Figure 14. Dissolved Oxygen Measurements by Location ........................................... 38

Figure 15. San Luis Rey Daily Influent Flow in November 2009 ................................. 39

Figure 16. Daily Total Raw Influent Flow ................................................................. 39

Figure 17. San Luis Rey Daily Effluent Flow in November 2009 ................................. 40

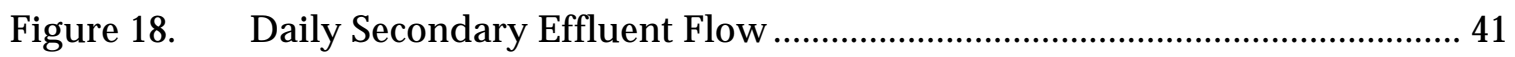

Figure 19. Temperature Parameters in November ..................................................... 42

Figure 20. Daily Temperature in November …........................................................ 42

Figure 21. Effluent Pump Load (kW), November 2009............................................... 43

Figure 22. Daily Effluent Pump Load (kW), November 2009 ..................................... 43

Figure 23. Centrifuge Load $(\mathrm{kW})$ in November 2009 .................................................... 44

Figure 24. Daily Centrifuge Load (kW) in November 2009 ......................................... 44

Figure 25. Blower Load $(\mathrm{kW})$ in November 2009 ........................................................ 45

Figure 26. Daily Blower Load $(\mathrm{kW})$ in November 2009 ….......................................... 45

Figure 27. Flow and Dissolved Oxygen Correlation - Summer .................................. 46

Figure 28. Flow and Dissolved Oxygen Correlation - Winter ..................................... 46

Figure 29. Temperature and Dissolved Oxygen Correlation - Summer ...................... 47

Figure 30. Temperature and Dissolved Oxygen Correlation - Winter ......................... 47

Figure 31. Temperature and Flow Correlation - Summer ........................................ 48

Figure 32. Temperature and Flow Correlation - Winter ............................................. 48

Figure 33. Blower Load and Dissolved Oxygen Correlation - Winter ........................ 49

Figure 34. Load Reduction at San Luis Rey During Normal Facility Operation ......... 50

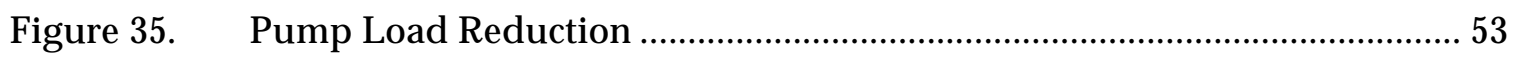

Figure 36. Facility Load Reduction from Pumps …....................................................... 53

Figure 37. Centrifuge Load Reduction, Weekday ….................................................. 56 
Figure 38. Centrifuge Load Reduction, Weekend ….................................................... 57

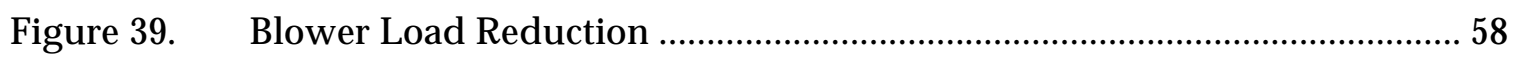

Figure 40. Facility Load Reduction from Blowers …................................................... 59

Figure 41. Dissolved Oxygen Response to Blower Demand Response Test - 10/7/2009 60

Figure 42. Turbidity Response to Blower Demand Response Test - 10/7/2009........ 61

Figure 43. Dissolved Oxygen Response to Blower Demand Response Test - 12/10/2009 62 


\begin{abstract}
This case study enhances the understanding of open automated demand response opportunities in municipal wastewater treatment facilities. The report summarizes the findings of a 100 day submetering project at the San Luis Rey Wastewater Treatment Plant, a municipal wastewater treatment facility in Oceanside, California. The report reveals that key energy-intensive equipment such as pumps and centrifuges can be targeted for large load reductions. Demand response tests on the effluent pumps resulted a $300 \mathrm{~kW}$ load reduction and tests on centrifuges resulted in a $40 \mathrm{~kW}$ load reduction. Although tests on the facility's blowers resulted in peak period load reductions of $78 \mathrm{~kW}$ sharp, short-lived increases in the turbidity of the wastewater effluent were experienced within 24 hours of the test. The results of these tests, which were conducted on blowers without variable speed drive capability, would not be acceptable and warrant further study.

This study finds that wastewater treatment facilities have significant open automated demand response potential. However, limiting factors to implementing demand response are the reaction of effluent turbidity to reduced aeration load, along with the cogeneration capabilities of municipal facilities, including existing power purchase agreements and utility receptiveness to purchasing electricity from cogeneration facilities.
\end{abstract}

Keywords: Open automated demand response, energy efficiency, controls, wastewater treatment facilities, demand response, field study 



\section{Executive Summary}

\section{Overview}

Since 2006, the Industrial Demand Response Team, which is part of the Demand Response Research Center (DRRC) at Lawrence Berkeley National Laboratory (LBNL), began researching and evaluating demand response (DR) opportunities in industrial facilities. First, the research team collected and analyzed data on recommended DR strategies included in utility integrated audits. Second, the team supported several California electric utilities and their contractors to identify potential Open Automated Demand Response (OpenADR) industrial participants and provided technical assistance in evaluating the DR sites. Third, the research team conducted indepth analyses of industrial sectors that appeared to have OpenADR potential and analyzed industrial DR technical capacity.

This report builds on ongoing DRRC research, development, demonstration, and deployment activities of the DRRC related to OpenADR. OpenADR is a set of continuous and open communication signals and systems provided over the Internet to allow facilities to automate their demand response with no "human in the loop." OpenADR is intended to standardize DR event information between DR service providers (utilities/Independent System Operators) and consumers (facilities/participants and aggregators).

In 2008, municipal wastewater treatment facilities were selected as a focus of LBNL's OpenADR research because these facilities are energy-intensive and have significant electricity demand during utility peak periods. Many wastewater treatment facilities have already implemented energy efficiency measures that can provide a base for participation in OpenADR programs and tariffs.

The first phase of LBNL's wastewater research resulted in the PIER Report, Opportunities for Energy Efficiency and Automated Demand Response in Wastewater Treatment in California. This report concluded that wastewater treatment facilities are excellent candidates for OpenADR. Energy efficiency and load management technologies already installed in many wastewater treatment facilities may enable successful participation in demand response events. Individual equipment controls and centralized control systems that are installed as part of the facility process controls or for energy efficiency and load management purposes may also provide the necessary conditions and allow the degree of control necessary to conduct demand response activities. Further, facility control systems are suitable for open automated demand response when they are integrated into centralized control systems. Facilities which have implemented energy efficiency measures and have centralized control systems may be able to shift or shed process loads in response to financial incentives, utility bill savings, and/or opportunities to enhance reliability of service. Control technologies installed for energy efficiency and load management purposes can often be adapted for OpenADR at little additional cost. These improved controls may prepare facilities to be more receptive to OpenADR due to both increased confidence in the opportunities for controlling energy cost/use and access to real-time data.

The second phase of this research puts these findings into practice at the San Luis Rey Wastewater Treatment Plant, to enhance the understanding of open automated demand 
response opportunities in wastewater treatment facilities. This report presents the results seen during this case study period of October 2, 2009 - January 10, 2010.

\section{Research Goals}

The goal of the DRRC industrial research is to facilitate deployment of industrial OpenADR that is economically attractive and technologically feasible. Such OpenADR can carry out load reduction activities using customized pre-programmed OpenADR strategies that can be activated upon receiving a DR event or price signal. It also can maximize load reduction savings while maintaining effluent quality to satisfy regulations. The goal in conducting this research is to provide policy makers, utilities, and facility management with the information necessary to design, retrofit, and operate energy efficient wastewater treatment facilities capable of participating in demand response events. Decisions concerning participation in OpenADR and load management require facility operators to acquire knowledge about the magnitude, time, and duration of their energy use. This leads to one of the team's research hypotheses, that facilities participating in energy efficiency programs will be more, not less, likely to initiate OpenADR and load management actions because they will have a more complete understanding of their energy use. This knowledge can assist a facility in evaluating:

- The potential benefits of energy efficiency and demand response.

- The limitations and risks of demand response depending on facility technologies, energyuse profile, and the characteristics of the wastewater.

- The types of technology installations or retrofits needed for energy efficiency and OpenADR.

- The impact of different strategies for demand response events.

- How specific facility equipment or systems would be controlled during a demand response event.

\section{Methods}

This report was developed upon completion of the 100 day submetering period from October 2, 2009 - January 10, 2010 at the San Luis Rey Wastewater Treatment Plant located in Oceanside, California. The energy usage and demand of key equipment at the treatment plant was submetered, including effluent pumps, blowers, and centrifuges. Additional data were collected from the facility and various data sources, including influent and secondary effluent flow, $\mathrm{pH}$, dissolved oxygen levels, temperature, humidity, and effluent turbidity. This report presents the findings of this data collection and analysis, and the results of manual demand response tests conducted on the major energy using equipment. These findings are augmented with insight from the San Luis Rey Plant's facility manager.

\section{Key Findings}

This study reveals that municipal wastewater treatment facilities are good candidates for open automated demand response. These facilities are highly energy-intensive and key equipment such as pumps and centrifuges can be targeted for large load reductions. This research has also revealed that demand response strategies for aeration blowers may result in a short-lived decline in secondary effluent quality in municipal facilities. 
The San Luis Rey facility typically draws between $900-1,100 \mathrm{~kW}$ from the grid, and utilizes an additional $600-700 \mathrm{~kW}$ produced by the cogeneration facility. The analysis also found that the effluent pump load at the facility remains constant at $300 \mathrm{~kW}$ during normal facility operations. The centrifuge load remains steady at $40 \mathrm{~kW}$ during operation, but this equipment is shut down over the weekends. The aeration blower load typically varies between 200 and $300 \mathrm{~kW}$.

Further, this study observed that this facility maintains a stable level of dissolved oxygen even as influent flow varies. This accomplished through the use of a modulating value which adjusts the amount of air reaching the basin. Further, a slight correlation was seen between the outdoor air temperature and dissolved oxygen levels at this facility. Lastly, a small correlation was seen between influent flow and outdoor temperature at this facility.

Demand response tests on the effluent pumps at the San Luis Rey facility revealed the potential for a $204 \mathrm{~kW}$ (36 percent of pump load) peak period load reduction, and a maximum load reduction of $300 \mathrm{~kW}$ during the test. Tests on centrifuges revealed a peak period load reduction of $10 \mathrm{~kW}$ (30 percent of centrifuge load), and a maximum load reduction of $40 \mathrm{~kW}$ during the test. While the demand response tests on facility blowers resulted in peak period load reductions of $78 \mathrm{~kW}$ (31 percent of blower load), the tests also resulted in short-lived decline in secondary effluent quality, and therefore, without further research, this measure should not be considered as a viable load reduction strategy.

Although the demand response tests at the facility were successful, the cogeneration capabilities at the San Luis Rey facility restrict the plant's demand response potential. Because the facility's cogeneration capacity is such a large proportion of the total load, the San Luis Rey facility may have limited options in terms of demand response measures, especially as the site continues to become more energy efficient. The utility requires that the facility always have a positive load draw from the cogeneration meter. That is, all the power generated by the cogeneration system must be utilized by the facility and the utility also requires additional power to be purchased from the grid.

In summary, municipal wastewater treatment energy demand in California is high, and energyintensive equipment offer significant potential for open automated demand response. In particular, large load reductions can be seen by targeting effluent pumps and centrifuges. Limiting factors to implementing demand response are the reaction of effluent turbidity to reduced aeration load, along with the cogeneration capabilities of municipal facilities, including existing power purchase agreements and utility receptiveness to purchasing electricity from cogeneration facilities.

\section{Next Steps and Future Research}

This research has identified opportunities for additional study that would build on the body of knowledge developed through LBNL's wastewater treatment research. Future work should consider the following:

1. Enhance understanding of the effect of aeration blower shutdown on secondary effluent quality.

2. Utilize the results of the Industrial Controls Survey and discussions with control experts to better understand existing controls capability in wastewater treatment facilities. 
3. Conduct further study to understand the prevalence of cogeneration in wastewater treatment facilities and its relationship to DR potential;

4. Continue to survey the literature for case studies and technology advances that might affect OpenADR potential.

5. Develop DR Quick Assessment Tool for wastewater treatment facilities building on office and retail tools. This would benefit wastewater treatment facility operators by providing them with the capability to assess facility performance within some range of performance criteria thus enhancing their capabilities to implement OpenADR.

6. Scaling and standardizing the OpenADR for control systems to apply to wastewater treatment facilities to reduce implementation cost, and increase DR reliability and effectiveness.

7. Improve understanding of how facility operations impact the effectiveness of DR strategies and identify the best operation practices and behaviors to enhance the impact of DR activities. 


\subsection{Introduction}

The first phase of LBNL's wastewater research resulted in the PIER Report, Opportunities for Energy Efficiency and Automated Demand Response in Wastewater Treatment in California. This report concluded that wastewater treatment facilities are excellent candidates for open automated demand response (OpenADR).

A key finding from this report is that energy efficiency and load management technologies already installed in many wastewater treatment facilities may enable successful participation in demand response events. Individual equipment controls and centralized control systems that are installed as part of the facility process controls or for energy efficiency and load management purposes may also provide the necessary conditions and allow the degree of control necessary to conduct demand response activities. Further, facility control systems are suitable for open automated demand response when they are integrated into centralized control systems. Facilities which have implemented energy efficiency measures and have centralized control systems may be able to shift or shed process loads in response to financial incentives, utility bill savings, and/or opportunities to enhance reliability of service. Control technologies installed for energy efficiency and load management purposes can often be adapted for OpenADR at little additional cost. These improved controls may prepare facilities to be more receptive to OpenADR due to both increased confidence in the opportunities for controlling energy cost/use and access to real-time data.

The second phase of this research puts these findings into practice in a submetering study at the San Luis Rey Wastewater Treatment Plant. Wastewater treatment facilities have the potential to benefit from the implementation of OpenADR and energy efficiency strategies. There have been few case studies of the implementation of demand response strategies in municipal wastewater treatment facilities. By submetering key facility equipment during the case study period of October 2, 2009 - January 10, 2010, this report seeks to fill this knowledge gap by analyzing how manual demand response tests effect facility load and key facility parameters.

\section{Open Automated Demand Response in Wastewater Treatment Facilities}

In 2001, wastewater treatment facilities in California consumed 2,012 GWh of electricity (California Energy Commission 2005). The California Energy Commission forecasted that energy use in wastewater treatment is likely to become significantly higher, given California's continued growth (California Energy Commission 2005). In the next 15 years, the EPA estimates that demand from water and wastewater facilities will increase by 20 percent due to increasing populations and more stringent regulations (Environmental Protection Agency 2008). Further, wastewater treatment plant energy demand is especially high during the summer months, particularly in areas with hot summers like Southern California(Natural Resources Defense Council 2004). The facility demand required to treat and transport wastewater is significant during the peak energy demand periods experienced by the electrical utilities (Natural Resources Defense Council 2004). This, combined with the characteristic energy-intensity of the wastewater treatment process, makes wastewater treatment facilities prime candidates for open automated demand response.

Demand response (DR) is a set of actions taken to reduce electric loads when contingencies, such as emergencies or congestion, occur that threaten supply-demand balance and/or market 
conditions occur that raise electric supply costs. DR programs and tariffs are designed to improve the reliability of the electric grid and to lower the use of electricity during peak times to reduce the total system costs (Flex your Power 2008) (Pacific Gas and Electric Company 2008). OpenADR is a set of standard, continuous, open communication signals and systems provided over the Internet to allow facilities to automate their demand response with no "human in the loop"(Piette 2009).

Implementing industrial OpenADR presents a number of challenges, both practical and perceived. Some of these include: the wide variation in loads and processes, resourcedependent loading patterns that are driven by outside factors such as time-critical processing, the perceived uncertainties associated with the control capabilities for implementing OpenADR strategies, and concerns about interrupting the scheduled processes and assuring product quality regulations.

Wastewater treatment facilities have the potential to benefit from the implementation of OpenADR and energy efficiency strategies. There have been few case studies of the implementation of demand response strategies in municipal wastewater treatment facilities. This report seeks to fill this knowledge gap by submetering key energy-intensive equipment in a municipal wastewater treatment plant, analyzing how manual demand response tests effect facility load and key wastewater parameters, and discussing the results and potential for OpenADR with the facility manager.

\section{Benefit to California}

This report focuses on energy efficiency and OpenADR applications within municipal wastewater treatment facilities because energy consumption in these facilities accounts for some of the largest electrical loads in municipal processes. In the United States, estimates for energy use in water and wastewater treatment range from 75,000 to 100,000 GWh annually (Consortium for Energy Efficiency 2006; Environmental Protection Agency 2008). Within California, water and wastewater treatment comprises 5 percent of total energy consumption (Fuller 2003). In the next 15 years, loads have been predicted to increase by 20 percent due to increasing populations and more stringent regulations (Environmental Protection Agency 2008). Pumps and aeration systems in wastewater treatment facilities contribute about 75 percent of the total energy use (Department of Environmental Protection Bureau of Land \& Water Quality 2002).

\section{Report Organization}

This section describes the context, rationale, potential, and benefit to California of implementing open automated demand response in wastewater treatment facilities.

Section 2, San Luis Rey Wastewater Treatment Plant, introduces the case study facility, their operations, regulations, treatment processes, controls, and existing load management opportunities.

Section 3, Project Overview, describes the submetering project methodology and key equipment operations and provides an overview of the data collection effort. 
Section 4, Facility Baseline Analysis, reviews the facility energy use and the baseline facility parameters measured, including dissolved oxygen, flow, temperature, and the submetered equipment.

Section 5, Demand Response Test Results, summarizes the results from the manual demand response tests.

Section 6, Conclusions and Recommendations, provides conclusions.

Section 7, References, lists references. 


\subsection{San Luis Rey Wastewater Treatment Plant}

The following section provides an introduction to the San Luis Rey Wastewater Treatment Plant. First, the San Luis Rey Wastewater Treatment Plant's operations are described. This section also provides an overview of the facility's wastewater treatment process, and details the effluent regulations the facility is required to meet. Finally, this section describes the cogeneration potential at the facility, along with current load management strategies and existing control systems.

\subsection{San Luis Rey Wastewater Treatment Plant Description}

The city of Oceanside's Water Utilities Department operates and manages over 500 miles of water lines that distribute water throughout the city, and maintains 12 water reservoirs with a capacity of 50.5 million gallons. The city obtains its water supply from the San Diego County Water Authority and groundwater from the Mission Basin. The city also reclaims wastewater at the San Luis Rey Wastewater Treatment Plant and uses it for irrigation.

All of the city's sewage is collected by the Wastewater Division and treated at two wastewater treatment plants, the San Luis Rey Wastewater Treatment Plant and the La Salina Wastewater Treatment Plant. The San Luis Rey facility serves areas east of I-5 and the La Salina facility serves all areas west of I-5, downtown, and along the coast.

This report focuses on the San Luis Rey facility. Two wastewater treatment process chains are operated within the San Luis Rey facility, termed Plant 1 and Plant 2 . The original wastewater treatment process chain, Plant 1, was built in 1970, and has a capacity of 10.7 million gallons of wastewater per day. Plant 2 was built in 2004 and has a capacity of 4.7 million gallons per day. Currently, the two process chains treat an average of 9.5 million gallons per day, with peak processing during wet weather reaching about 11.0 million gallons per day. The facility operates at an average electricity demand of $1.3 \mathrm{MW}$, with peak demand reaching $2 \mathrm{MW}$. Figure 1 shows an aerial view of the San Luis Rey facility. The location of the targeted energy-intensive equipment (see Section 3.1 below) that was submetered as part of this study is noted. 


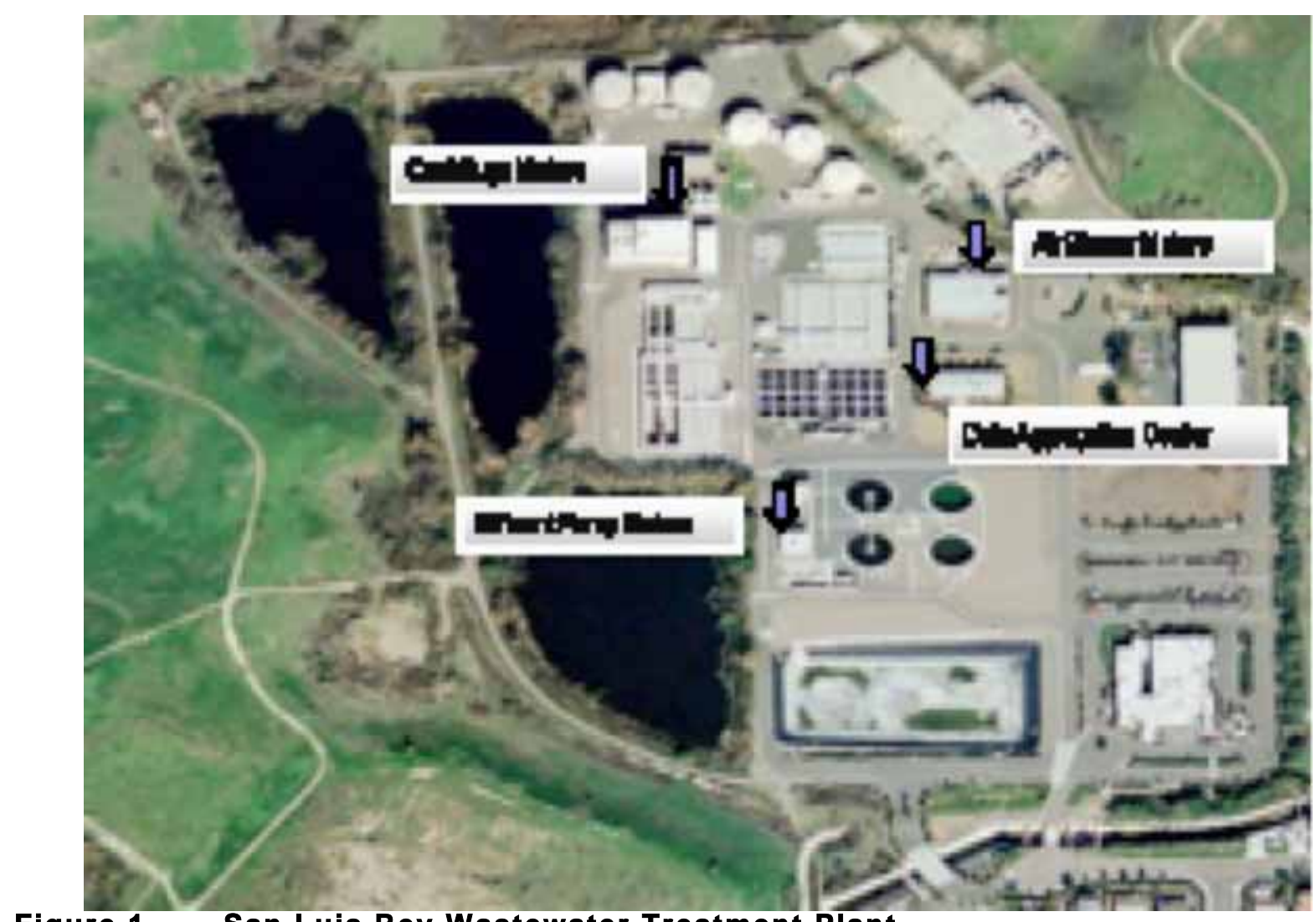

Figure 1. San Luis Rey Wastewater Treatment Plant

Image Source: Google

\subsubsection{Description of Plant Operations}

The San Luis Rey Wastewater Treatment Plant operates continuously, 24 hours per day, treating wastewater from the city of Oceanside and pumping treated wastewater effluent through the outfall line into the Pacific Ocean and to water reclamation facilities. Facility operators continuously monitor and maintain the facility's operations. The following section describes the technology chain of the wastewater treatment process at the San Luis Rey facility. Note that the description uses the term influent to describe wastewater which enters a process or area and the term effluent to describe wastewater which leaves a process or area.

\subsubsection{Wastewater Treatment Process}

Figure 2 shows a technology diagram of wastewater treatment in the facility. The shaded boxes in the figure show the plant components that include equipment submetered during the project period. 


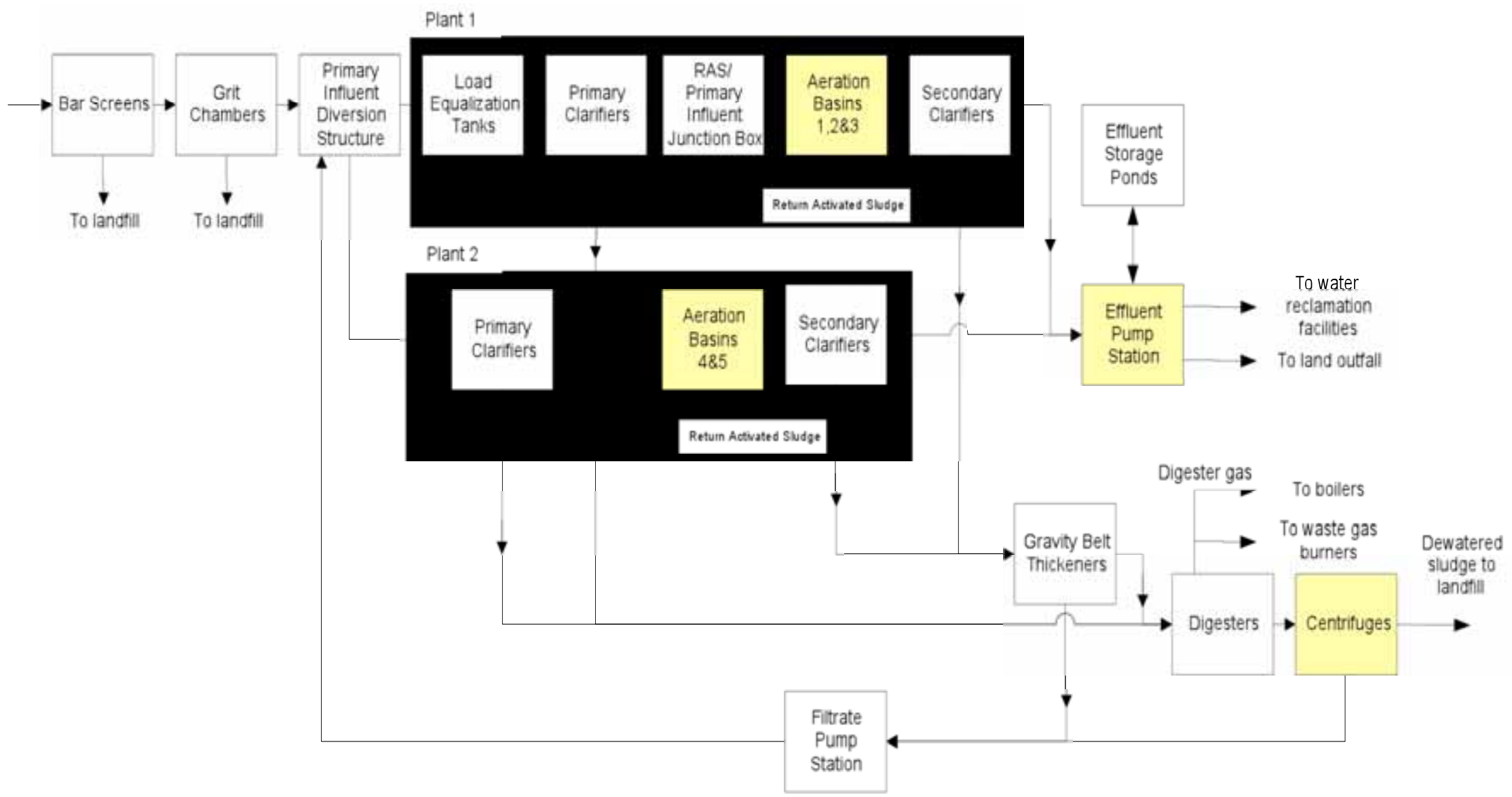

Figure 2. San Luis Rey Technology Diagram

*Submetered equipment is highlighted; the submetered blowers are located in Aeration Basins 1-5. 
The two major stages of wastewater treatment at San Luis Rey are primary and secondary treatment. Primary treatment allows solids to settle out while secondary treatment uses biological processes for further purification.

As part of the primary treatment at the San Luis Rey facility, the wastewater influent first passes through bar screens which remove large solid objects such as rags and sticks. The influent then passes through grit chambers where cinders, sand and small stones are settled out. The removal of these solids prevent the grit from wearing out the pumps and filling the downstream tanks later in the process (New Mexico Environment Department 2007).

The influent then flows into the primary diversion structure where it is divided between the two process chains, Plant 1 and Plant 2, shown in Figure 2, where it undergoes secondary treatment. Throughout the rest of this report, Plant 1 and Plant 2 are considered as one technology path and are not further distinguished.

Influent first enters load equalization tanks to prevent large surges of wastewater from disrupting treatment processes. Wastewater treatment operations run more efficiently and smoothly when influent flow is near constant. These load equalization tanks have a capacity of 2 million gallons which prevents large surges of wastewater entering the process chain. In the primary clarifiers, solids are further settled out of the influent, and oil and grease are skimmed off the water surface. Next, the wastewater enters aeration basins where microorganisms break down organic material. This process increases the biological oxygen demand in the wastewater, and therefore, dissolved oxygen levels decrease. The wastewater is aerated to maintain dissolved oxygen levels so the microorganisms can perform this process.

Next, in the secondary clarifiers, solids and liquids are separated. The thickened sludge resulting from secondary clarification is returned back to the aeration basins as Return Activated Sludge (RAS). This maintains a specific solids/microorganisms concentration in the effluent (Mines 2009).

After secondary clarification, effluent is discharged via effluent pumps to the ocean, water reclamation facilities, or land outfall, or it is stored in effluent storage ponds and pumped out of the facility at a later time. The effluent storage ponds at the San Luis Rey facility have a capacity of 10 to 15 million gallons, which could store over a full day of treated wastewater from the plant.

The sludge from the secondary clarifiers enters sludge treatment, which uses gravity belt thickeners to thicken the sludge before it is sent to holding tanks. Polymers are often added at this stage in order to improve sludge separation. There are four anaerobic digesters at the facility, which break down the organic portion of the sludge so the non-organic solids can be disposed of in landfills or used as fertilizers (Global Energy Partners LLC 2007). A byproduct of anaerobic digestion is biogas which contains 50-70 percent methane, 30-45 percent carbon dioxide, and water vapor (Global Energy Partners LLC 2007). The San Luis Rey Wastewater Treatment Plant collects this biogas and uses it in the cogeneration unit, described further in Section 2.4.1.

Next, the centrifuges separate out the sludge before the water can be recycled through the system again. The San Luis Rey facility shuts down its centrifuge system every Friday afternoon 
until Monday mornings. It is turned off because no solid waste shipments occur during the weekend. The solids separated in the centrifuge are transported to a landfill via truck, with an average of 1.5 trips taken per day. Additional wastewater that is removed from the sludge is rerouted back through the entire treatment process via the filtrate pump station.

\subsection{San Luis Rey Effluent Regulations}

Municipal wastewater treatment facilities are responsible for carrying out inspection, surveillance, and monitoring procedures to ensure wastewater is in compliance with the conditions of federal or state permits (Environmental Protection Agency 2004). Federal and local permits typically regulate conventional pollutants such as biological oxygen demand, suspended solids, fecal coliform, $\mathrm{pH}$, oil, and grease (Environmental Protection Agency 2002). Total dissolved solids, nitrogen, phosphorus, heavy metals, and organics are also important measures of the wastewater quality and are used in establishing wastewater effluent regulations.

The San Luis Rey Wastewater Treatment Plant processes wastewater effluent to treatment standards set by the U.S. EPA through a National Pollutant Discharge Elimination System (NPDES) permit. Table 1 lists the key wastewater constituents monitored by the San Luis Rey facility. Detailed effluent regulations for the facility are presented in Appendix A.

The secondary effluent parameters the San Luis Rey facility is most concerned with when treating wastewater are Biological Oxygen Demand (BOD) and Total Suspended Solids (TSS). The facility manager also listed $\mathrm{pH}$ as an important parameter, but noted that the facility never comes close to violating the $\mathrm{pH}$ range regulation. These key parameters are further described below.

Table 1. San Luis Rey Effluent Regulations Based on Secondary Treatment

\begin{tabular}{|c|c|c|c|c|c|}
\hline \multirow[t]{3}{*}{ Constituent } & \multirow[t]{3}{*}{ Units } & \multicolumn{4}{|c|}{ Effluent Limitations } \\
\hline & & \multirow{2}{*}{$\begin{array}{l}\text { Average } \\
\text { Monthly }\end{array}$} & \multirow{2}{*}{$\begin{array}{l}\text { Average } \\
\text { Weekly }\end{array}$} & \multicolumn{2}{|c|}{ Instantaneous } \\
\hline & & & & Min & Max \\
\hline \multirow[t]{3}{*}{ BOD 5-day $20^{\circ} \mathrm{C}$} & $\mathrm{mg} / \mathrm{l}$ & 25 & 40 & & \\
\hline & Ibs/day & $4.4 \mathrm{E}+3$ & $7.0 \mathrm{E}+3$ & & \\
\hline & $\%$ & \multicolumn{4}{|c|}{$\begin{array}{l}\text { The average monthly percent removal shall not be less than } \\
\qquad 85 \text { percent. }\end{array}$} \\
\hline \multirow{3}{*}{$\begin{array}{l}\text { Total Suspended } \\
\text { Solids }\end{array}$} & $\mathrm{mg} / \mathrm{l}$ & 30 & 45 & & \\
\hline & Ibs/day & $5.2 E+3$ & $7.8 \mathrm{E}+3$ & & \\
\hline & $\%$ & \multicolumn{4}{|c|}{$\begin{array}{l}\text { The average monthly percent removal shall not be less than } \\
\qquad 85 \text { percent. }\end{array}$} \\
\hline $\mathrm{pH}$ & $\begin{array}{l}\text { Standard } \\
\text { Units }\end{array}$ & & & 6.0 & 9.0 \\
\hline
\end{tabular}

BOD is an estimate of the amount of oxygen required for the decomposition of organic matter under aerobic conditions. When large amounts of organic matter are present, the decomposition process consumes oxygen and reduces the amount available for aquatic animals. This number is 
determined by measuring the depletion of dissolved oxygen (DO) over a period of 5 days and is reported as 5-day $\mathrm{BOD}$ or $\mathrm{BOD}_{5}$. $\mathrm{DO}$ indicates the amount of oxygen present in water, and is necessary for microorganisms to breakdown organic material present in the water. DO concentrations vary daily and seasonally and tend to be lower during summer months because biochemical reactions use more oxygen in higher temperatures (Metcalf \& Eddy Inc. 2003).

TSS are particles that cannot be collected by a filter and that remain suspended in the wastewater even after treatment (Massachusetts Water Resources Authority 2007). These solid pollutants may come from urban runoff and agricultural land, industrial wastes, bank erosion, bottom feeders, and algae growth (North Dakota Department of Health 2005). Lastly, pH levels are a measure of the effluent's acidity or basicity. Large fluctuations in $\mathrm{pH}$ levels have been shown to have adverse effect on marine life (Massachusetts Water Resources Authority 2007).

\subsection{Existing Controls at San Luis Rey}

The San Luis Rey Wastewater Treatment Plant has a Supervisory Control and Data Acquisition (SCADA) system which is capable of controlling all equipment in the facility. Extensive use of the SCADA system was implemented in 2004 when Plant 2 was commissioned. The facility is also equipped with twelve programmable logic controls (PLCs), which are connected to the existing SCADA system.

PLCs are electronic devices located close to facility equipment and are capable of independently maintaining certain field conditions. A basic PLC contains a central processing unit and input/output sensors. The PLC interprets and implements software instructions, performs calculations and comparisons, makes logical decisions, and allows for communication within the system (Kogge 2008). PLCs are used to automate monitoring and control and cause logical procedures to be executed when certain field conditions are met (Communication Technologies Inc. 2004).

The San Luis Rey facility's SCADA system is located in the facility operations room, seen in Figure 1, and monitors critical operations and process loops. The data manager in the server room collects data from all PLCs and forwards information to the SCADA system for real-time data. The SCADA system can also be monitored remotely through a web-based interface. The Human Machine Interface is an Intellution System hosted within an on-site server located in the facility IT server room. The Intellution software allows facility operators to track and manage plant operations.

Table 2 lists the systems partially or fully controlled by SCADA at the San Luis Rey facility. 
Table 2. San Luis Rey Wastewater Treatment Plant Equipment Controls

\begin{tabular}{|l|c|}
\hline \multicolumn{1}{|c|}{ Equipment } & $\begin{array}{c}\text { Fully or partially } \\
\text { controlled by SCADA }\end{array}$ \\
\hline Grit Removal & Fully \\
\hline Aeration basins & Fully \\
\hline Sludge Pumps & Fully \\
\hline Gravity Belt Thickener & Fully \\
\hline Centrifuges & Fully \\
\hline Waste Gas Burners & Fully \\
\hline Cogeneration & Fully \\
\hline Digesters & Fully/Partially \\
\hline Influent flows & Partially \\
\hline Head Works & Partially \\
\hline Flow Equalization & Partially \\
\hline Secondary Clarification & Partially \\
\hline Blowers & Partially \\
\hline Tank Levels & Partially \\
\hline Reclaimed Water & Partially \\
\hline Scrubbers & Partially \\
\hline
\end{tabular}

Noted above, the digesters have a mix of partial and full control, with partial defined as monitoring only and full defined as monitoring and PLC-controlled feedback/control. Digesters 1, 2, and 3, built in 1970, are partially controlled by the SCADA system. Digester 4, built in 2004, is fully controlled by the SCADA system.

The SCADA system provides real-time control. It can be programmed with set points for key facility parameters and code can be written for the facility to automatically meet these set points. From the technical perspective, the facility is equipped to host Web Services (XML) and is capable of being fully automated for OpenADR.

\subsection{Load Management at the San Luis Rey Facility}

\subsubsection{Cogeneration}

In December 2009, the San Luis Ray facility installed generators capable of producing $730 \mathrm{~kW}$ of on-site generated energy. The engines are designed to run on either natural gas or digester gas. The digester gas is the byproduct of the anaerobic digestion of solids removed during wastewater treatment, and in most cases consists of about 65 percent methane. Waste heat from the engines is used to warm-up the anaerobic digesters. The San Luis Ray facility uses the cogeneration capabilities for daily peak load management to avoid demand charges and to minimize electrical purchases from the grid.

The cogeneration facility is owned and operated by CalPower. The San Luis Rey facility supplies CalPower will all the digester gas produced from anaerobic digestion at no cost. CalPower, in turn, supplies electricity to the facility at a fixed rate which is lower than SDG\&E's rate. When the San Luis Rey facility's digester flow drops below 150 standard cubic feet per 
minute, they supplement the digester gas provided to CalPower with natural gas. The maximum amount of natural gas that can be used to supplement digester gas as fuel is 25 percent. CalPower also recovers heat from the digesters to pre-heat the process water feeding the boiler system. The boiler water backs up the cogeneration hot water loop to assure proper digester operation.

CalPower requires that the cogeneration plant produce a minimum of $560 \mathrm{~kW}$ and have a balance supplied by SDG\&E. The cogeneration plant line is tied directly back to the SDG\&E transformer, which supplements the power produced by the cogeneration. The agreement with SDG\&E does not allow the facility to sell power back to the grid. As a result, the San Luis Rey facility must have a positive demand on the meter, regardless of the amount of electricity generated by the cogeneration unit. Because of this, the facility has very little flexibility with what equipment can be shut down, as they often do not draw much energy from the utility. On the meter that is coordinated with the cogeneration power production, the facility often draws only $300 \mathrm{~kW}$ from the grid.

The facility's energy demand was often lower than what could be provided by the cogeneration unit, so after the cogeneration plant was commissioned, the two main transformers (connected to SDG\&E meters) were configured to redistribute the load to balance plant operations. Transformer \#2, which is coordinated with the cogeneration system, now has the capacity to supply $600 \mathrm{~kW}$ to 1,000 $\mathrm{kW}$ from the grid. However, most of this demand is supplied by the cogeneration system. Single line diagrams for both process chains at the San Luis Rey facility are shown in Appendix B, describing the electrical connection of the major systems and how power is distributed through the four SDG\&E meters.

Because the facility's cogeneration capacity is so large, the San Luis Rey facility may have limited options for demand response measures, especially as the site continues to become more energy efficient. The utility requires that the facility always have a positive load draw from the cogeneration meter. That is, all the power generated by the cogeneration system must be utilized by the facility and the utility also requires additional power to be purchased from the grid. Therefore, all new equipment is placed on the cogeneration meter, including the submetered pumps and centrifuges, to increase the load draw from that meter. Further investigation concerning how representative this arrangement is of California municipal wastewater treatment facilities is needed.

The facility is extremely cautious about the equipment operation on the cogeneration meter, ensuring that the facility load never drops below the power being produced in the cogeneration unit. This further limits the potential for demand response, because most load reduction potential is from equipment on the cogeneration meter. 


\subsection{Project Overview}

This section provides an overview of the submetering project. First, the key equipment at the San Luis Rey Wastewater Treatment Plant that was submetered is described. Then the technology used for the submetering project is outlined, along with the measuring methodology that was used.

\subsection{Key Equipment at San Luis Rey Wastewater Treatment Plant} Energy efficiency and OpenADR strategies which target highly energy-intensive equipment will produce the greatest energy and demand savings. Aeration and pumping systems are often large energy users; however, other equipment also has a high electricity demand. In many wastewater treatment facilities, the main equipment end users of electricity are aeration, wastewater pumping, dissolved air flotation, anaerobic digestion, trickling filters, and lighting (Energy Conservation Task Force of the Water Environment Federation 1997).

The key equipment at the San Luis Rey facility submetered during the project period was the three effluent pumps, two centrifuges, and two blowers, which account for on average 45 percent of the total facility electricity demand. This section describes the typical operation of this equipment. 


\subsubsection{Effluent Pumps}

The San Luis Rey Wastewater Treatment Plant is outfitted with three effluent pumps, shown in Figure 3. During normal facility operation, the facility runs two of the three pumps, with the third serving as emergency backup. Backup service is rotated among the three motors.

As depicted in Figure 2, these pumps are used to pump treated wastewater effluent from the secondary clarifiers to water reclamation facilities or out to the Pacific Ocean.

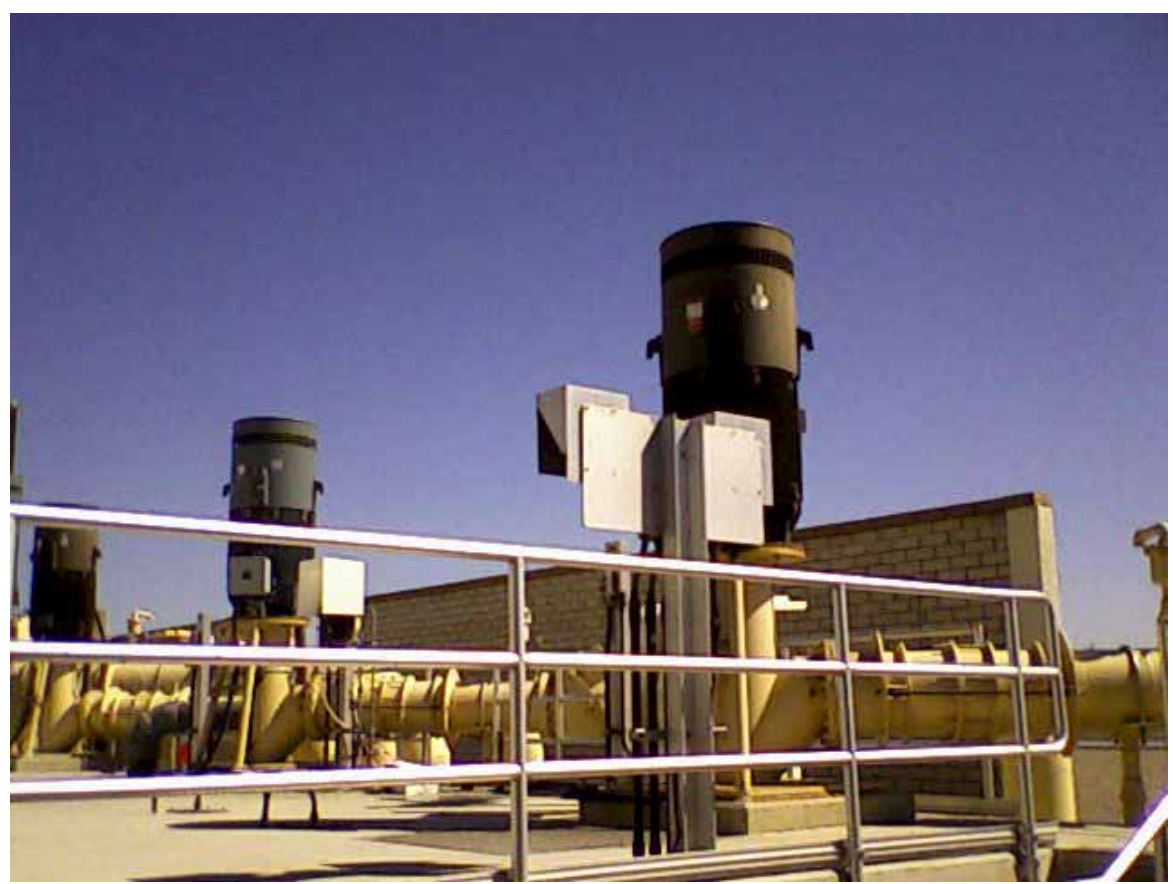

Figure 3. Effluent Pumps at San Luis Rey 


\subsubsection{Centrifuges}

The centrifuge system at the San Luis Rey Wastewater Treatment Plant receives wastewater from the digesters, and separates out the treated solids from the wastewater effluent downstream of the digesters. The treated solids are transported via trucks to a landfill. Each Friday afternoon the centrifuge operation is shut down until Monday morning because no solid waste shipments occur during the weekend. The centrifuge system is seen in Figure 4 . There are two centrifuges at the facility, and only one centrifuge runs during normal plant operation. The second unit serves as an emergency backup, and backup service rotates between the two centrifuges. Centrifuge operation is also rotated to allow for maintenance.

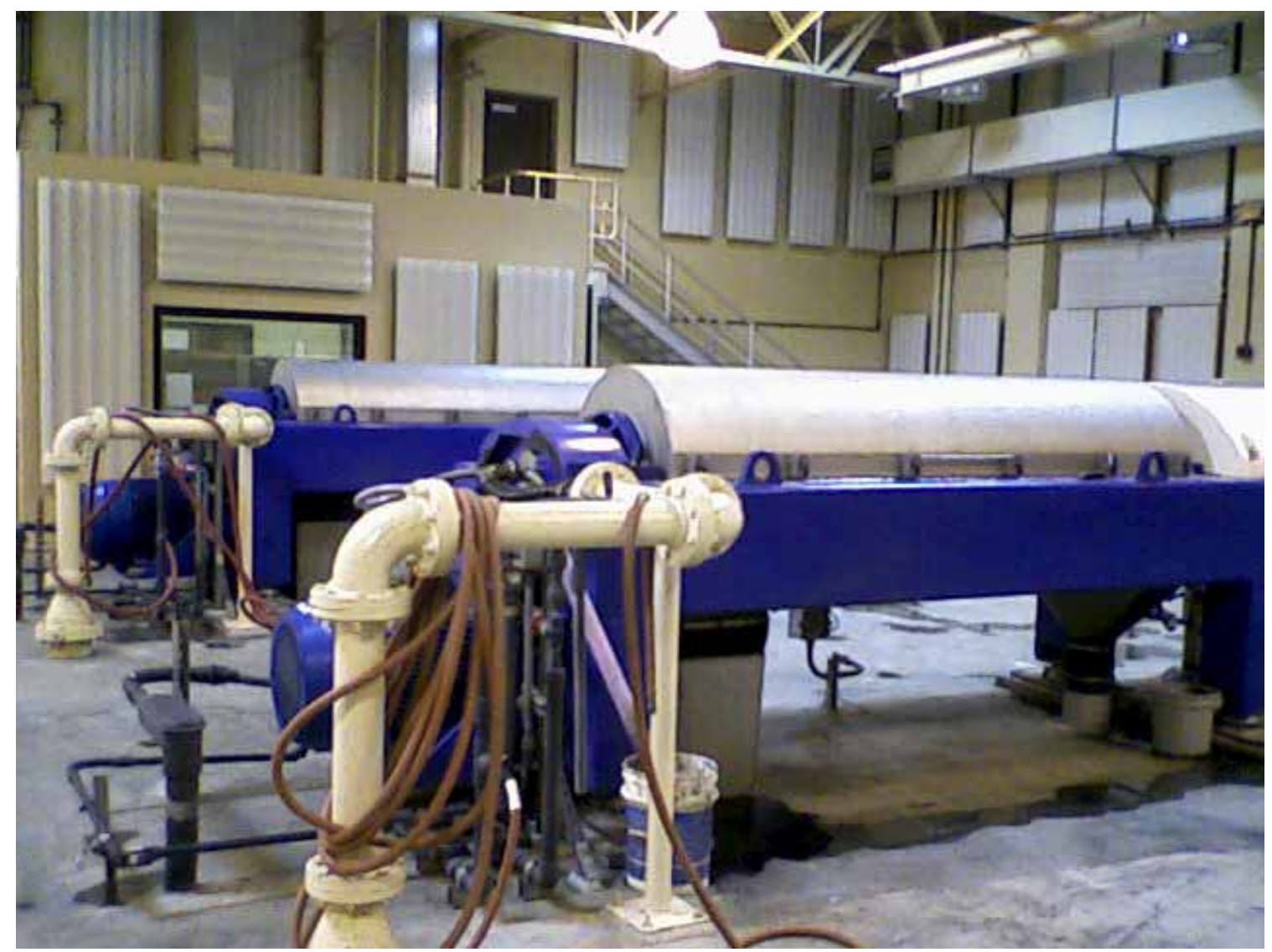

Figure 4. Centrifuges at San Luis Rey 


\subsubsection{Blowers}

The blowers at the San Luis Rey Wastewater Treatment Plant are used in the aeration basins, shown in Figure 5. There are two blowers at the facility, which maintain a specified level of dissolved oxygen in the wastewater effluent. The San Luis Rey facility uses mostly fine bubble diffusers in the aeration basins. Only one blower runs during normal plant operation. The second unit serves as an emergency backup, and backup service rotates between the two blowers. The blowers are also rotated to allow for maintenance. The air flow delivered by the blowers is regulated by modulating valves, located at each of the five aeration basins.

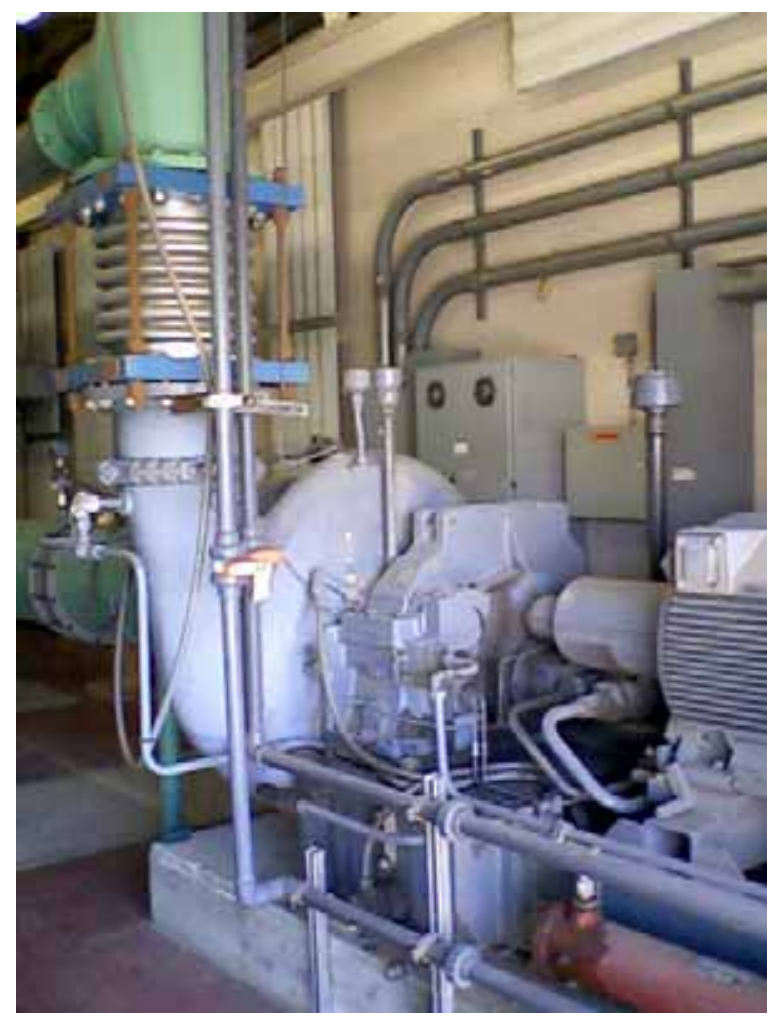

Figure 5. Blower at San Luis Rey 


\subsection{Data Collection}

The following section describes in detail how each type of data was collected for this project. The data collection types could be grouped in four categories: end-use submetering, total facility energy demand data from the utility meters, data from the facility SCADA system, and weather data. Table 3 provides a complete summary of the data gathered.

Table 3. Data Collection Summary

\begin{tabular}{|c|c|}
\hline Submetering & $\begin{array}{l}\text { Centrifuge 1, kW } \\
\text { Centrifuge 2, kW } \\
\text { Effluent Pump 1, kW } \\
\text { Effluent Pump 2, kW } \\
\text { Effluent Pump 3, kW } \\
\text { Blower 1, kW } \\
\text { Blower 2, kW }\end{array}$ \\
\hline Utility & Total Facility Load, kW \\
\hline Facility Data & $\begin{array}{l}\text { Dissolved Oxygen (10 locations), mg/l } \\
\text { Influent Flow - Mesa Garrison, mil gal/15 minutes } \\
\text { Influent Flow - Mission, mil gal/15 minutes } \\
\text { Influent Flow - North Valley, mil gal/15 minutes } \\
\text { Total Raw Influent Flow, mil gal/15 minutes } \\
\text { Plant } 1 \text { Influent Flow, mil gal/15 minutes } \\
\text { Plant } 2 \text { Influent Flow, mil gal/15 minutes } \\
\text { Secondary Effluent Flow, mil gal/15 minutes } \\
\text { Plant } 1 \text { Effluent Turbidity, NTU } \\
\text { Combined Effluent Turbidity, NTU } \\
\text { Influent Temp, }{ }^{\circ} \mathrm{F} \\
\text { Influent pH }\end{array}$ \\
\hline Weather & $\begin{array}{l}\text { Dry-bulb Outdoor Temperature, }{ }^{\circ} \mathrm{F} \\
\text { Relative Humidity, \% } \\
\text { Dew Point, }{ }^{\circ} \mathrm{F}\end{array}$ \\
\hline
\end{tabular}

The following section outlines the data collection methods for each type of data used in this report. 


\subsubsection{Submetering Data}

A submetering system was installed using equipment supplied by Energy ICT. The equipment measures the demand and energy use of the following systems: three effluent pumps, two centrifuges, and two blowers. Further information about the Energy ICT system can be found in Appendix C.

The schematics in Figure 6 describe the seven total motors that were submetered. The submetered data were stored on a data concentrator unit (Web Z2), which was housed in the main plant control room. These data were polled every two hours and transferred through the Internet to a remote database hosted by Energy ICT. The submetered data were collected and reported at 5 minute intervals throughout the project period.
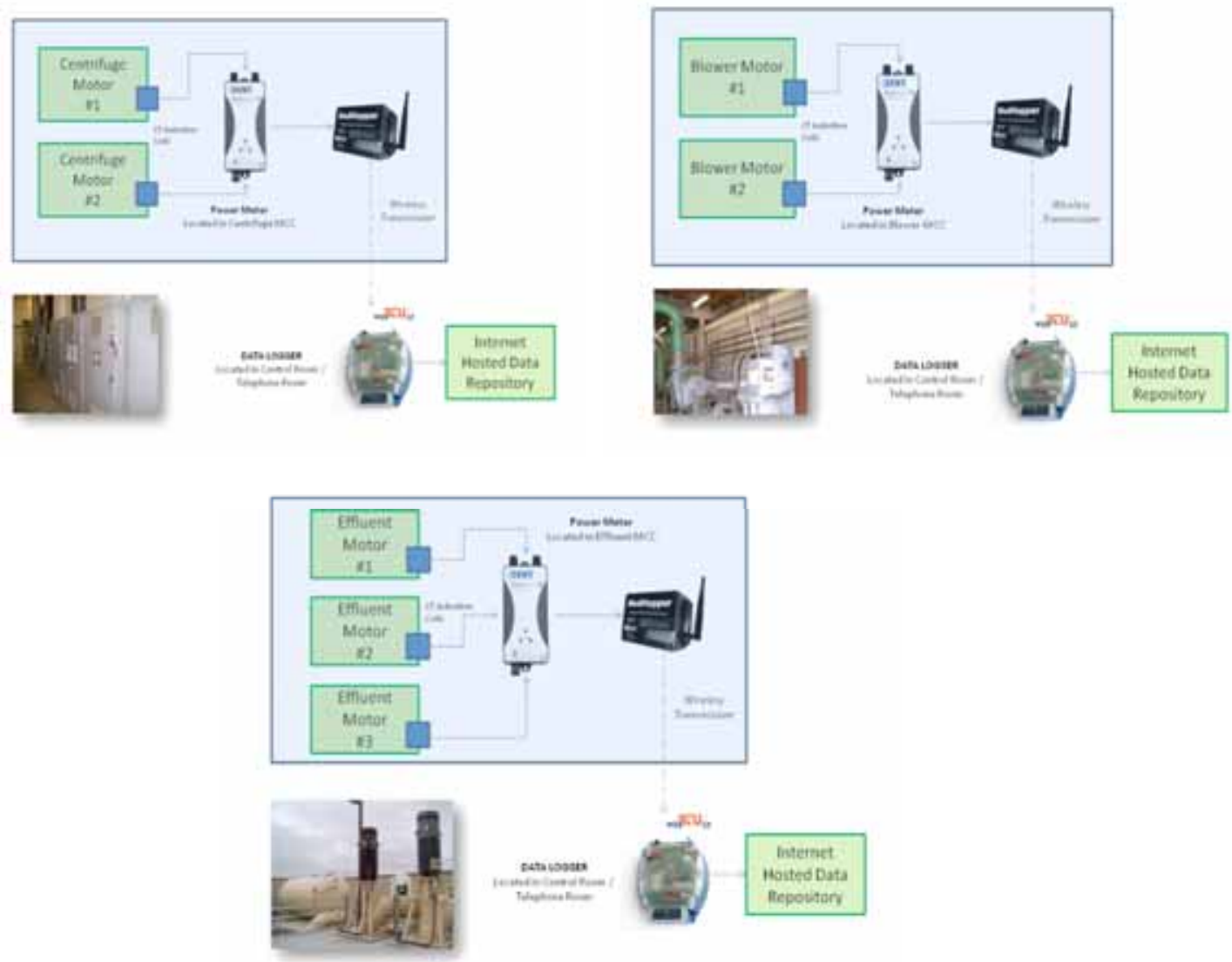

\section{Figure 6. Submetering Schematics}

\subsubsection{Utility Data}

Utility data were collected directly from SDG\&E. SDG\&E reports energy use data for each of the facility's four meters at 15 minute intervals. The 15 minute energy use data were used to determine an average load for each 15 minute interval during the project period. 
The San Luis Rey facility has four main SDG\&E meters. The major equipment each meter serves is listed below.

1. Meter \# 1, termed Old Effluent Meter, serves Headworks; Plant 1 Primary \& Secondary Clarifiers; Gravity Belt Thickener, and Digesters 1-3.

2. Meter \# 2, termed Blowers Meter, serves Blowers

3. Meter \# 3, termed New Effluent Meter, serves Plant 2 Primary \& Secondary Clarifiers, Secondary Effluent Pump Station, and one Centrifuge

4. Meter \# 4, termed Centrifuge Meter, serves Plant 2 Primary \& Secondary Clarifiers, Secondary Effluent Pump Station, Digester 4, and one Centrifuge

\subsubsection{Facility Data}

Facility data such as influent flow, dissolved oxygen levels in each basin, turbidity, and influent $\mathrm{pH}$ were collected during the project period. The San Luis Rey facility collects these data for its operations, and provided these parameter reports weekly. These data were reported in 15 minute intervals.

Figure 7 shows the placement of the dissolved oxygen sensors at the facility. 10 dissolved oxygen probes were placed in the facility's five aeration basins, one in the middle of each basin, and one at the end.
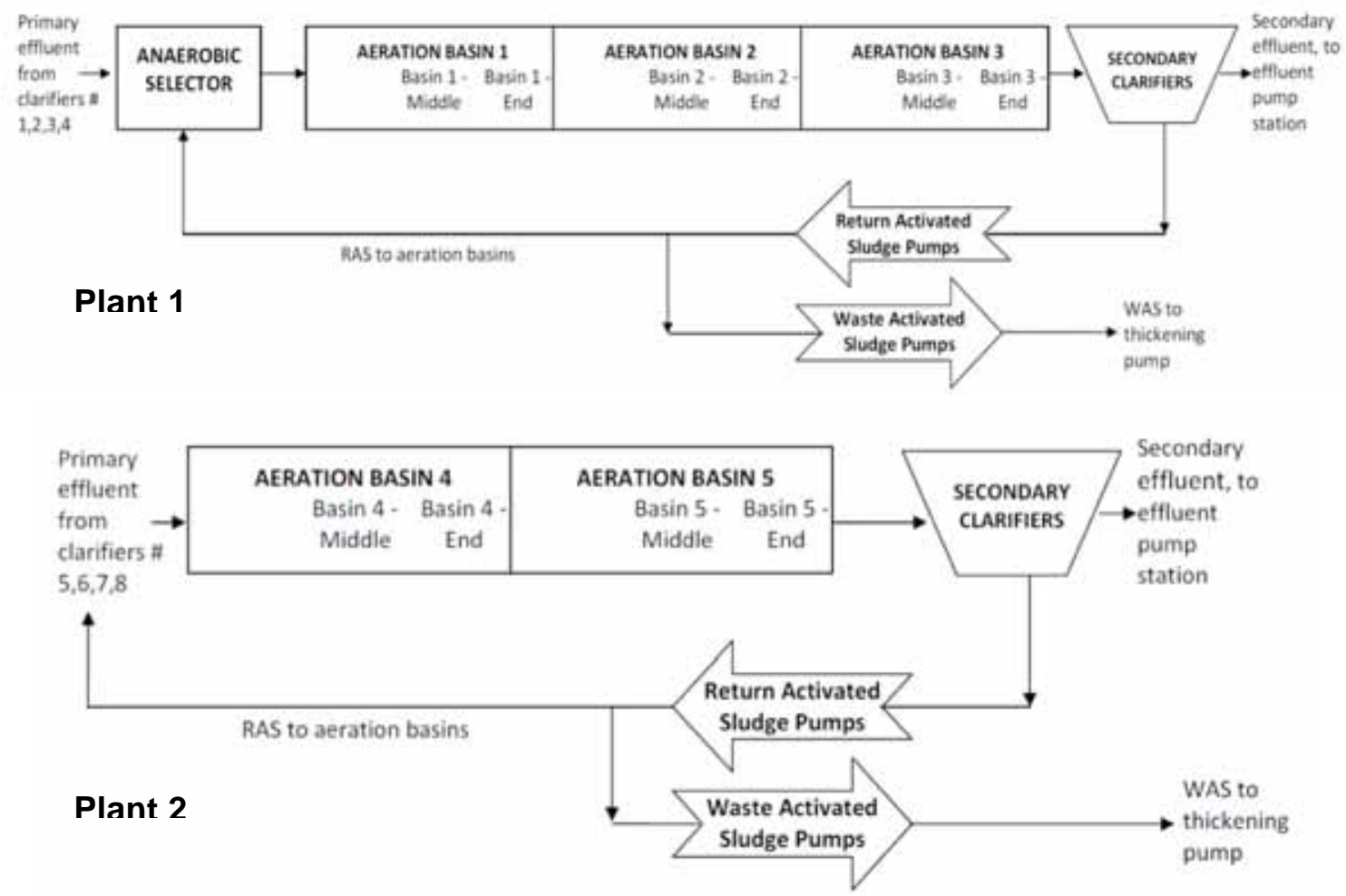

Figure 7. Placement of Dissolved Oxygen Sensors at San Luis Rey 


\subsubsection{Weather Data}

Weather data including dry-bulb outdoor temperature, dew point temperature, and relative humidity were collected at hourly intervals during the project period. Data were collected from the Weather Underground (http:/ / www.wunderground.com) from a weather station located at the Oceanside Municipal Airport, located 2.2 miles from the San Luis Rey facility (Weather Underground Inc 2010). A map of the weather station in Appendix D shows the proximity of the weather station to the San Luis Rey Wastewater Treatment Plant. 


\subsection{Facility Baseline Analysis}

This section describes the results of the San Luis Rey Wastewater Treatment Plant analysis. The analysis examined facility load data for 2009, along with the 100 day submetering data from October 2, 2009 - January 10, 2010.

\subsection{Facility Load Variability}

As discussed in Section 3.2.2, facility electricity demand data were collected from four utility meters and summed to determine total facility load. The Load Variability Derivation Tool, developed by LBNL, was used to determined the total facility load variability (LBNL 2008).

Figure 8 shows the hourly load variability from 2009 total facility data (utility-supplied power only) at the San Luis Rey Wastewater Treatment Plant, before the cogeneration facility was brought online. The facility load for each 15 minute period is averaged for the entire year and shown in dark blue dots. The maximum and minimum facility load for each time increment is also shown. The band around the average shows one standard deviation of the average facility load. Overall, the San Luis Rey Wastewater Treatment Plant has little load variability throughout the day. The total facility load variability is 3.23 percent, revealing that throughout the 2009 period, hourly load variation fluctuated very little.

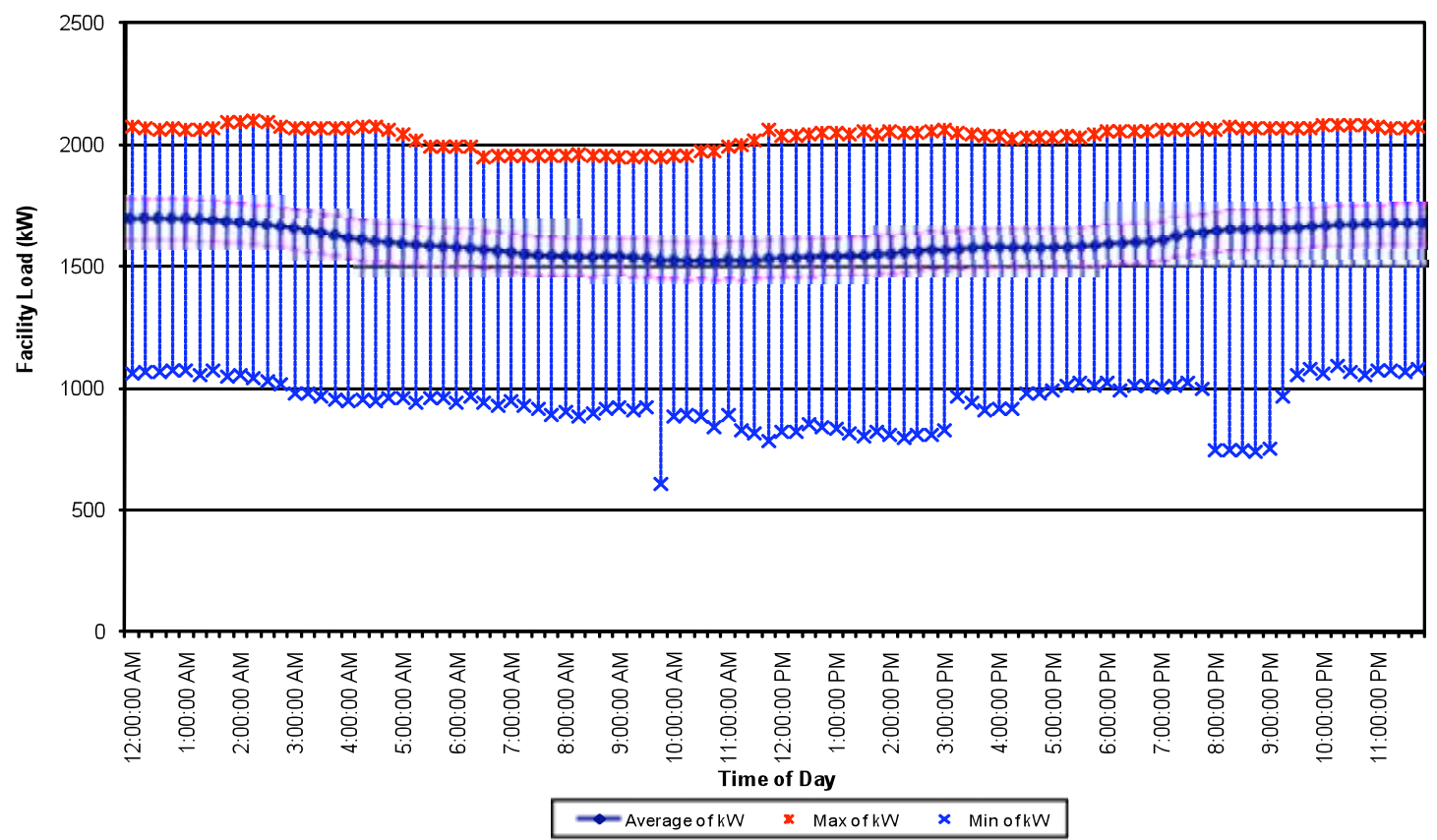

Figure 8. 2009 San Luis Rey Facility Load Variability by Hour, No Cogeneration 
Figure 9 shows the hourly load variability from 2010 total facility data (utility-supplied power only) at the San Luis Rey Wastewater Treatment Plant, after the cogeneration facility was brought online. With the cogeneration unit producing between $600-700 \mathrm{~kW}$ of onsite-generated electricity, very little load variation is seen at the facility; the total facility load variability with the cogeneration unit running is less than 1 percent.

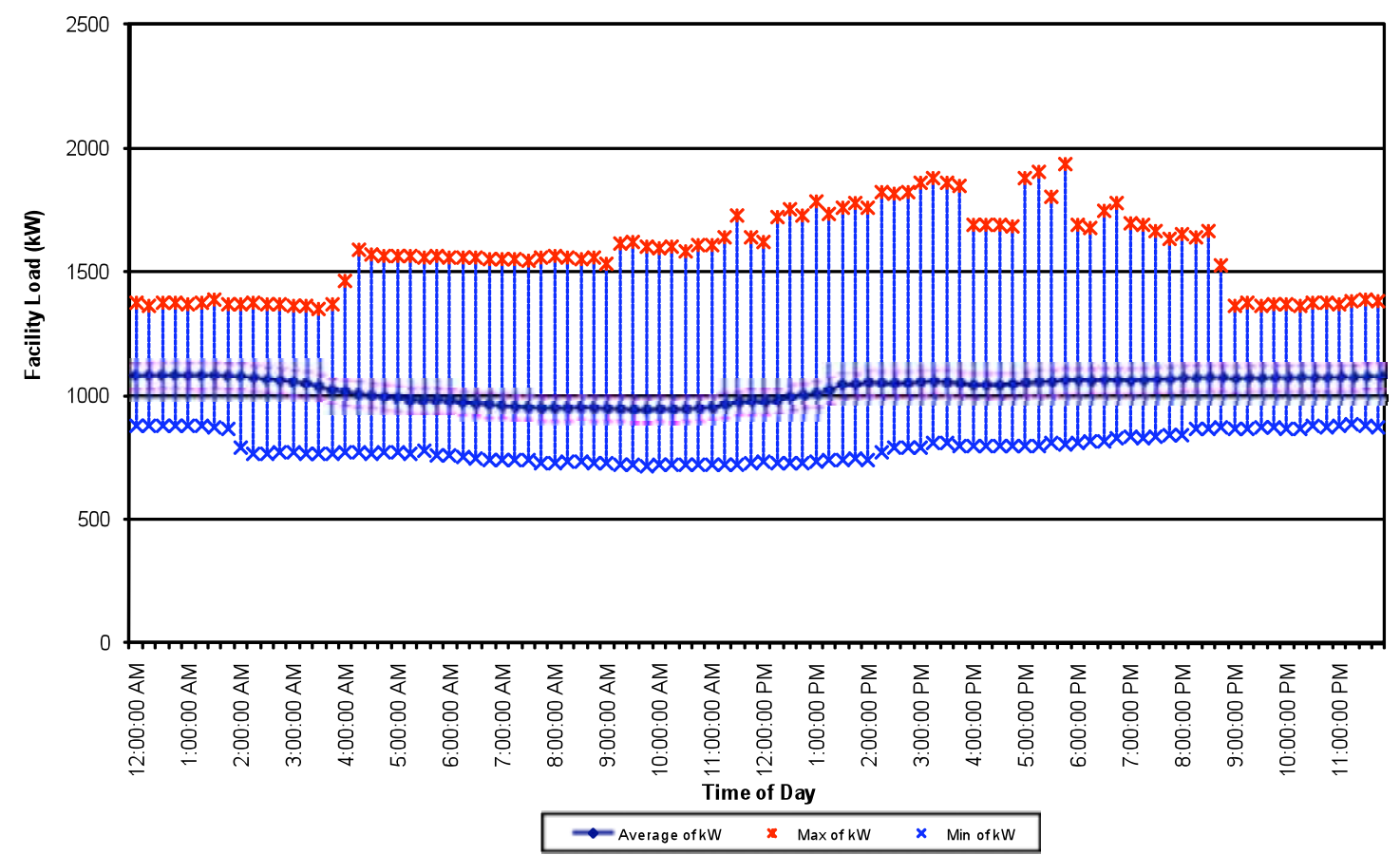

Figure 9. 2010 San Luis Rey Facility Load Variability by Hour (January-May), With Cogeneration

Figure 8 and Figure 9 clearly depict the difference in facility load draw from the utility meters before and after the cogeneration unit was installed. In 2009, before the cogeneration unit, the facility's average electricity demand from the utility was around 1,500-1,700 kW. Once the cogeneration unit was installed, the facility's load draw from the utility meters averaged between 900-1,100 kW.

Next, we compared the variability of the facility's summer and winter load for 2009. Figure 10 and Figure 11 show the summer and winter load variability by hour for the San Luis Rey facility, respectively. Based on an assessment of data from the summer of 2009, the facility's summer load variability was 3.81 percent. In the same way, the facility's winter load variability for 2009 was found to be 3.23 percent. 


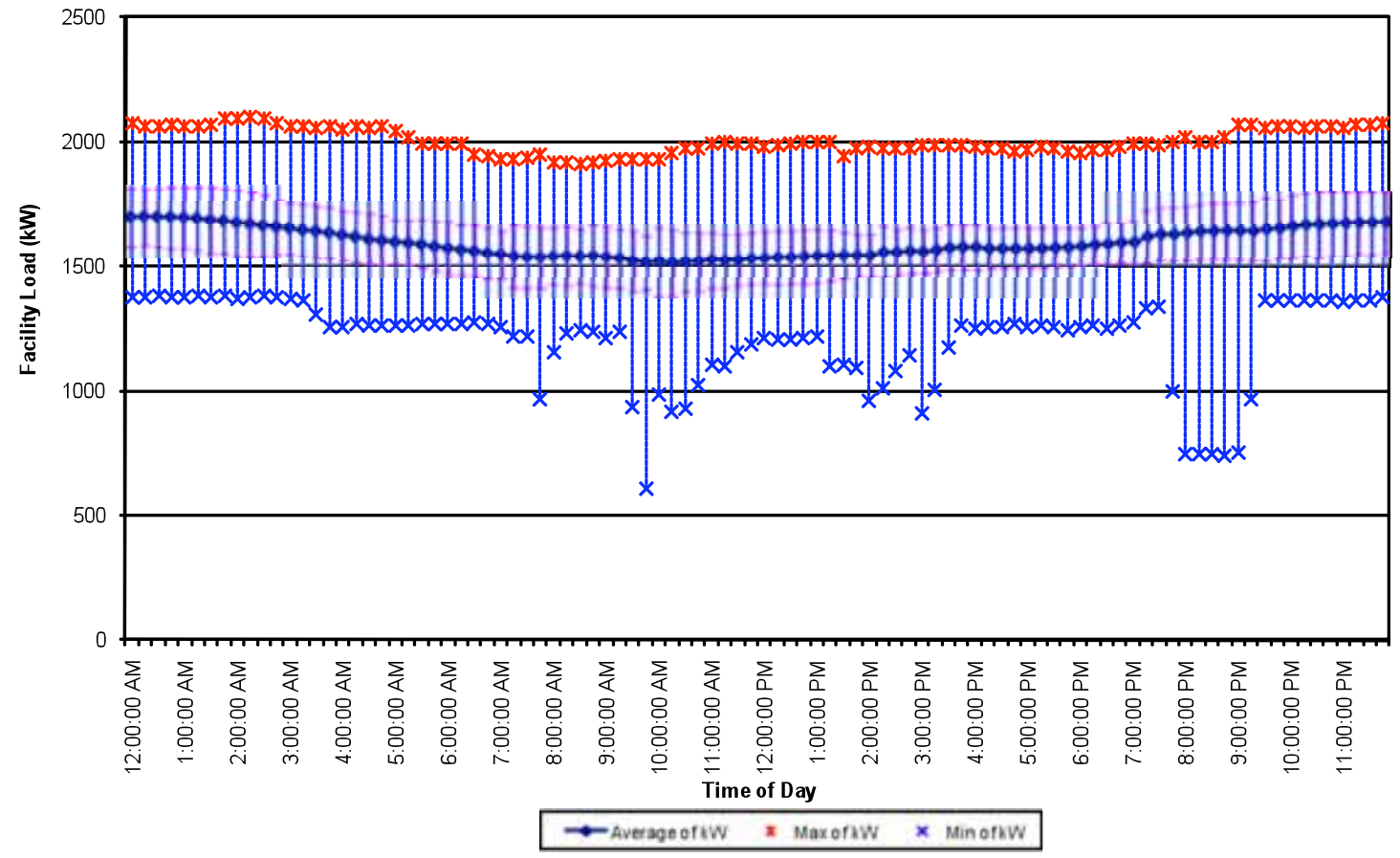

Figure 10. San Luis Rey Facility Load Variability by Hour - Summer 2009 (No Cogeneration)

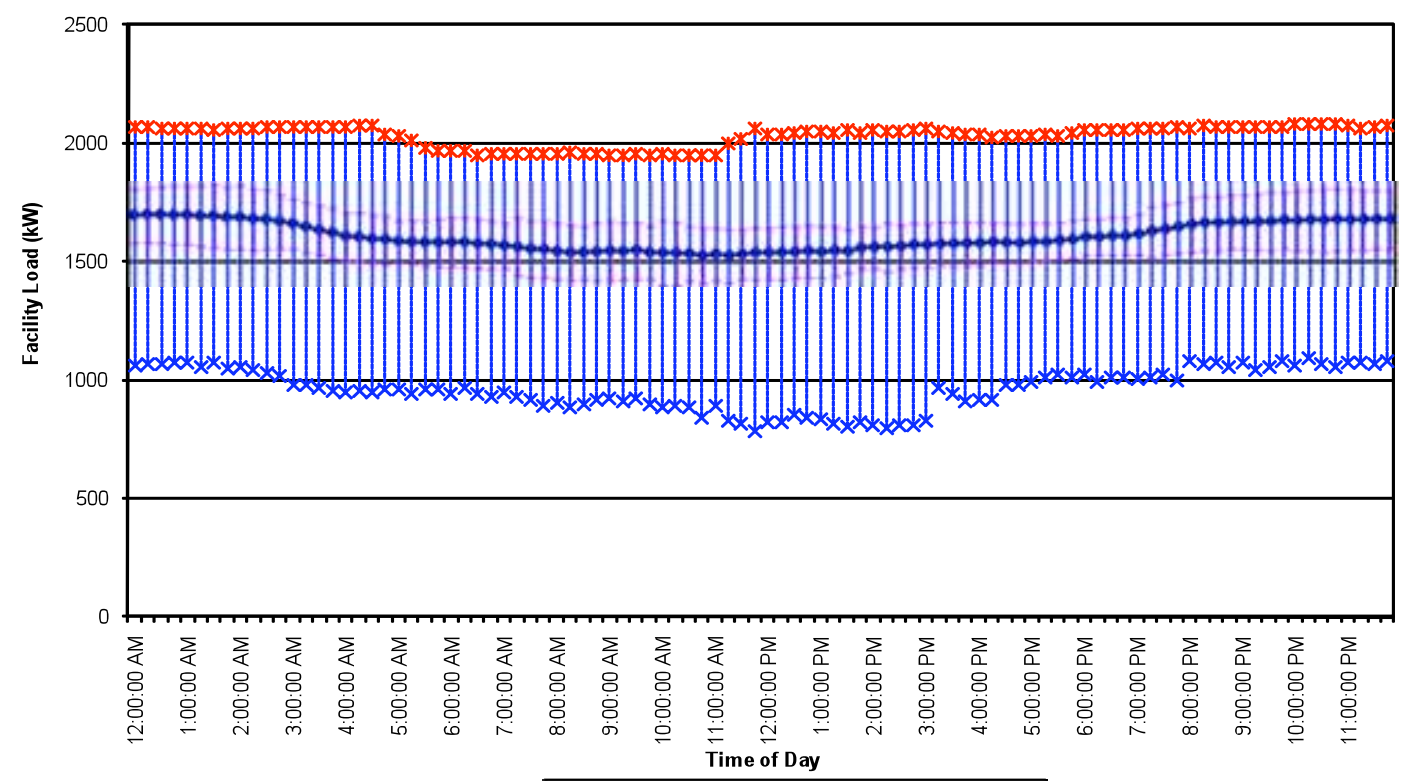

$\rightarrow$ Average of kW $\times$ Max of kW $\times$ Min of kW

Figure 11. San Luis Rey Facility Load Variability by Hour - Winter 2009 (No Cogeneration) 
As seen in Figure 10 and Figure 11, the San Luis Rey facility's electricity demand is slightly more variable in the summer period. SDG\&E's peak demand period is between $11 \mathrm{AM}$ and 6 PM. While the facility's electricity demand does not ramp up until 4 PM in the summer, the facility's demand is still high during the utility's peak period, making it a good candidate for OpenADR.

\subsection{Dissolved Oxygen}

Measurements of DO levels were also taken during the 100 day project period. Figure 7 shows the placement of the DO sensors at the San Luis Rey Wastewater Treatment Plant. Two DO sensors are located in each of the five basins. Measurements from all 10 DO sensors were taken every 15 minutes. The information from the DO sensors is transmitted to modulating valves in each basin. These valves control the amount of air the blowers inject into the aeration basins. When the DO levels rise above or drop below a programmed DO setpoint, the modulating valves adjust the amount of air reaching the basins to maintain a constant level of DO.

Figure 12 and Figure 13 show the typical daily fluctuation in DO levels seen during a week in November and a week in August, respectively. The daily fluctuation of the average DO levels in Plant 1, which is an average of all sensors in Basins 1-3, is displayed for nine days in each month. The average DO levels in Plant 1 range from about 1.0 to $2.0 \mathrm{mg} / \mathrm{L}$, with an average of $1.3 \mathrm{mg} / \mathrm{L}$. As seen in Figure 12 and Figure 13, DO levels start to increase around 6 AM, and decrease around 3 PM.

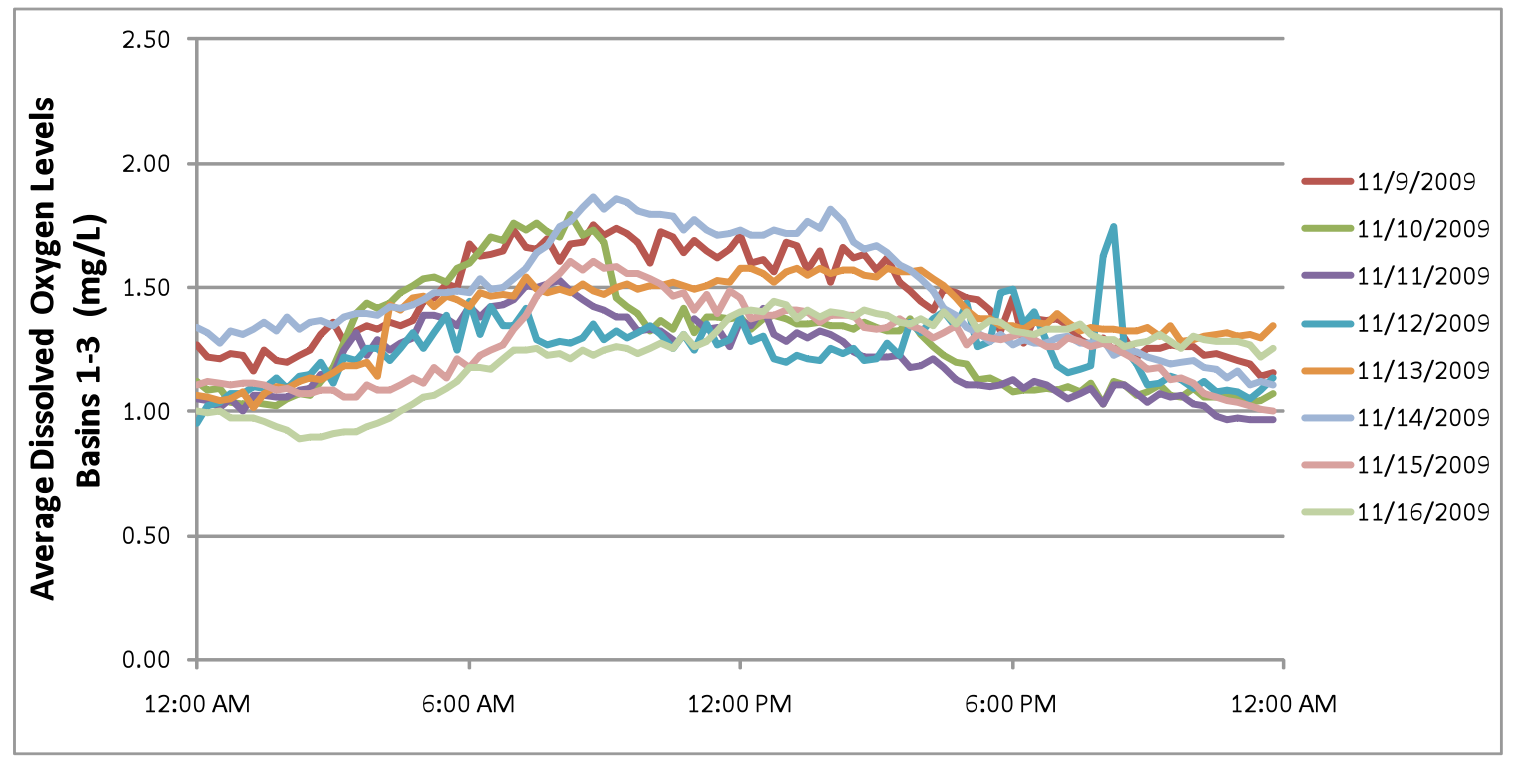

Figure 12. Daily Dissolved Oxygen Measurements - November 2009 


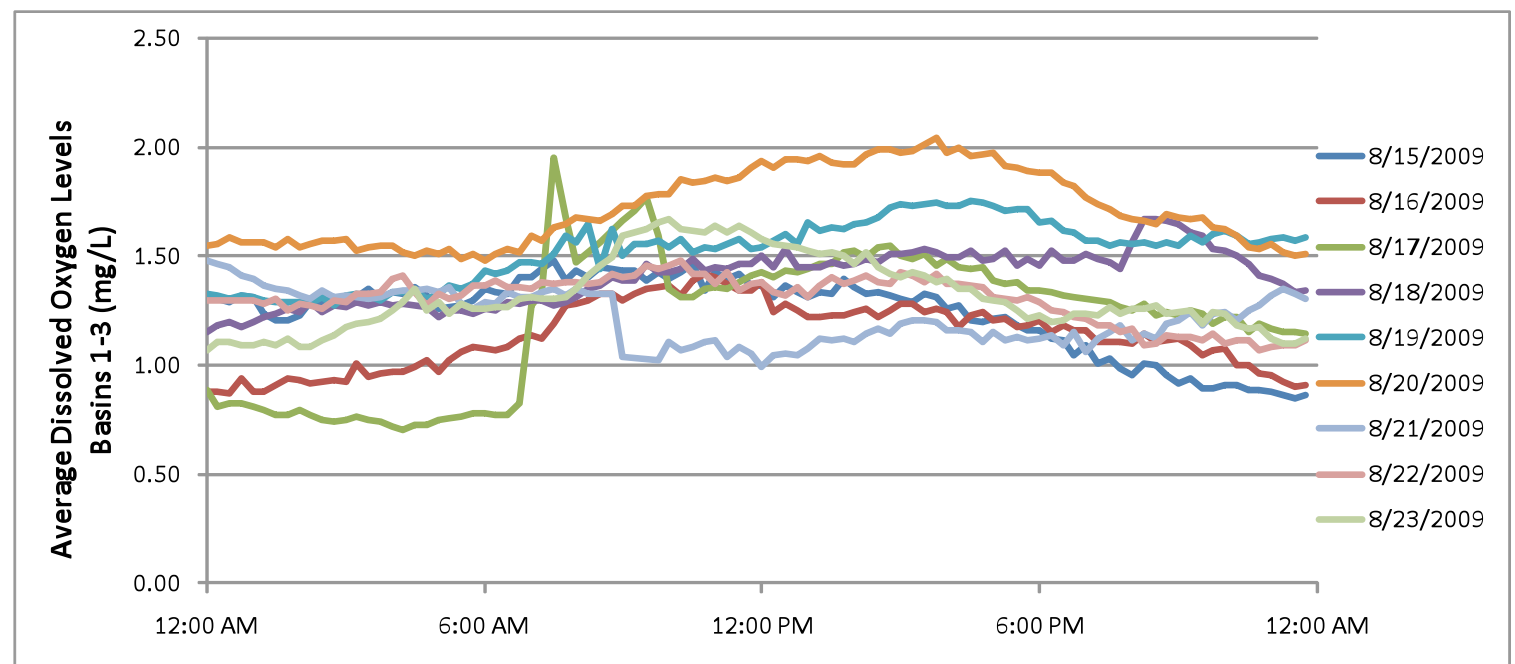

Figure 13. Daily Dissolved Oxygen Measurements - August 2009

Because there is no air in the secondary clarifiers, bacteria strip oxygen off of remaining nitrate in the sludge, releasing nitrogen gas. This nitrogen gas causes sludge to rise to the top of the clarifiers, instead of settling on the bottom, disrupting the treatment process. To avoid this problem, the San Luis Rey facility prevents nitrate from entering the secondary clarifiers by turning off the aeration blowers in the middle of the treatment process.

Figure 14 shows the impact on dissolved oxygen levels of this operational process. Dissolved oxygen levels decrease as wastewater moves through the facility because the aeration blowers are turned off in the middle of the treatment process chain. 


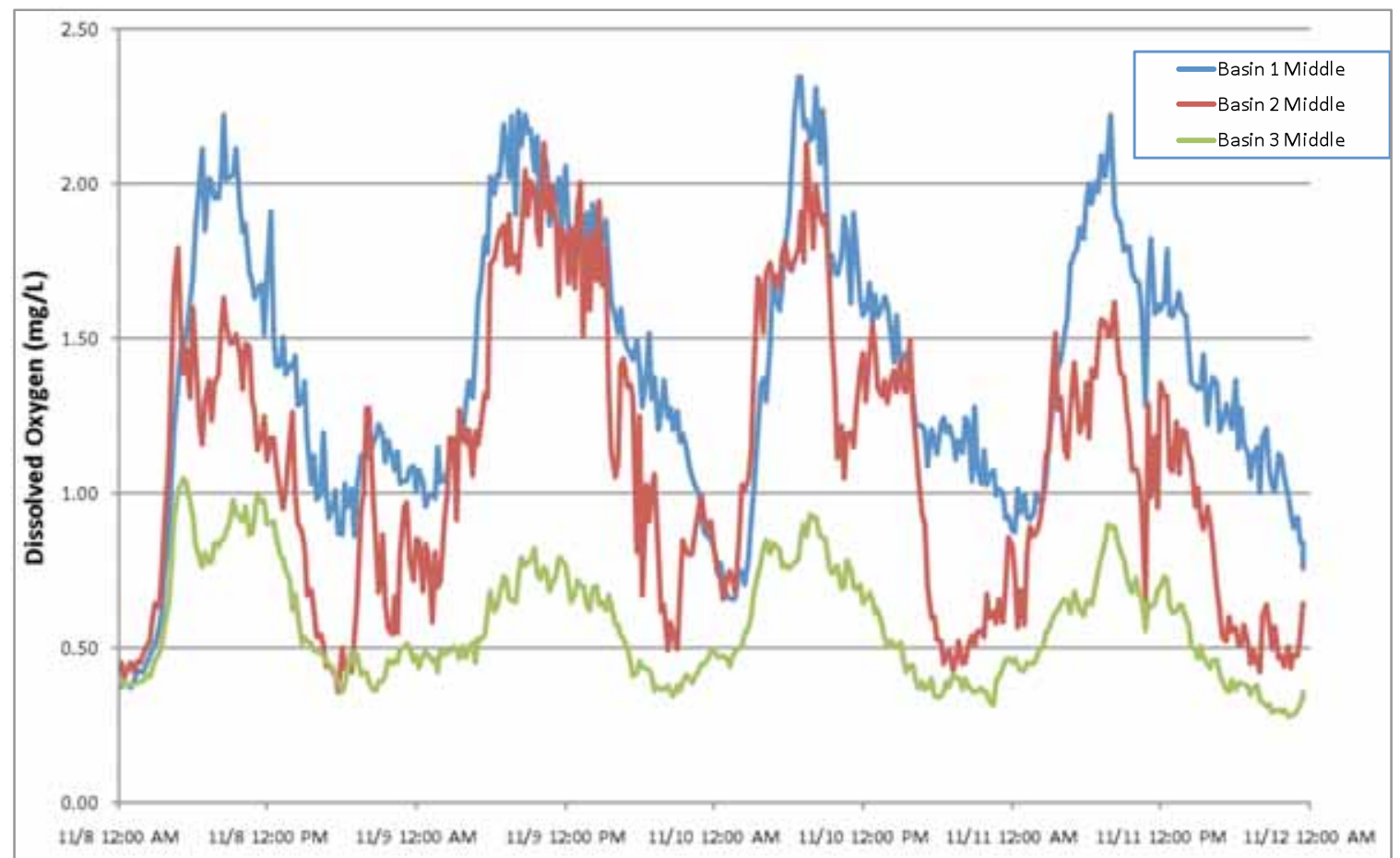

Figure 14. Dissolved Oxygen Measurements by Location

\subsection{Influent Flow}

Measurements of the raw influent flow to the San Luis Rey Wastewater Treatment Plant were also taken during the project period. Influent flow readings were taken every 15 minutes. Figure 15 shows the daily influent flow into the facility for 13 days in November 2009. Little variation in daily influent flow is seen, although slightly greater influent flow is reported during the weekend days (November 8, 14, and 15). The average weekday flow in November was 8.47 million gallons per day, while the average weekend flow was 9.02 million gallons per day. 


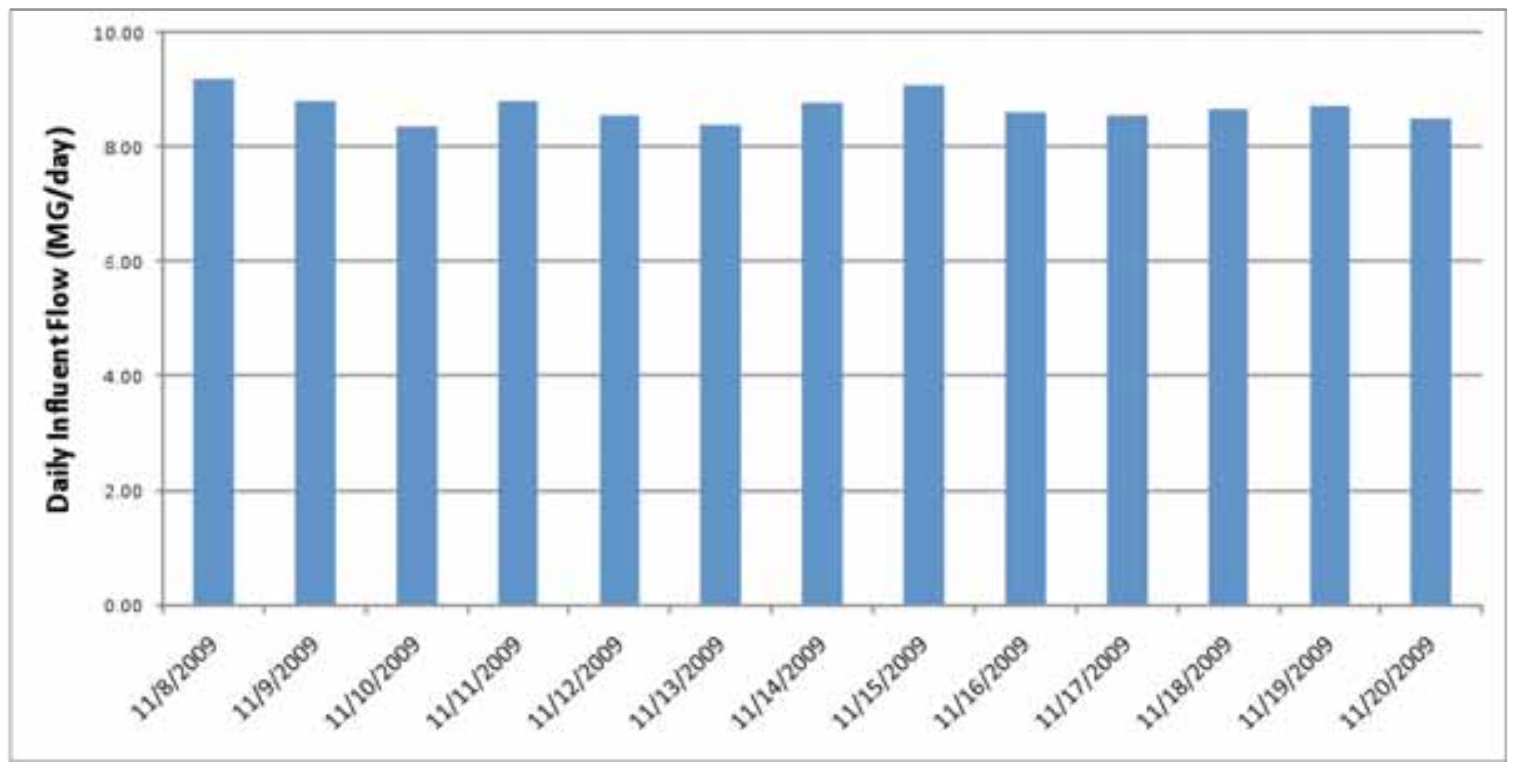

Figure 15. San Luis Rey Daily Influent Flow in November 2009

While the day to day fluctuation in influent flow is very small, total raw influent flow varies throughout the day. Figure 16 shows that influent flow sharply increases around 6 AM, and peaks in the early mornings around 9 AM. Another peak is seen in the evening around 8 PM. The slight shift in flow can be seen on the weekend days November 8, 2009, November 14, 2009, and November 15, 2009, with peak weekend flow occurring around 12 PM. On the weekdays, a morning peak of 0.48 million gallons per hour was seen at $9 \mathrm{AM}$, and an evening peak of 0.47 million gallons per hour was seen at $8 \mathrm{PM}$. On the weekends, influent flow peaked at an average of 0.56 million gallons per hour from 11 AM to $1 \mathrm{PM}$, with a slight peak seen in the evenings at an average of 0.49 million gallons per hour at 7 PM.

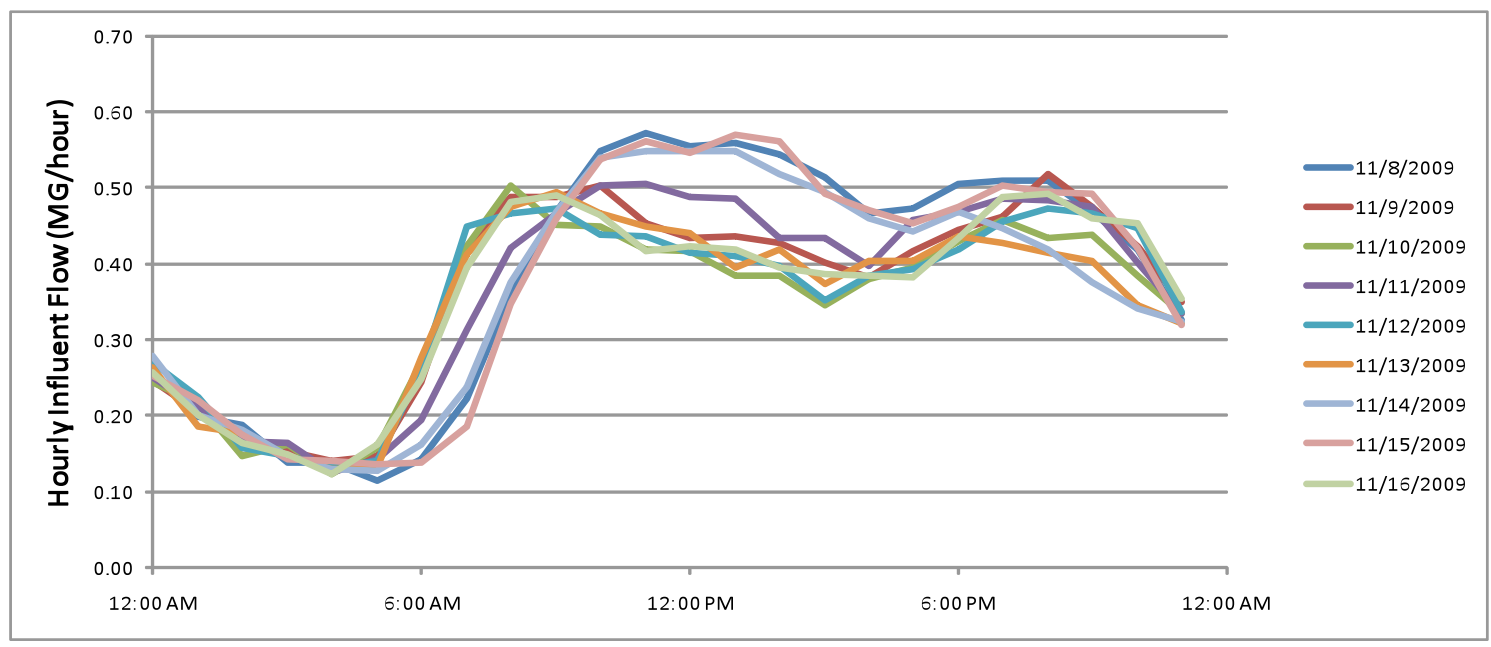

Figure 16. Daily Total Raw Influent Flow 


\subsection{Secondary Effluent Flow}

Secondary effluent flow data were collected in 15 minute intervals during the metering period. Figure 17 shows the daily secondary effluent flow for 13 days in November 2009. Similar to daily influent flow, little variation in daily secondary effluent flow is seen. The average weekday effluent flow in November was 8.95 million gallons per day, while the average weekend flow was 9.10 million gallons per day.

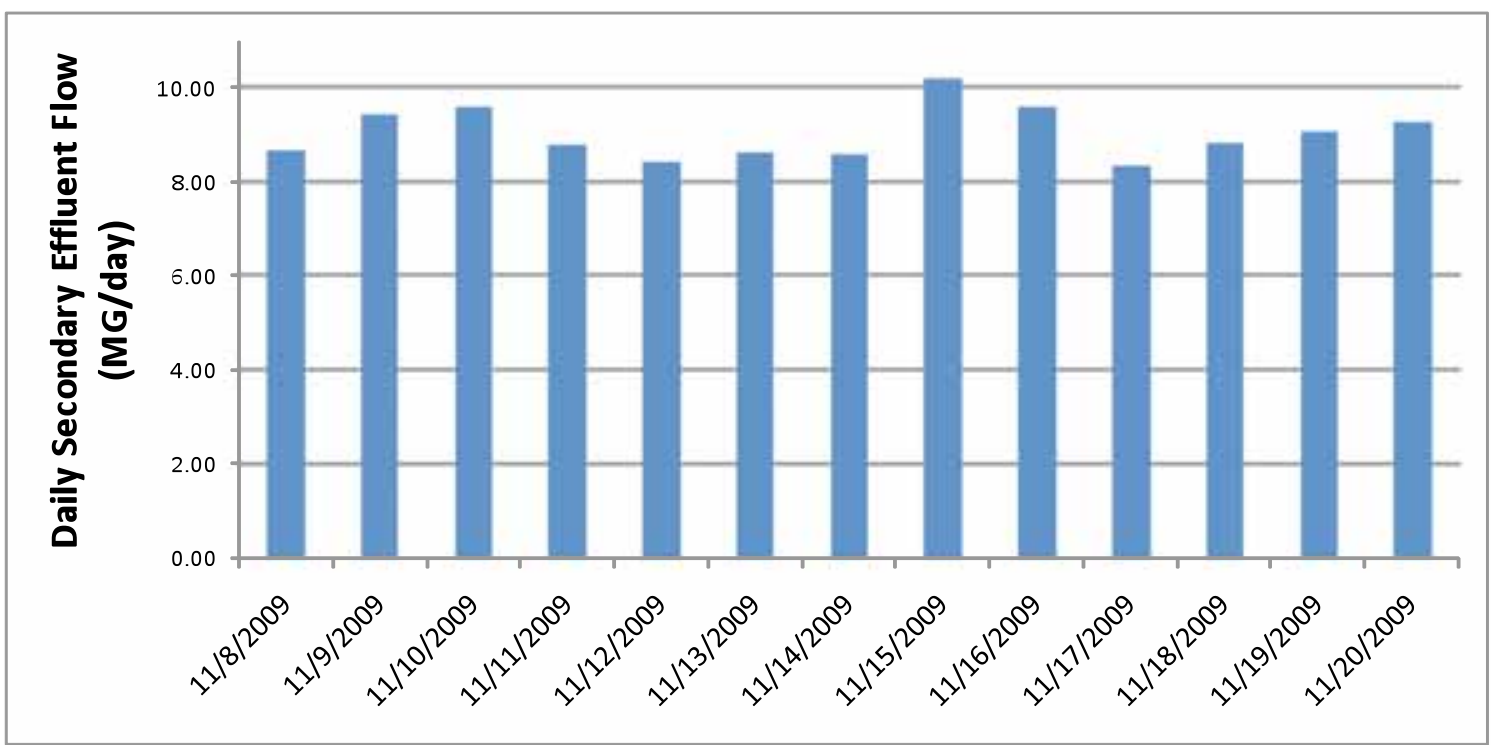

Figure 17. San Luis Rey Daily Effluent Flow in November 2009 
Additionally, while wastewater influent flow varies greatly throughout the day, secondary effluent flow remains constant. Figure 18 shows 13 days of effluent flow measurements. Most days flow remains constant throughout the day at 0.40 million gallons per hour. The increase seen on November 15, 2009 is due to facility operators turning on additional effluent pumps for a few hours in order to lower the storage pond levels.

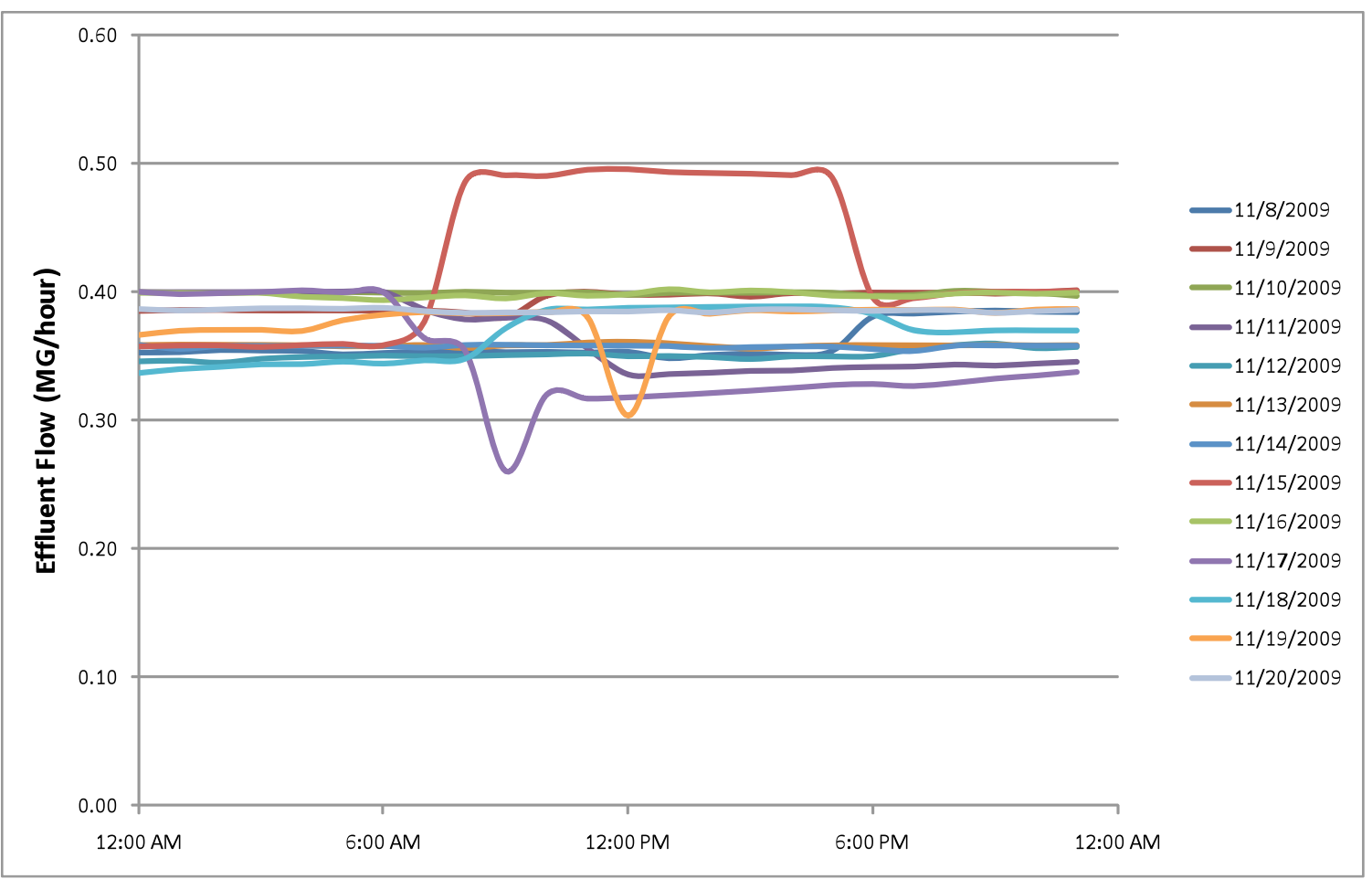

\section{Figure 18. Daily Secondary Effluent Flow}

While wastewater influent flow varies dramatically throughout the day, the San Luis Rey facility is able to maintain a constant secondary effluent flow by using the load equalization tanks, seen in Figure 2, which have a storage capacity of 2 million gallons. The effluent storage ponds, which have a capacity of 10 to 15 million gallons, are also used to equalize wastewater flow.

\subsection{Temperature}

Outdoor dry-bulb temperature data were collected during the 100 day project period. Figure 1 shows the temperature fluctuation during a week in November 2009. During the test period, temperature typically ranged from $50^{\circ} \mathrm{F}$ to $70^{\circ} \mathrm{F}$. 


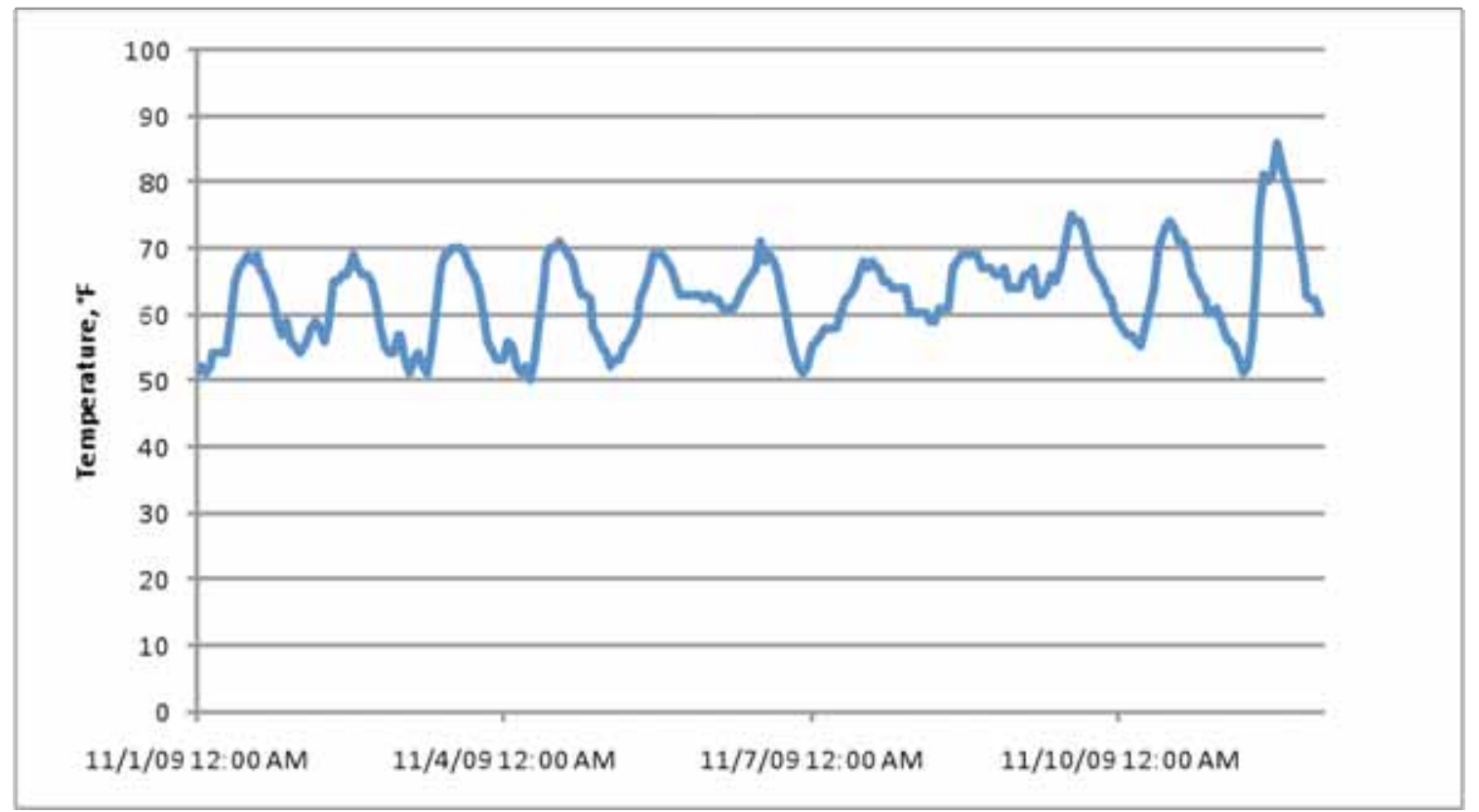

Figure 19. Temperature Parameters in November

Figure 20 shows a typical daily temperature profile during the project period. Little temperature variation was seen during the test period.

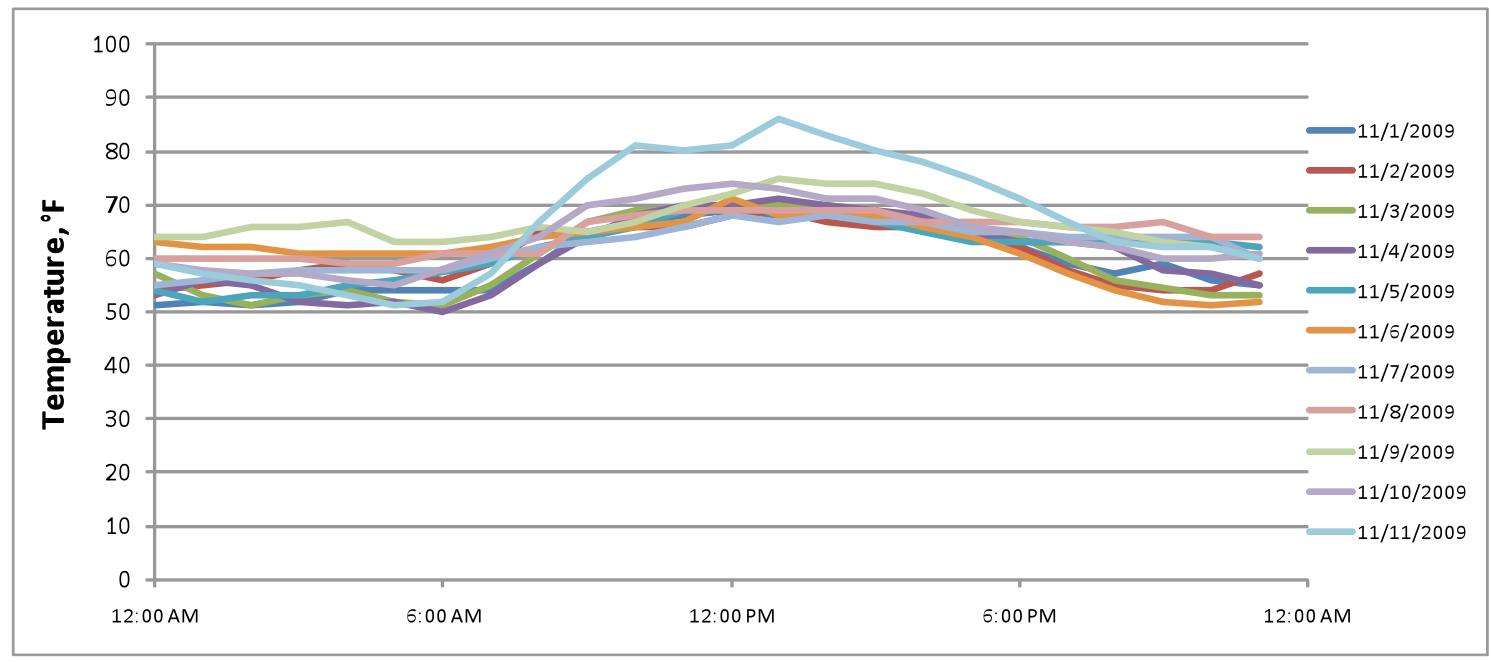

Figure 20. Daily Temperature in November

\subsection{Submetered Equipment}

The following section describes the operation of the three equipment types submetered during the project period. Typical daily and weekly load is shown for each equipment type. Load data from November 2009 are shown because there were no demand response tests conducted during this month of the project, therefore the load represents typical operation.

\subsubsection{Effluent Pumps}

Figure 21 shows 10 days of effluent pump operation in November 2009. The effluent pumps have a fairly consistent load around $300 \mathrm{~kW}$, with slight variations throughout the week. 


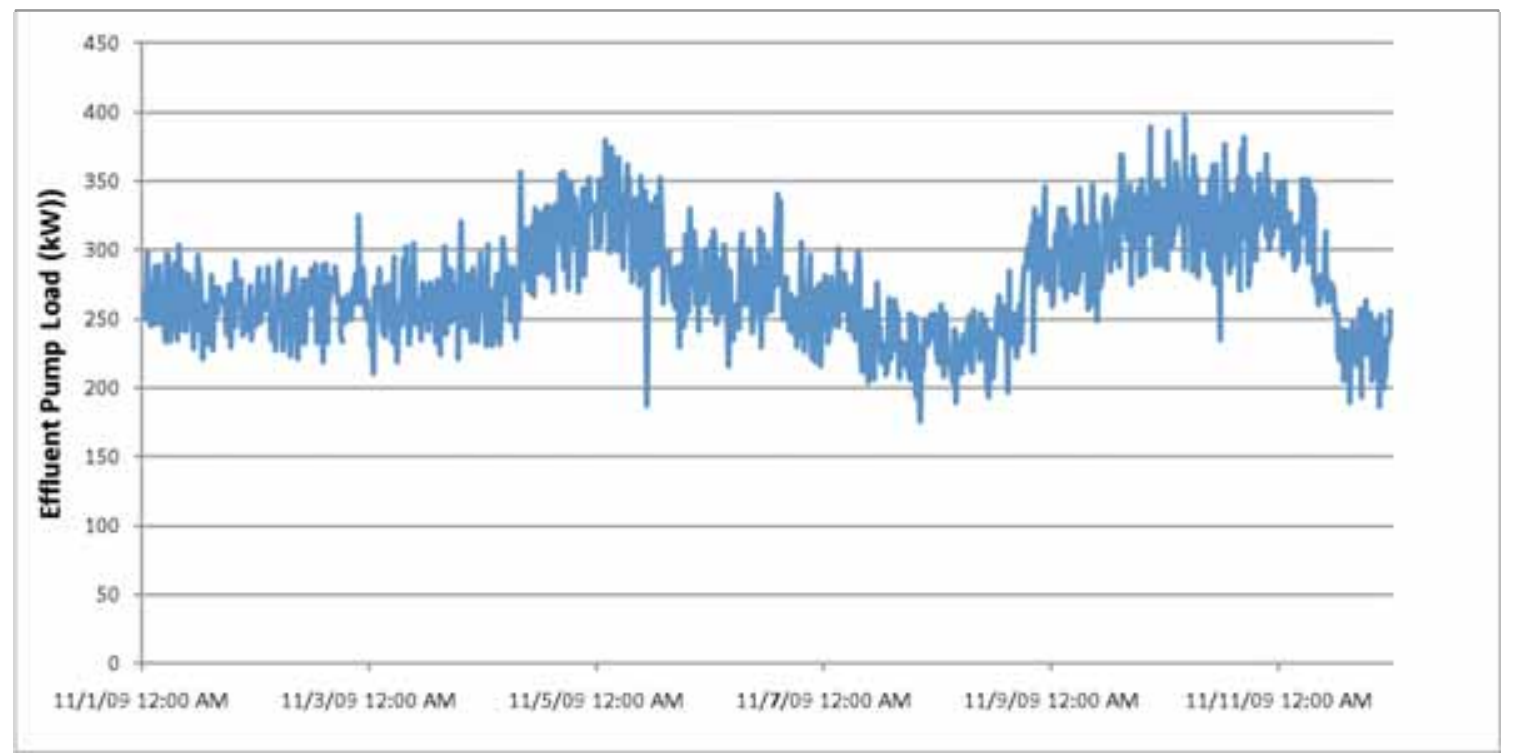

Figure 21. Effluent Pump Load (kW), November 2009

Figure 22 shows daily effluent pump load in November 2009. The effluent pump load varies little throughout the day, and pump load remains around $300 \mathrm{~kW}$ consistently throughout the day.

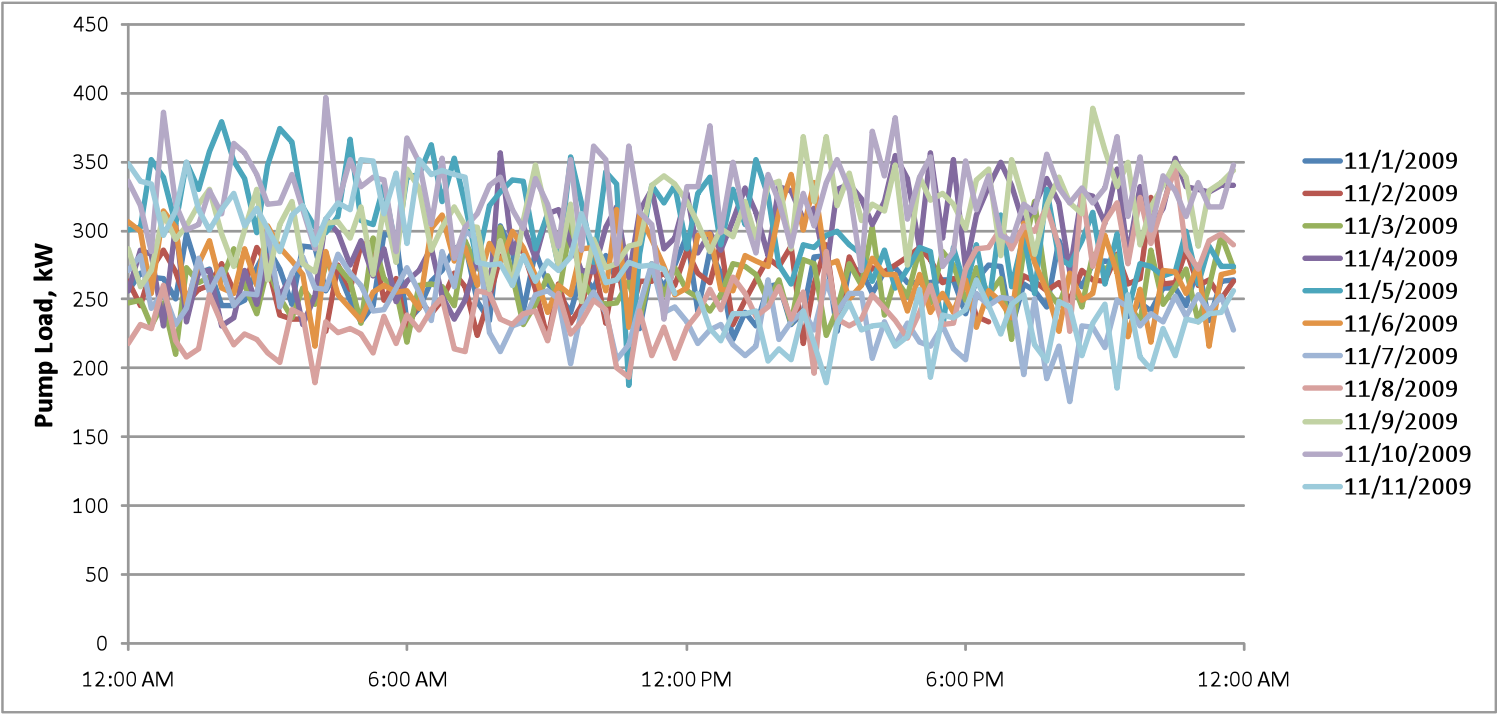

Figure 22. Daily Effluent Pump Load (kW), November 2009

\subsubsection{Centrifuges}

Figure 23 shows 10 days of centrifuge load in November 2009. As discussed in Section 3.1.2, the centrifuges are shut down on Friday afternoons and remain off until Monday morning, because no solids are removed from the plant over the weekend. Figure 23 clearly shows the weekend periods when the centrifuges are shut down. 


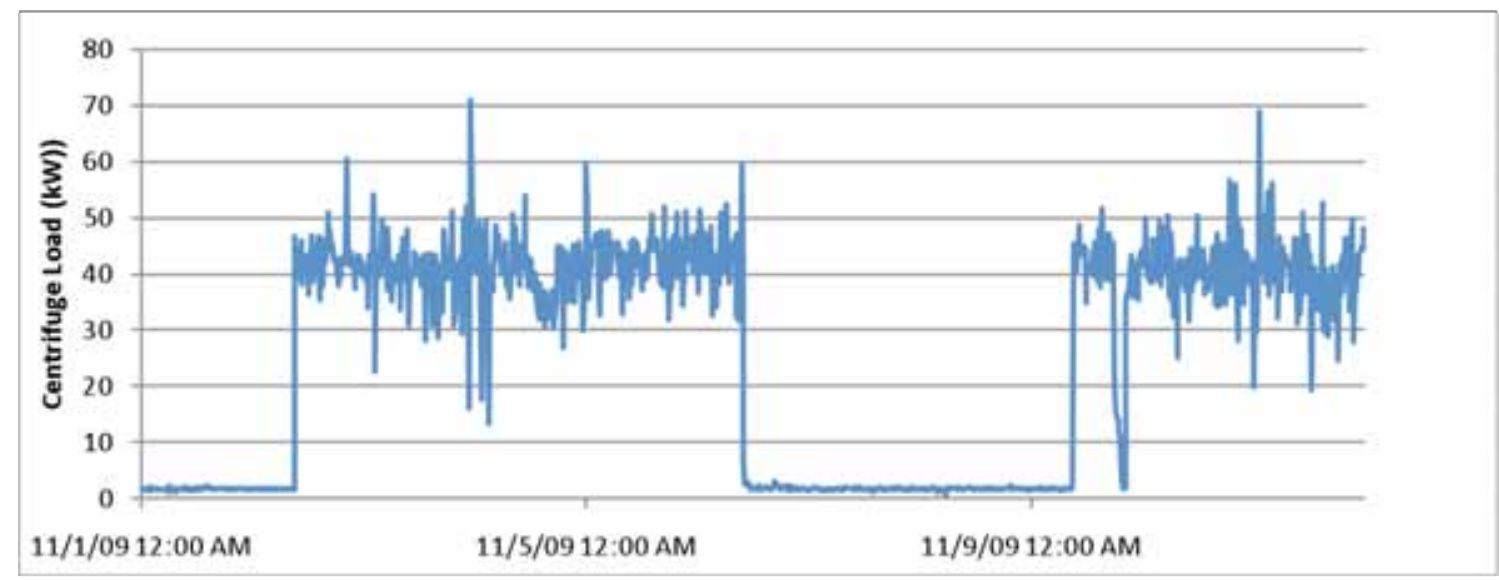

Figure 23. Centrifuge Load (kW) in November 2009

Figure 24 shows the daily centrifuge load in November 2009. The days when the centrifuges are turned on or off midday result in days with load dropping to $0 \mathrm{~kW}$. The centrifuge load varies around an average of $40 \mathrm{~kW}$ when the units are turned on.

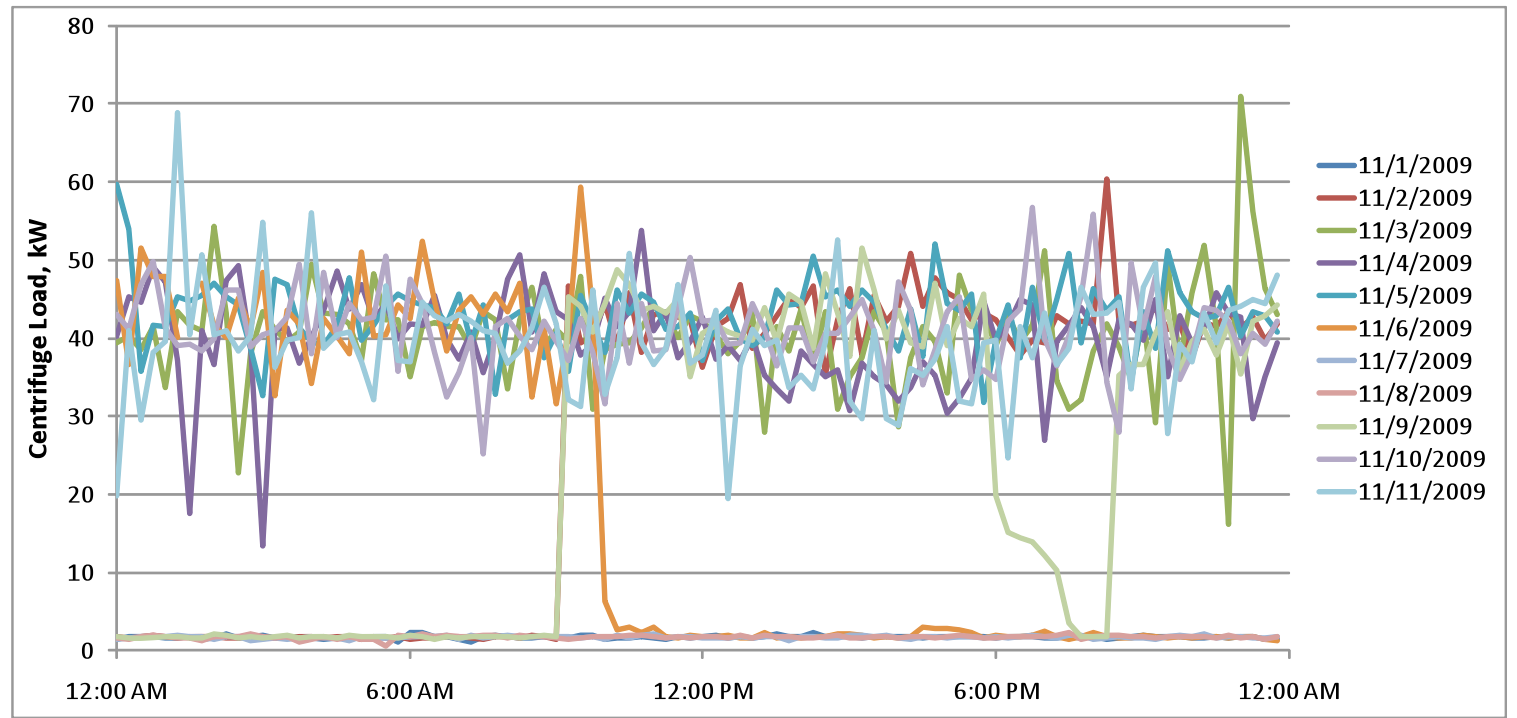

Figure 24. Daily Centrifuge Load (kW) in November 2009

\subsubsection{Blowers}

Figure 25 shows 10 days of blower load in November 2009. The blower load varies between 200 $\mathrm{kW}$ to $300 \mathrm{~kW}$. 


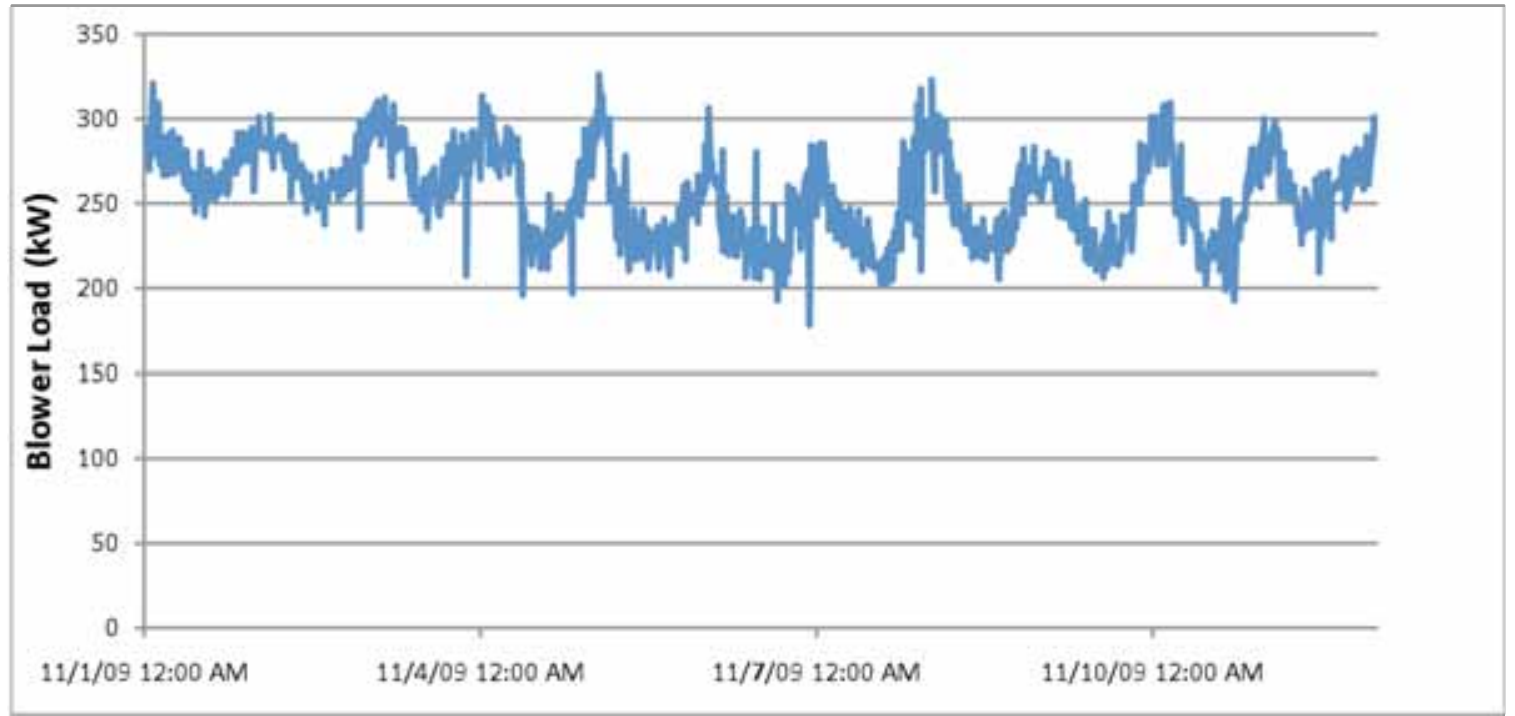

Figure 25. Blower Load (kW) in November 2009

Figure 26 shows daily blower load in November 2009. The blower load is lower midday, and ramps up around 4:00 PM.

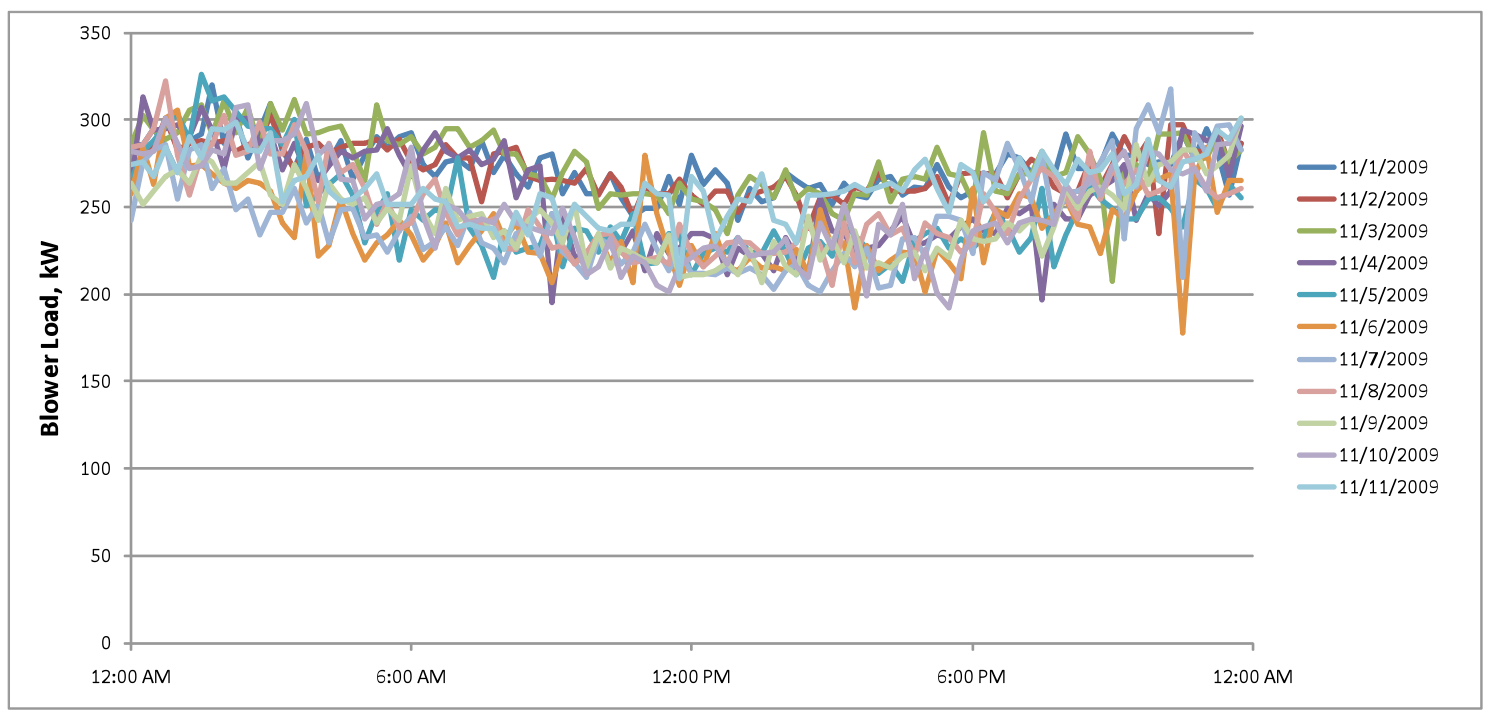

Figure 26. Daily Blower Load (kW) in November 2009

\subsection{Parameter Correlation}

Key facility parameters were analyzed during summer and winter periods to understand how they relate to one another. This section discusses the correlations found between total influent flow, average dissolved oxygen levels, and temperature.

Figure 27 and Figure 28 show the correlation between influent flow and average dissolved oxygen levels during the summer and winter period, respectively. These figures show that the facility maintains dissolved oxygen levels according to a programmed DO setpoint even as 
influent flow varies. As discussed in Section 3.1.3, this is accomplished through the use of a modulating value which allows the facility to adjust oxygen levels according to readings from dissolved oxygen sensors, so that as influent flow fluctuates, a constant supply of oxygen is maintained in each basin.

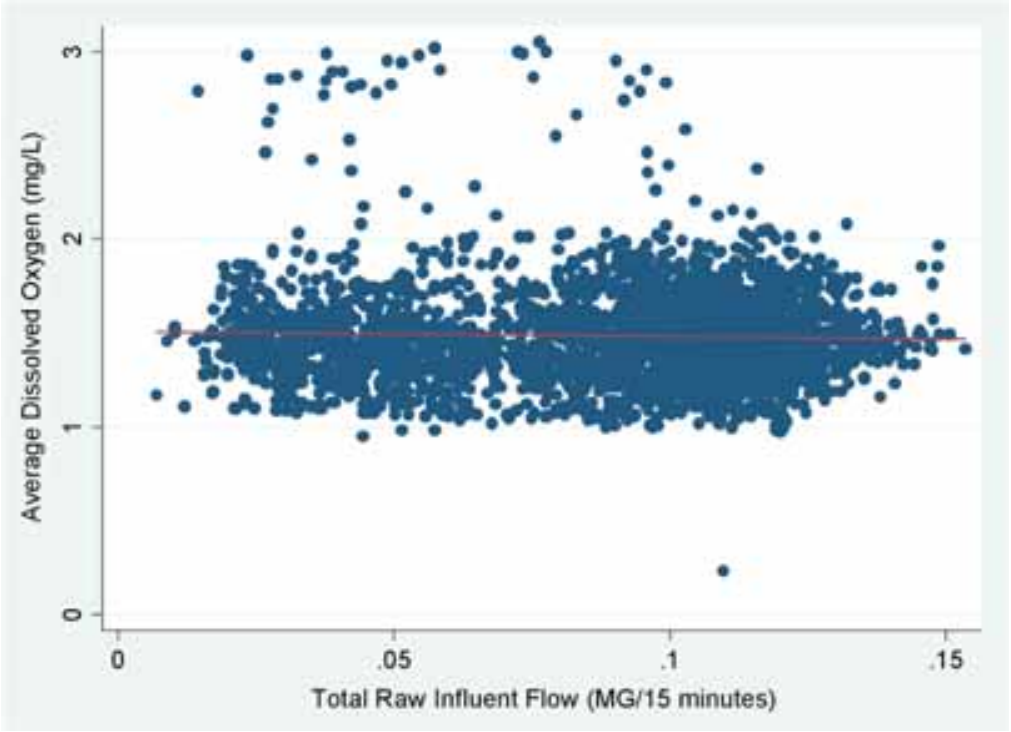

Figure 27. Flow and Dissolved Oxygen Correlation - Summer

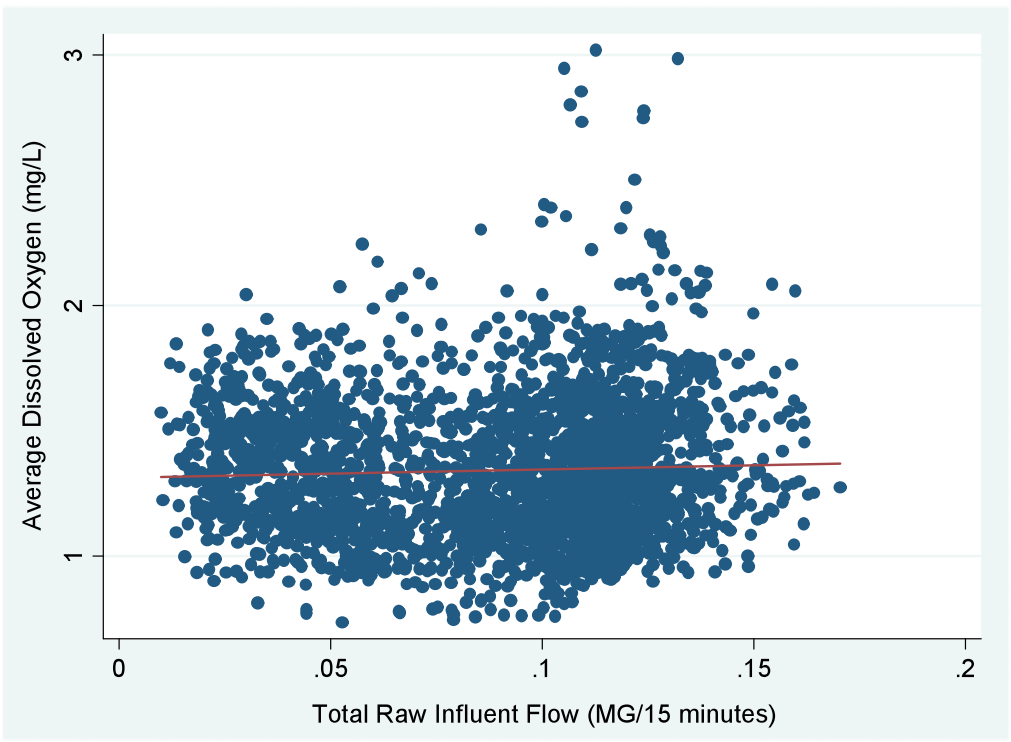

Figure 28. Flow and Dissolved Oxygen Correlation - Winter

Figure 29 and Figure 30 show the correlation between outdoor temperature and average dissolved oxygen levels during the summer and winter period, respectively. These figures show that the facility maintains dissolved oxygen levels according to a programmed DO setpoint 
even as temperature varies. Just as the facility controls DO in response to changes in influent flow, dissolved oxygen sensors send a signal to the modulating valve, which adjusts the amount of air reaching each basin, so that a constant level of DO is maintained in each basin even as temperature fluctuates.

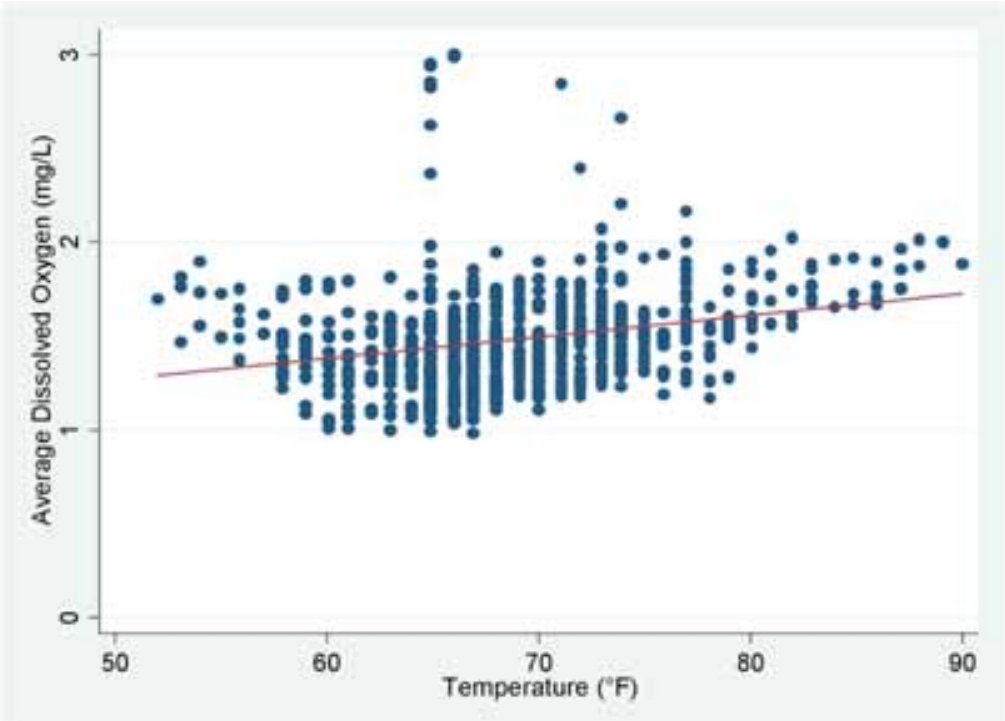

Figure 29. Temperature and Dissolved Oxygen Correlation - Summer

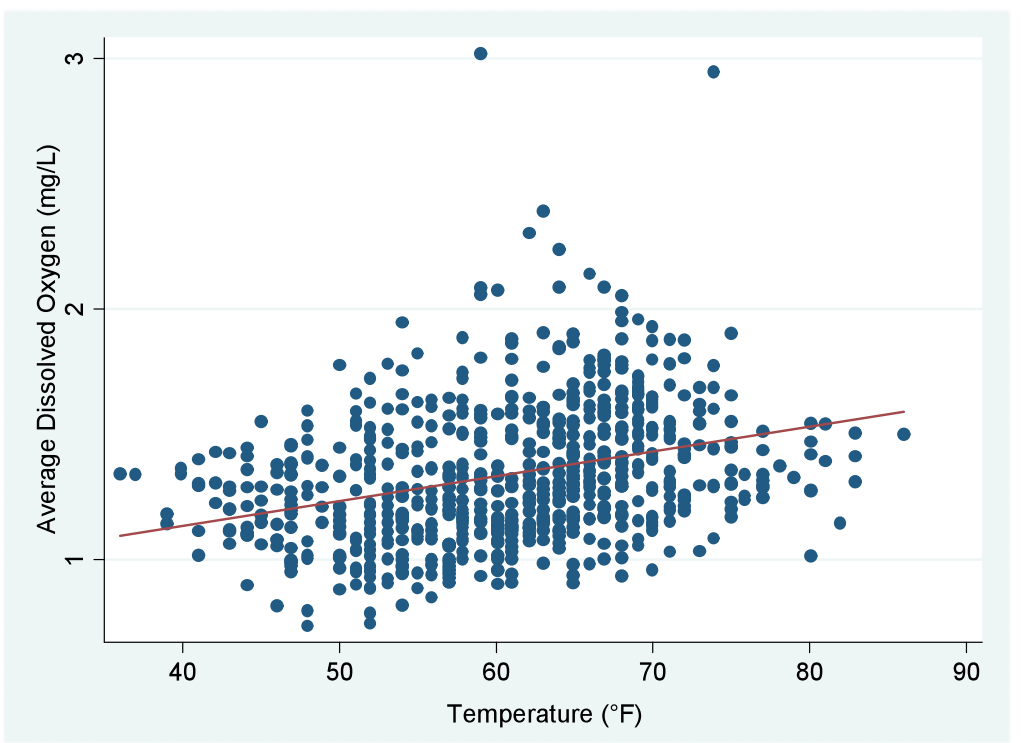

Figure 30. Temperature and Dissolved Oxygen Correlation - Winter

Figure 1 and Figure 32 show the correlation between outdoor temperature and total influent flow during the summer and winter period, respectively. The correlation coefficient $R^{2}$ is 0.29 for the summer and 0.40 for the winter. This indicates that there is a slight correlation between these parameters. That is, as temperature increases, the average influent flow into the San Luis 
Rey facility increases. This relationship reveals that water use in the city of Oceanside increases with temperature; one explanation for this correlation could be that irrigation in the city increases with higher temperatures.

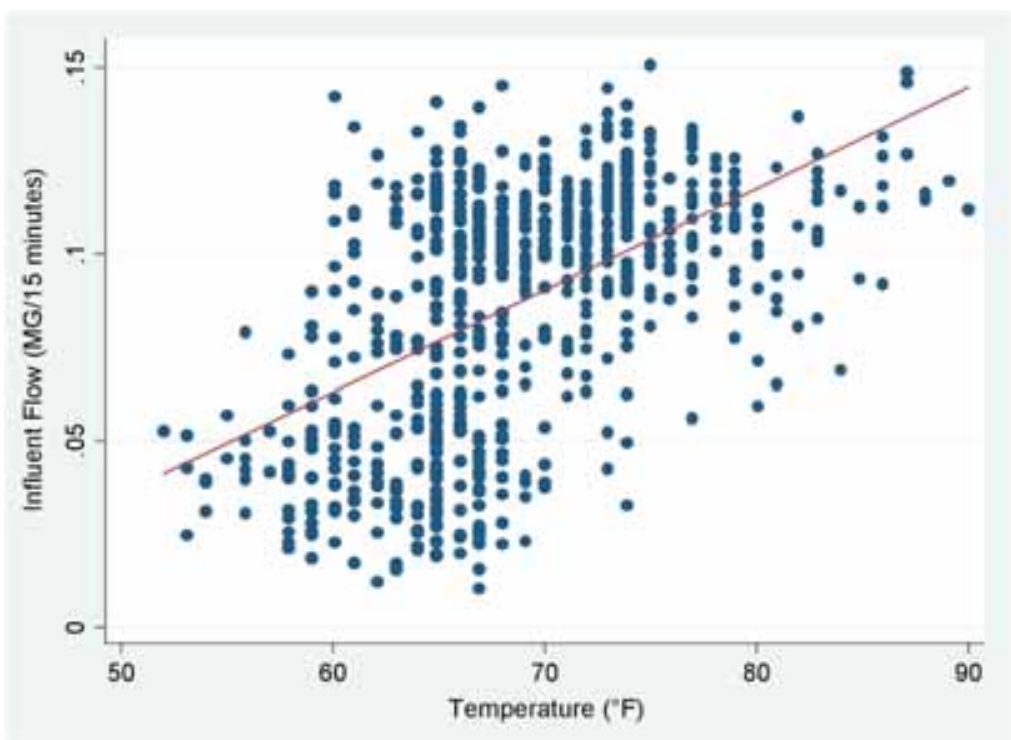

Figure 31. Temperature and Flow Correlation - Summer

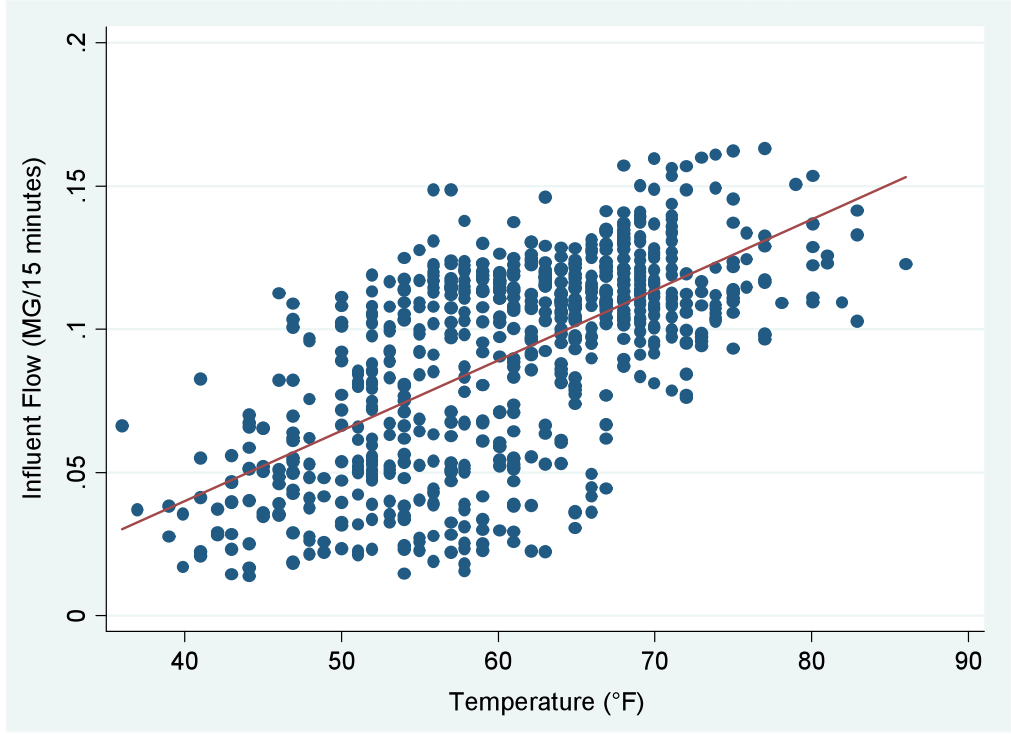

Figure 32. Temperature and Flow Correlation - Winter

Figure 1 shows the relationship between blower load and average dissolved oxygen levels during the winter period. No summer data is shown because the blower load was not submetered during this time. No relationship is seen between the blower load and average dissolved oxygen levels because the facility controls air flow by using a modulating valve. This allows the facility to adjust oxygen levels as influent flow fluctuates, maintaining a constant supply of oxygen. Further, the blowers are not equipped with VFDs, so they operate at a 
constant speed. Therefore, the energy use of the blowers remains constant even while the amount of air reaching the basin varies.

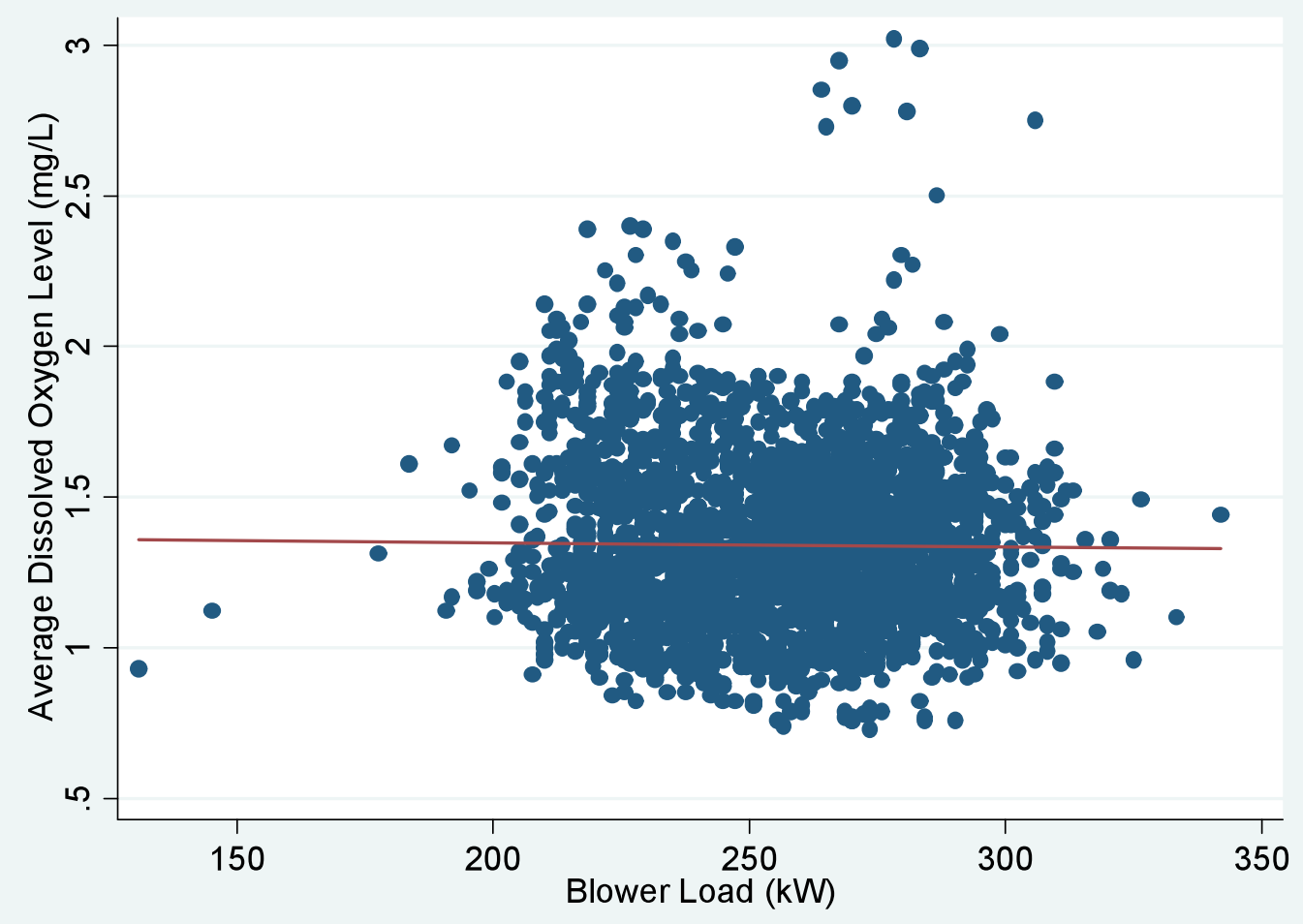

Figure 33. Blower Load and Dissolved Oxygen Correlation - Winter 


\subsection{Demand Response Tests Results}

This section describes the results of manual demand response tests that were conducted on key facility equipment. The tests occurred mostly during the 100 day submetering period, but a few tests were conducted prior to the metering period. Energy-intensive equipment including effluent pumps, centrifuges, and blowers were each shutdown during normal facility operations for periods ranging from only a few hours to several days in the case of the centrifuges.

\subsection{Facility Demand Reduction Results}

Figure 34 shows the facility load reduction from manual demand response which occurred on May 21, 2009, before the start of the submetering period and the installation of cogeneration. This load reduction is from the shutdown of facility equipment including two effluent pumps during normal facility operation and therefore represents the facility-level impact from implementing several demand response strategies at once. The San Luis Rey facility was able to reduce facility demand by an average of $540 \mathrm{~kW}$, or 30 percent of total facility load.

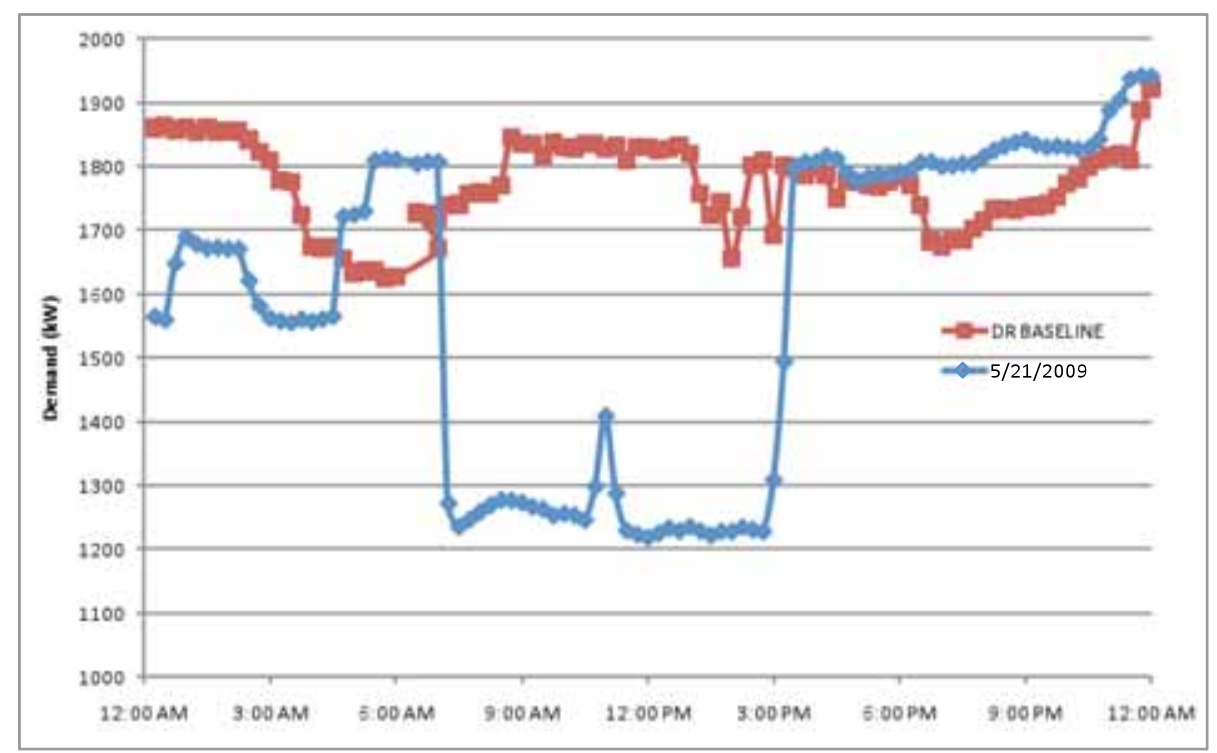

Figure 34. Load Reduction at San Luis Rey During Normal Facility Operation

During the 100 day submetering period, no aggregated demand response tests such as this were conducted. Figure 34 represents the demand reduction that would likely result from implementing multiple demand response strategies during a single demand response event.

The following section disaggregates the total facility results and discusses the demand reduction potential from the facility's key equipment.

\subsection{Equipment Demand Reduction Results}

This section describes the outcome of the demand response events resulting from tests on each of the key equipment. Manual demand response tests were performed over the project period on each of the three key pieces of equipment in the San Luis Rey Wastewater Treatment Plant. The results of these equipment based tests illustrate the demand response potential of the 
facility, and demonstrate the potential for demand response in other municipal wastewater treatment facilities.

\subsubsection{Pumps}

Throughout the 100 day submetering period, five manual demand response tests were conducted on the facility's three effluent pumps. As discussed in Section 3.1.1, the San Luis Rey facility typically operates two of the three effluent pumps at all times. Each demand response test involved fully turning off either one or two pumps. When the pumps are turned off, wastewater effluent flows into the effluent storage ponds which have a capacity of 10 to 15 million gallons. The collected wastewater is pumped out of the facility during off peak hours.

Table 4 and Table 5 shows the results from the five demand response tests conducted during the project period. The actual demand during the manual tests is shown compared to the average baseline demand. The baseline demand was determined similarly to the standard March 2010 baseline, which averages the three days of the last 10 with the highest peak demand (Coughlin 2008). Unlike the March 2010 baseline, which ignores weekends, the baseline used to compare pump demand reductions includes weekends because the facility pumps operate normally during weekends. The baseline does not include days on which additional demand response tests were conducted.

Table 4 shows the demand reduction results during the full 24 hour period the test occurred, and Table 5 shows the DR results during the peak period. The average demand reduction from pumps was $153 \mathrm{~kW}$, or 27 percent of pump load, during the full day of reduction, and $204 \mathrm{~kW}$, or 36 percent, reduction during the peak period. The increase in demand seen on December 7 , 2009 resulted from the facility pump load shifting to after the demand reduction period. The facility response to this demand response test is seen in Figure 36. The demand reduction results from October 14, 2009 and October 15, 2009 are large because on these days a 24 hour shutdown of the effluent pumps was conducted from 10 AM on October 14, 2009 to 10 AM on October 15, 2009. The results from December 11, 2009 are more representative, with a two hour manual test resulting in a full day load reduction of 12 percent of pump load, and a peak period load reduction of 34 percent of pump load. 
Table 4. Pump Results - Full Day Demand

\begin{tabular}{|c|c|c|c|c|}
\hline & Average Demand & $\begin{array}{c}\text { Average Baseline } \\
\text { Demand }\end{array}$ & \multicolumn{2}{|c|}{ Average Demand Reduction } \\
\hline & kW & kW & kW & $\%$ \\
\hline $\mathbf{1 0 / 1 4 / 2 0 0 9}$ & 143 & 526 & 383 & $73 \%$ \\
\hline $\mathbf{1 0 / 1 5 / 2 0 0 9}$ & 267 & 526 & 259 & $49 \%$ \\
\hline $\mathbf{1 0 / 1 9 / 2 0 0 9}$ & 428 & 589 & 162 & $27 \%$ \\
\hline $\mathbf{1 2 / 7 / 2 0 0 9}$ & 393 & 317 & -76 & $-24 \%$ \\
\hline $\mathbf{1 2 / 1 1 / 2 0 0 9}$ & 279 & 316 & 37 & $12 \%$ \\
\hline Average & 302 & 455 & 153 & $27 \%$ \\
\hline
\end{tabular}

Table 5. Pump Results - Peak Period Demand

\begin{tabular}{|c|c|c|c|c|}
\hline & Average Demand & & Average & duction \\
\hline & kW & kW & kW & $\%$ \\
\hline $10 / 14 / 2009$ & 8 & 583 & 574 & $99 \%$ \\
\hline $10 / 15 / 2009$ & 439 & 583 & 144 & $25 \%$ \\
\hline $10 / 19 / 2009$ & 357 & 616 & 259 & $42 \%$ \\
\hline $12 / 7 / 2009$ & 383 & 317 & -66 & $-21 \%$ \\
\hline $12 / 11 / 2009$ & 211 & 319 & 108 & $34 \%$ \\
\hline Average & 280 & 483 & 204 & $36 \%$ \\
\hline
\end{tabular}

Figure 35 illustrates the pump load reduction from one demand response test which occurred on December 11, 2009. This test involved shutting down all three effluent pumps for a two hour window during the peak period. During this period, the pump baseline was around $319 \mathrm{~kW}$, and shutting down all pumps resulted in a average peak load reduction of $108 \mathrm{~kW}$ over the seven hour peak period. 


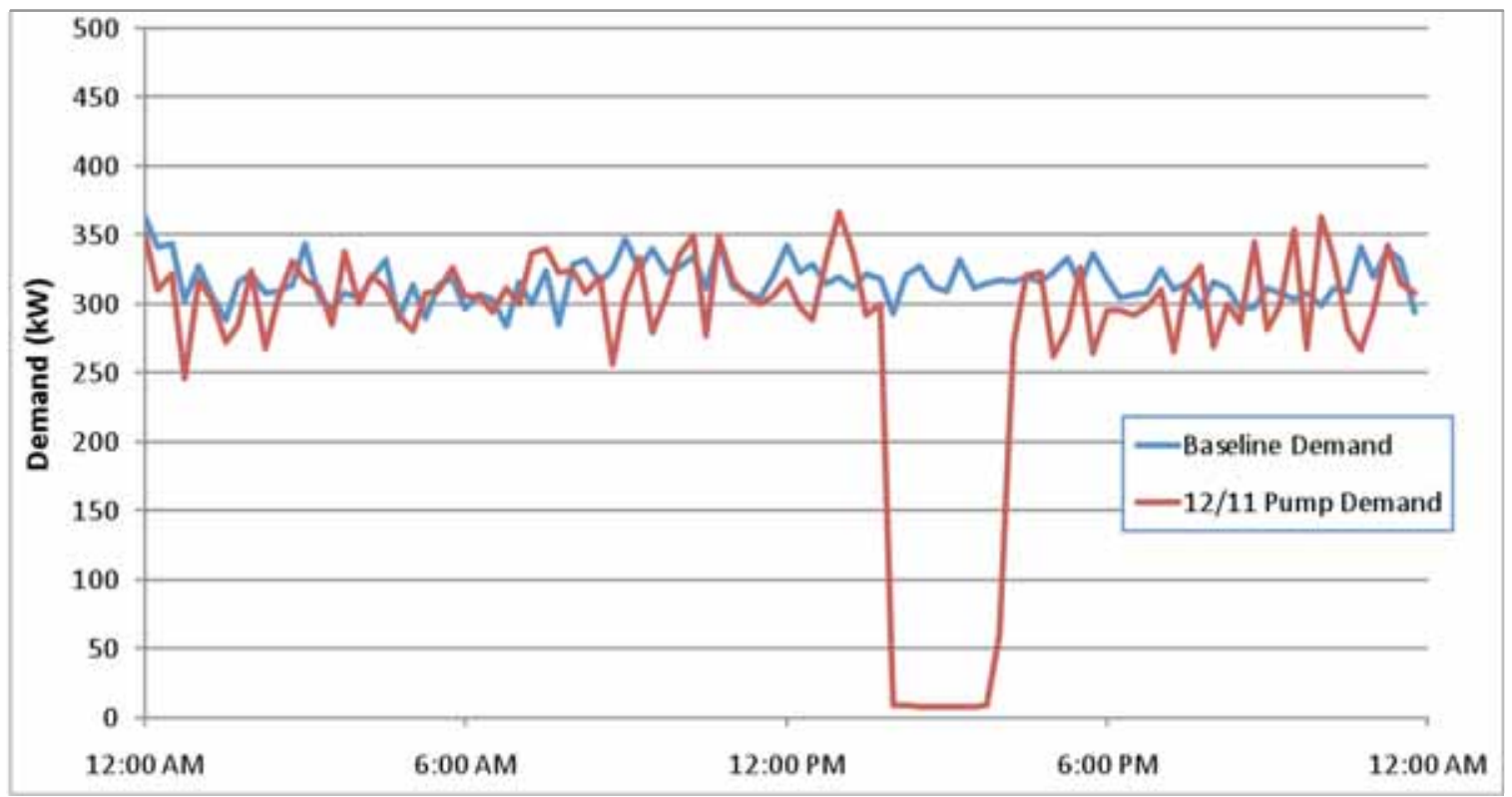

Figure 35. Pump Load Reduction

Figure 36 shows the impact of the pump load reduction on total facility demand from the demand response test which occurred on December 7, 2009. One pump was shut off during this period, but because there was a rebound in pump load lasting for several hours after the manual test, the results seen in Table 4 and Table 5 show an increase in pump demand on this day. Overall, during the peak period, this demand response test resulted in a total facility demand reduction of $75 \mathrm{~kW}$, or 6 percent, and an average full day demand decrease of $42 \mathrm{~kW}$, or 3 percent of total facility load.

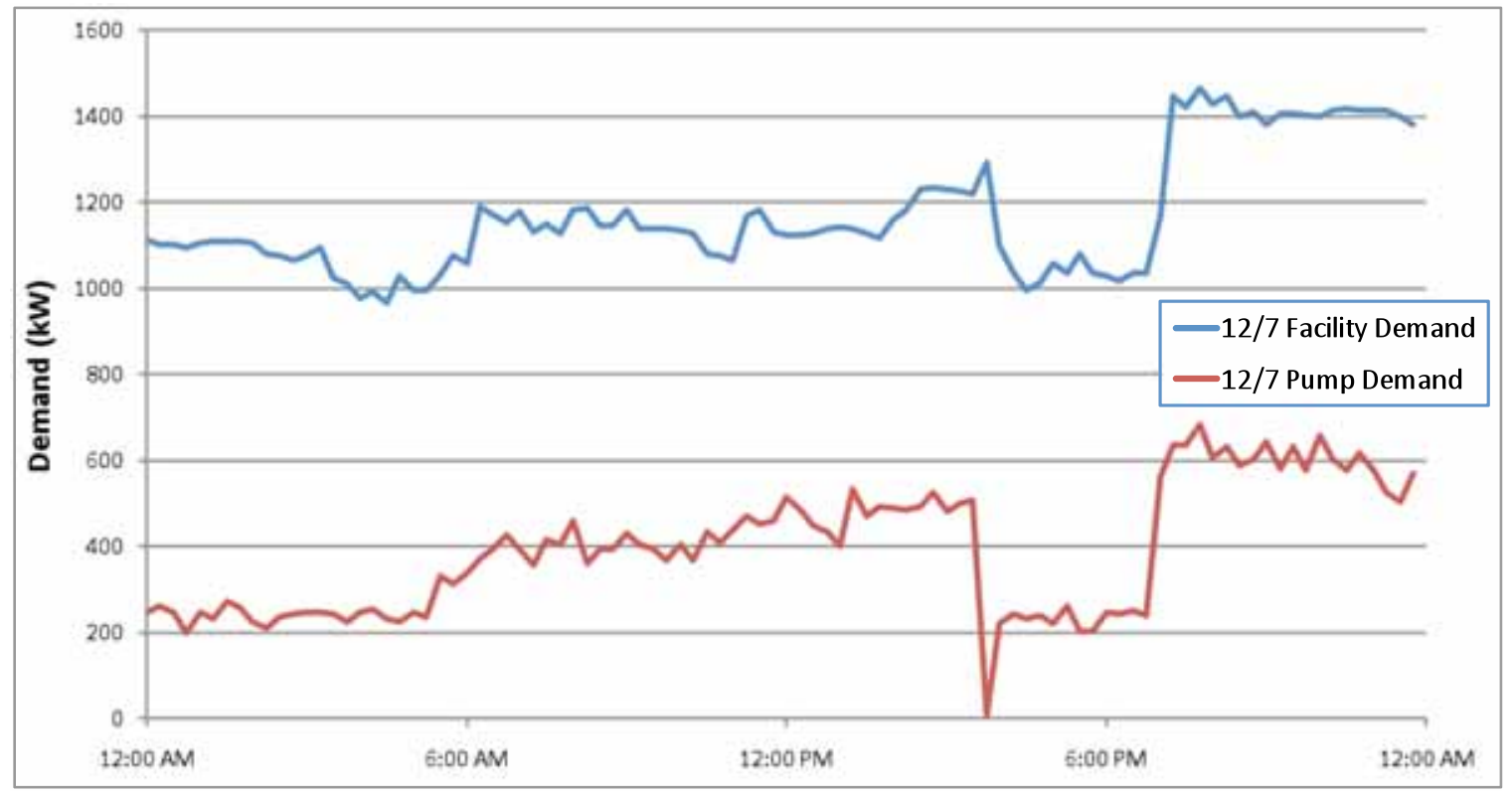

Figure 36. Facility Load Reduction from Pumps

Overall, the initial test results reveal that the San Luis Rey facility's effluent pumps can provide a great deal of load reduction during peak periods. The five manual demand response tests 
demonstrate an average peak load reduction of $202 \mathrm{~kW}$, and significant demand reductions were seen from the shutdown of one of the two operating effluent pumps during the peak period.

\subsubsection{Centrifuges}

As discussed in Section 3.1.2, the San Luis Rey Wastewater Treatment Plant's centrifuge system is operated Monday through Friday, and shut down on the weekends, because no solid waste shipments occur during the weekend. The facility only runs one of the two centrifuges at a time, and the second unit serves as emergency backup. The load reduction potential of the centrifuge system was determined through manual tests during the week, and by analyzing the load drop from the weekend shutdowns.

Table 6 shows the full day demand reduction results from 10 manual demand response tests on the facility's centrifuges during the week, and Table 7 shows the results during the peak period. The centrifuge baseline was determined in a similar fashion as the March 2010 baseline. However, since the centrifuges were ramped down on Fridays, and ramped up on Mondays, the analysis does not include Fridays or Mondays in the baseline calculation to avoid including ramping periods in the average load. The average demand reduction from centrifuges was 6 $\mathrm{kW}$, or 18 percent of centrifuge load during the full 24 hour period the load reduction occurred during. The average peak period demand reduction was $10 \mathrm{~kW}$, or 30 percent of centrifuge load. Demand reduction results from October 27, 2009 and January 13, 2010 appear small because the short duration of the demand reduction was averaged into the seven hour peak period. Peak period demand reduction on December 3, 2009 is also low because most of the test occurred outside of peak period, but a 20 percent full day demand reduction was measured on this day. 
Table 6. Centrifuge Results - Full Day Demand, Weekday Tests

\begin{tabular}{|c|c|c|c|c|}
\hline & Average Demand & Average Baseline Demand & \multicolumn{2}{c|}{ Average Demand Reduction } \\
\cline { 2 - 5 } & $\mathbf{k W}$ & $\mathbf{k W}$ & $\mathbf{k W}$ & $\%$ \\
\hline $\mathbf{1 0 / 2 7 / 2 0 0 9}$ & 38 & 41 & 3 & $7 \%$ \\
\hline $\mathbf{1 1 / 9 / 2 0 0 9}$ & 36 & 41 & 5 & $11 \%$ \\
\hline $\mathbf{1 1 / 2 0 / 2 0 0 9}$ & 31 & 40 & 10 & $24 \%$ \\
\hline $\mathbf{1 1 / 2 4 / 2 0 0 9}$ & 27 & 35 & 8 & $22 \%$ \\
\hline $\mathbf{1 2 / 3 / 2 0 0 9}$ & 29 & 36 & 7 & $20 \%$ \\
\hline $\mathbf{1 2 / 9 / 2 0 0 9}$ & 29 & 36 & 7 & $19 \%$ \\
\hline $\mathbf{1 2 / 1 6 / 2 0 0 9}$ & 24 & 33 & 9 & $27 \%$ \\
\hline $\mathbf{1 2 / 2 3 / 2 0 0 9}$ & 24 & 32 & 8 & $25 \%$ \\
\hline $\mathbf{1 2 / 3 0 / 2 0 0 9}$ & 24 & 32 & 7 & $23 \%$ \\
\hline $\mathbf{1 / 1 3 / 2 0 1 0}$ & 32 & 32 & 1 & $2 \%$ \\
\hline Average & 30 & 36 & 6 & $18 \%$ \\
\hline
\end{tabular}

Table 7. Centrifuge Results - Peak Period Demand, Weekday Tests

\begin{tabular}{|c|c|c|c|c|}
\hline & Average Demand & Average Baseline Demand & \multicolumn{2}{c|}{ Average Demand Reduction } \\
\cline { 2 - 5 } & $\mathbf{k W}$ & $\mathbf{k W}$ & $\mathbf{k W}$ & $\%$ \\
\hline $\mathbf{1 0 / 2 7 / 2 0 0 9}$ & 35 & 40 & 5 & $13 \%$ \\
\hline $\mathbf{1 1 / 9 / 2 0 0 9 ^ { \star }}$ & 42 & 40 & -2 & $-5 \%$ \\
\hline $\mathbf{1 1 / 2 0 / 2 0 0 9}$ & 30 & 39 & 9 & $23 \%$ \\
\hline $\mathbf{1 1 / 2 4 / 2 0 0 9}$ & 24 & 34 & 10 & $28 \%$ \\
\hline $\mathbf{1 2 / 3 / 2 0 0 9}$ & 32 & 36 & 4 & $11 \%$ \\
\hline $\mathbf{1 2 / 9 / 2 0 0 9}$ & 23 & 36 & 13 & $36 \%$ \\
\hline $\mathbf{1 2 / 1 6 / 2 0 0 9}$ & 14 & 33 & 20 & $59 \%$ \\
\hline $\mathbf{1 2 / 2 3 / 2 0 0 9}$ & 18 & 33 & 15 & $46 \%$ \\
\hline $\mathbf{1 2 / 3 0 / 2 0 0 9}$ & 10 & 32 & 22 & $68 \%$ \\
\hline $\mathbf{1 / 1 3 / 2 0 1 0}$ & 27 & 33 & 6 & $20 \%$ \\
\hline Average & 25 & 35 & 10 & $30 \%$ \\
\hline
\end{tabular}

*The demand response test on November 9, 2009 was conducted outside of the peak hours of $11 \mathrm{am}$ to $6 \mathrm{pm}$, so a full day demand reduction of $5 \mathrm{~kW}$ was seen, but peak period load increased $2 \mathrm{~kW}$.

Figure 37 shows the results of the weekday demand response tests on the centrifuges. Both motors were shut down for five hours on December 30,2009, resulting in a peak period load reduction of $22 \mathrm{~kW}$, or 68 percent, and a full day load reduction of $7 \mathrm{~kW}$, or 23 percent of centrifuge load. 


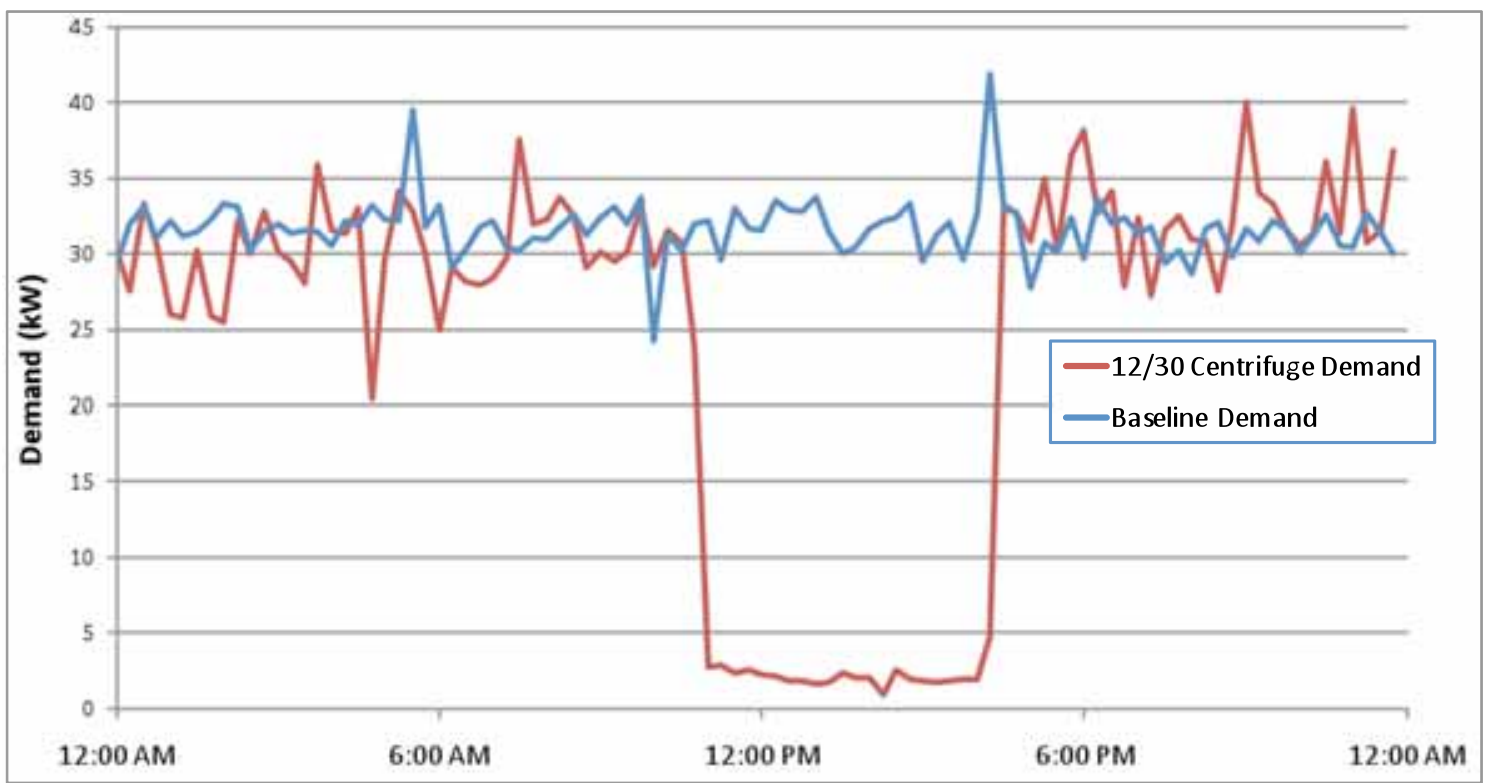

Figure 37. Centrifuge Load Reduction, Weekday

In addition to the manual demand response tests that occurred during the week, the facility load reduction potential was also analyzed based on the weekend shutdowns of the centrifuge system.

Table 8 shows the results from four weekend shutdown periods during which both centrifuges were shut down. The centrifuge load baseline was determined by averaging the full day demand during normal facility operation when one of the centrifuges is typically operating. The average demand reduction from the centrifuges was $40 \mathrm{~kW}$, or 96 percent of the centrifuge load.

Table 8. Centrifuge Results - Full Day Demand, Weekend Tests

\begin{tabular}{|c|c|c|c|c|}
\hline & \multirow{2}{*}{$\begin{array}{c}\text { Average Demand } \\
\text { kW }\end{array}$} & \multirow{2}{*}{$\begin{array}{c}\text { Average } \\
\text { Baseline } \\
\text { Demand } \\
\text { kW }\end{array}$} & \multicolumn{2}{|c|}{ Average Demand Reduction } \\
\hline & & & kW & $\%$ \\
\hline $10 / 17-10 / 18$ & 2 & 45 & 43 & $96 \%$ \\
\hline $10 / 24-10 / 25$ & 2 & 41 & 39 & $96 \%$ \\
\hline $10 / 31-11 / 1$ & 2 & 41 & 40 & $96 \%$ \\
\hline $11 / 7-11 / 8$ & 2 & 41 & 39 & $96 \%$ \\
\hline Average & 2 & 42 & 40 & $96 \%$ \\
\hline
\end{tabular}

Figure 38 shows the submetered data of the centrifuge demand over five days. The centrifuge load from October 15, 2009 through October 20, 2009 depicts the weekend shutdown, starting at 12 PM on Friday, October 16, 2009 through 12 PM on Monday, October 19, 2009. The figure clearly depicts the average load reduction potential of $40 \mathrm{~kW}$, met weekly without affecting the plant's ability to meet wastewater discharge regulations. 


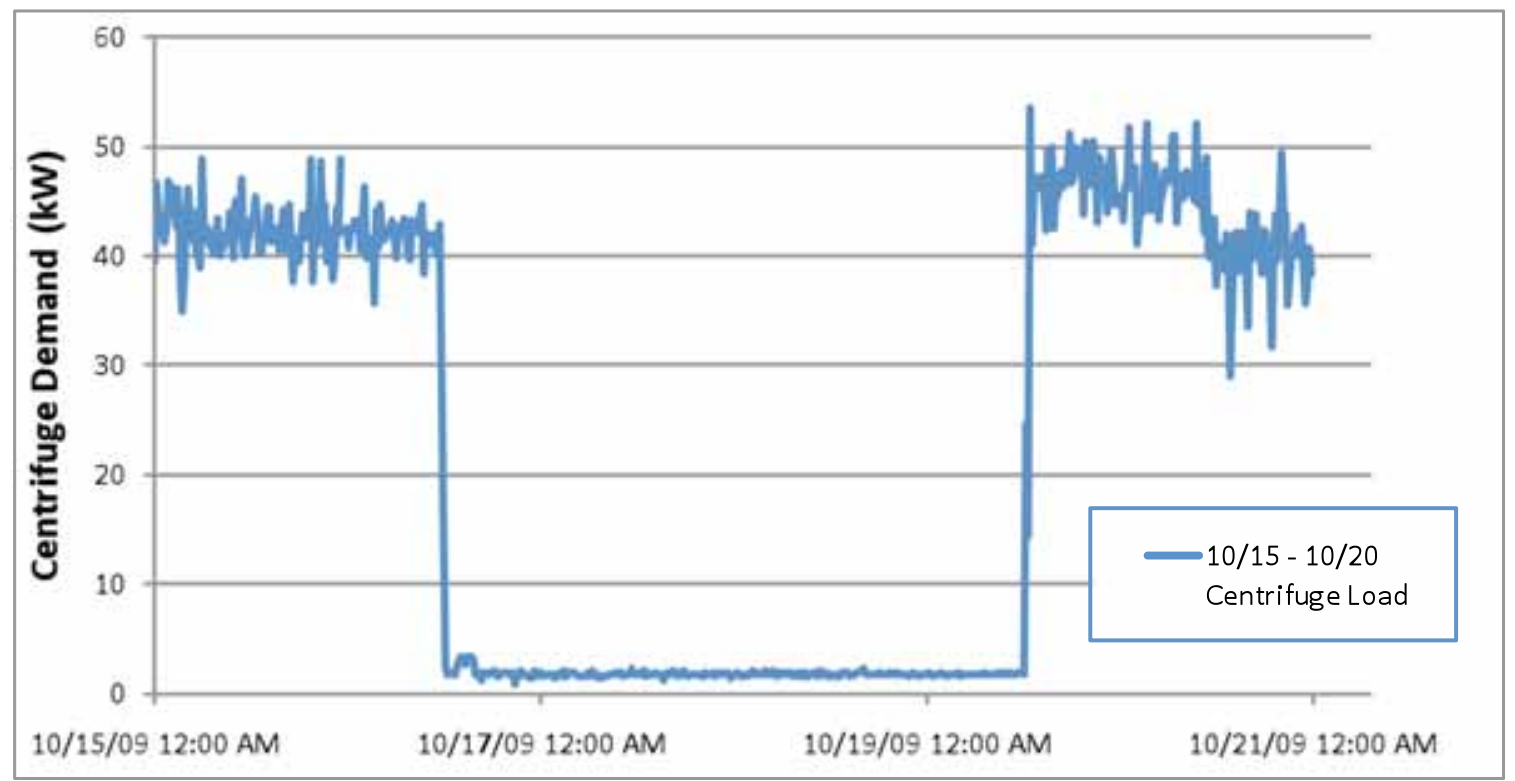

Figure 38. Centrifuge Load Reduction, Weekend

While the weekday centrifuge load reduction potential appears to be significantly lower than the full weekend shutdowns, the weekday demand response tests occurred for only a short (2-6) hour period. This short load reduction of nearly $40 \mathrm{~kW}$ for 2-6 hours was averaged into the full 24 day demand, resulting in an average full day demand reduction of $8 \mathrm{~kW}$. However, the weekend results reveal that the facility's centrifuge system can achieve a load reduction of up to $40 \mathrm{~kW}$ without affecting facility operations.

\subsubsection{Blowers}

Two manual demand response tests were conducted on the facility's two blowers during the project period. The aeration blowers are not equipped with VFDs, so the demand response test involved fully turning off one of the blower motors. Table 9 and Table 10 show the results from the two demand response tests. The baseline demand was determined similarly to the standard March 2010 baseline. Unlike the March 2010 baseline, which does not include weekends, the baseline used to compare blower demand reductions does include weekends because the facility blowers operate on a regular schedule during weekends. The baseline does not include days on which demand response tests were conducted.

Table 9 shows the demand reduction results during the full 24 hour period during which the test occurred, and Table 10 shows the load reduction results during the peak period. During the full day period, the average demand reduction from blowers was $31 \mathrm{~kW}$, or 12 percent of blower load. During the peak period, the average demand reduction was $78 \mathrm{~kW}$, or 31 percent of blower load. 
Table 9. Blower Results - Full Day Demand

\begin{tabular}{|c|c|c|c|c|}
\hline & Average Demand & $\begin{array}{c}\text { Average } \\
\text { Baseline } \\
\text { Demand }\end{array}$ & \multicolumn{2}{|c|}{ Average Demand Reduction } \\
\cline { 2 - 5 } & $\mathbf{k W}$ & $\mathbf{k W}$ & $\mathbf{k W}$ & $\%$ \\
\hline $\mathbf{1 0 / 7 / 2 0 0 9}$ & 228.2 & 266.5 & 38.3 & $14 \%$ \\
\hline $\mathbf{1 2 / 1 0 / 2 0 0 9}$ & 234.8 & 258.4 & 23.7 & $9 \%$ \\
\hline Average & 231.5 & 262.5 & 31.0 & $12 \%$ \\
\hline
\end{tabular}

Table 10. Blower Results - Peak Period Demand

\begin{tabular}{|c|c|c|c|c|}
\hline & Average Demand & $\begin{array}{l}\text { Average } \\
\text { Baseline } \\
\text { Demand }\end{array}$ & \multicolumn{2}{|c|}{ Average Demand Reduction } \\
\cline { 2 - 5 } & $\mathbf{k W}$ & $\mathbf{k W}$ & $\mathbf{k W}$ & $\%$ \\
\hline $\mathbf{1 0 / 7 / 2 0 0 9}$ & 171.8 & 259.4 & 87.6 & $34 \%$ \\
\hline $\mathbf{1 2 / 1 0 / 2 0 0 9}$ & 182.1 & 251.2 & 69.0 & $27 \%$ \\
\hline Average & 177.0 & 255.3 & 78.3 & $31 \%$ \\
\hline
\end{tabular}

Figure 39 shows the blower load reduction from one demand response test which occurred on December 10, 2009. This test involved shutting down both blower motors for a two hour window during the peak period. During the peak period, the blower load reduction was an average of $69 \mathrm{~kW}$ during the peak period. Figure 40 shows the impact of the blower load reduction on total facility demand from this demand response test.

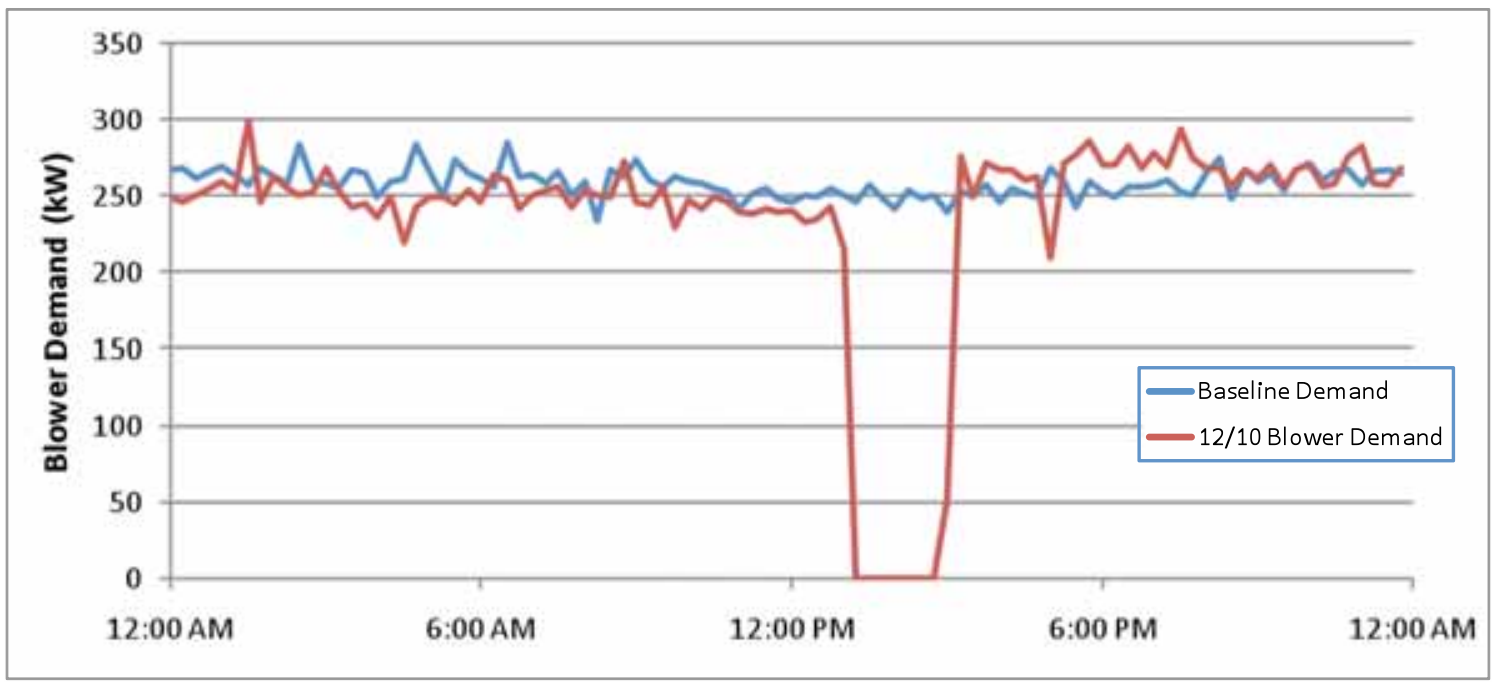

Figure 39. Blower Load Reduction 


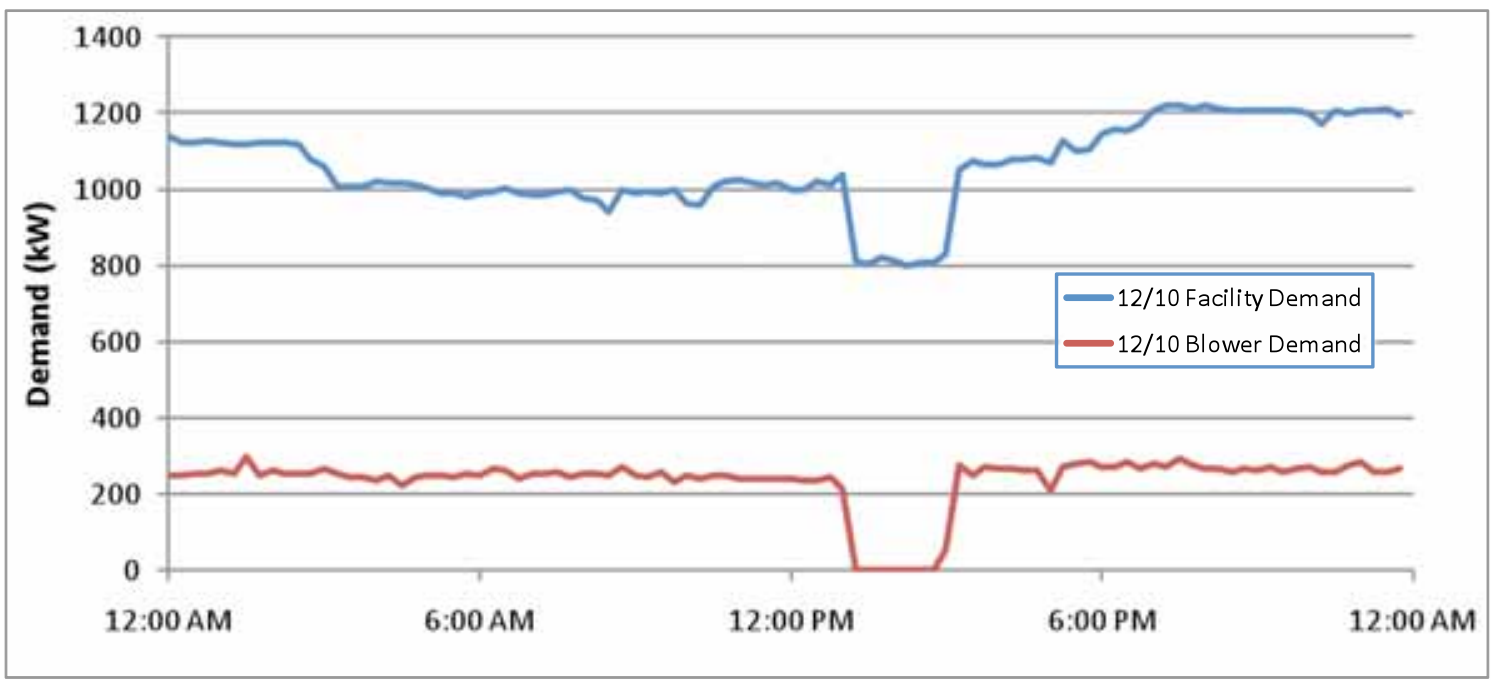

Figure 40. Facility Load Reduction from Blowers

While the manual demand response tests indicate that the San Luis Rey facility's blowers may have the potential for significant load reduction during the peak period, discussions with the facility revealed that the blower tests negatively impacted key facility parameters. The impact of these tests on plant operations is further discussed in the following section.

\subsection{Discussion of Demand Response Tests}

The results of most of the manual demand response tests revealed that the San Luis Rey Wastewater Treatment Plant was able to reduce a significant amount of its electricity demand for a short period during normal facility operations, indicating that it has excellent potential as a candidate for OpenADR. This conclusion is likely applicable to other similar municipal wastewater treatment facilities.

\subsubsection{Facility Response to Demand Response Tests on Blowers}

Figure 41 shows the dissolved oxygen response to the load reduction in facility blowers during the test on October 7, 2009. The San Luis Rey Wastewater Treatment Plant shut down the two blowers for a two hour period during this test. As seen in Figure 41, DO levels dropped from 2.0 to nearly $0.0 \mathrm{mg} / \mathrm{L}$ for a two hour period, and quickly rebounded when the blowers came back online. Average DO levels lagged slightly behind the blower load, falling shortly after the blower load was shut down, and similarly rebounding shortly after the blower load was turned on. This demand response test resulted in a $95.6 \mathrm{~kW}$ peak period demand reduction from the blower load. 


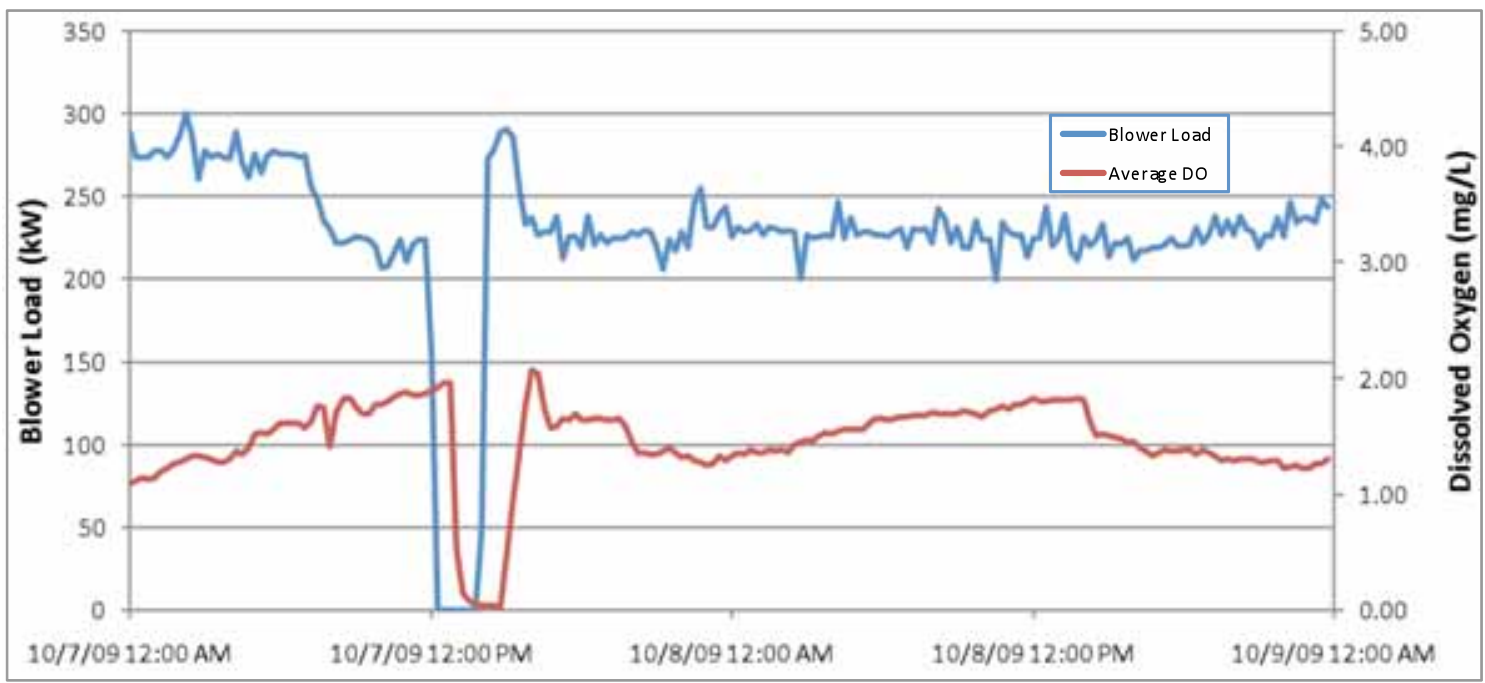

Figure 41. Dissolved Oxygen Response to Blower Demand Response Test October 7, 2009

However, the facility manager reported significant problems with the manual demand response tests on the two blowers. The facility manager noted that 24 hours after this test occurred that there was a sharp peak in secondary effluent turbidity (lasting about 5 hours), indicating that the total solids in the system were high. He stated that if this level of turbidity was above the turbidity limit of 10 NTU and were to have lasted for more than eight hours, the plant would have violated its EPA permit.

Figure 42 shows the turbidity change resulting from the demand response test on facility blowers. During the blower demand response tests, measured turbidity rose to just below regulatory levels, but was still considered safe. Turbidity measures the amount of solids present in the wastewater effluent. The normal range of turbidity is between 1 and 2 NTU.

During the manual demand response test on facility blowers, Plant 1 operated between 1 and 3 NTU, which is well within the regulatory limits, but Plant 2 operated near 10 NTU. As stated above, the plant's permit does not allow operations above 10 NTU for more than eight hours. 


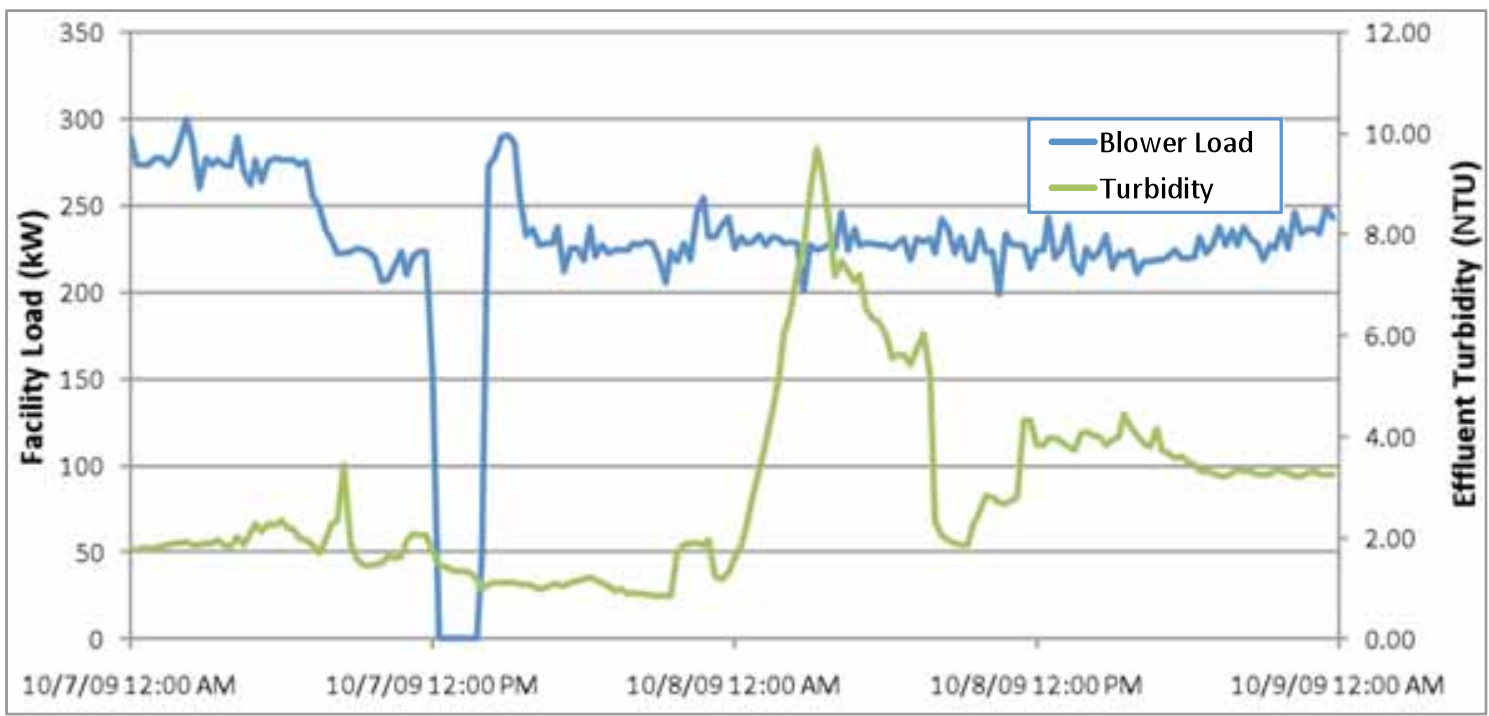

Figure 42. Turbidity Response to Blower Demand Response Test - October 7, 2009

This significant degradation of effluent quality in response to the manual demand response tests on facility blowers was unexpected. The demand response tests occurred around 1 PM, and the turbidity response did not start until 12 AM the following night. One additional blower test was conducted to confirm these unexpected results. Figure 43 shows the DO reduction resulting from the second blower demand response test, conducted on December 10, 2009. DO levels dropped from 1.5 to nearly $0.0 \mathrm{mg} / \mathrm{L}$ for a two hour period, and quickly rebounded when the blowers came back online. This demand response test resulted in a $78.8 \mathrm{~kW}$ peak period demand reduction from blower load and a $161 \mathrm{~kW}$ peak period demand reduction at the facility. 


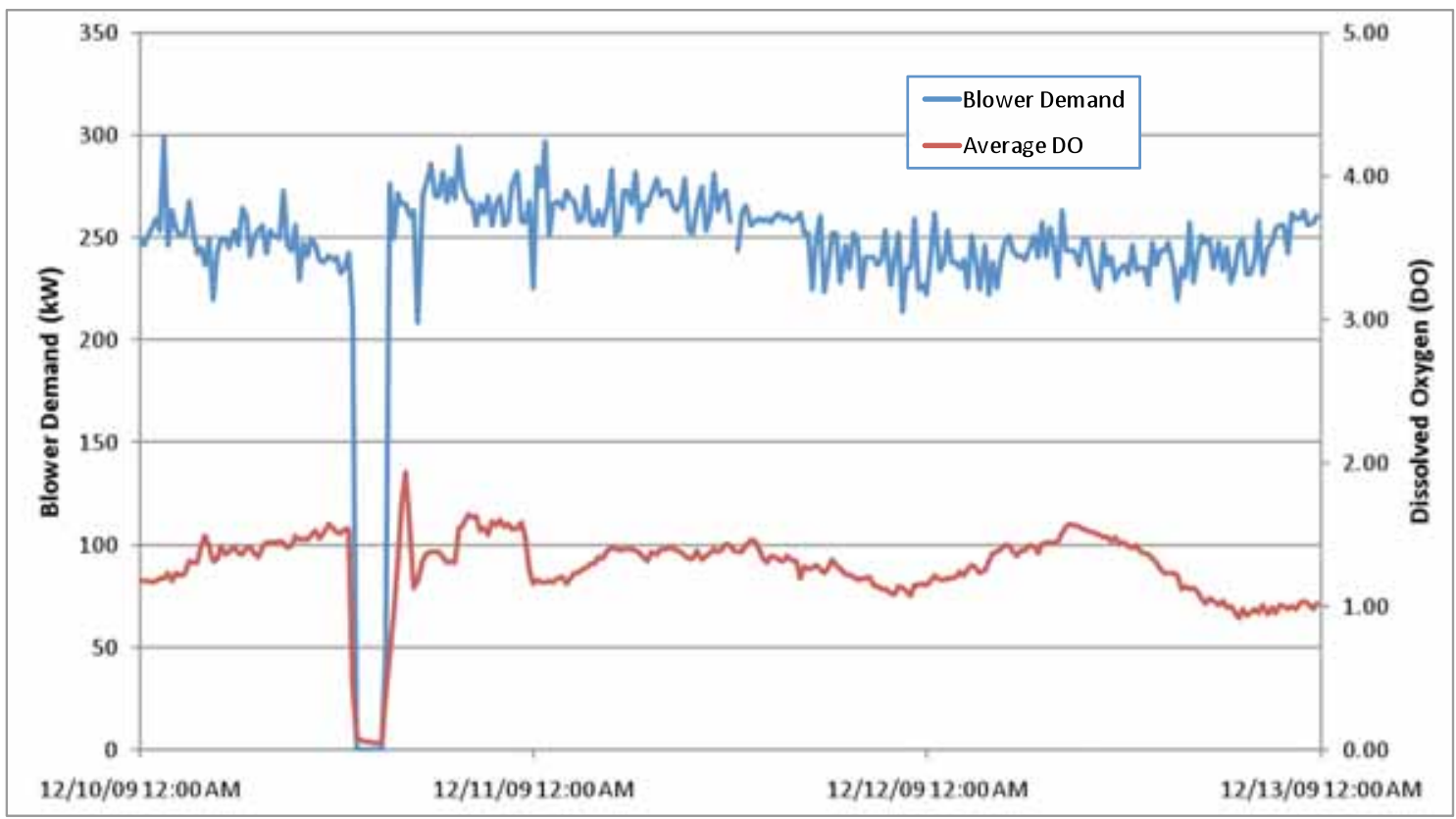

Figure 43. Dissolved Oxygen Response to Blower Demand Response Test December 10, 2009

However, just as in the previous demand response test on blowers, effluent turbidity sharply spiked almost 24 hours after the blowers were shut down. The same pattern of sharp turbidity increase lasted for 45 minutes. This confirmed that impacting the facility blowers for OpenADR is not an appropriate strategy for the San Luis Rey facility. The facility indicated that they would not consider this demand response strategy as a means to reduce facility load. 


\subsection{Conclusions}

The San Luis Rey Wastewater Treatment Plant study has confirmed that municipal wastewater treatment facilities are excellent candidates for open automated demand response. These facilities are highly energy-intensive and key equipment such as pumps and centrifuges can be targeted for large load reductions. Advanced controls such as SCADA systems may prepare facilities to be more receptive to open automated demand response due to access to real-time data and offering the degree of control integration required for the implementation of OpenADR.

\subsection{Demand Response Findings at the San Luis Rey Facility}

The analysis found that the effluent pump load at the facility remains constant at $300 \mathrm{~kW}$ during normal facility operations. The centrifuge load also was steady at $40 \mathrm{~kW}$ during operation, but this equipment was shut down over the weekends. The aeration blower load typically varies between 200 and $300 \mathrm{~kW}$. Further, this study found no correlation between the influent flow to the facility and the average dissolved oxygen levels measured in the wastewater. A slight correlation was seen between the outdoor air temperature and dissolved oxygen levels. Lastly, a small correlation was seen between influent flow and outdoor temperature.

Demand response tests on the effluent pumps at the San Luis Rey facility revealed the potential for a $204 \mathrm{~kW}$ (36 percent of pump load) peak period load reduction, and a $300 \mathrm{~kW}$ load reduction for the entire duration of the test. Tests on centrifuges revealed a peak period load reduction of $10 \mathrm{~kW}$ (30 percent of centrifuge load), and a $40 \mathrm{~kW}$ load reduction for the entire duration of the demand response test. While the demand response tests on facility blowers resulted in a short-lived turbidity increase, peak period load reductions of $78 \mathrm{~kW}$ (31 percent of blower load) were seen during these tests.

\subsection{Limitations in Wastewater Treatment Facilities}

The manual demand response tests conducted during the 100 day submetering period revealed that demand response strategies for aeration blowers may result in sharp, short-lived increases in turbidity in municipal facilities. Two demand response tests conducted on the facility blowers resulted in sharp spikes in effluent turbidity 12-24 hours after the test was conducted. This research determined that fully shutting down the blowers may not be a feasible demand response strategy for municipal wastewater treatment facilities.

Further, this research discovered that the cogeneration capabilities at the San Luis Rey facility severely limited the plant's demand response potential. The facility supplies all the digester gas that occurs as a byproduct of anaerobic digestion to CalPower, and must consume all the electricity from cogeneration on that meter, always having a positive draw from the utility. Because the facility's cogeneration capacity is so large, the San Luis Rey facility may have few options for demand response, especially as the site continues to become more and more energy efficient. This problem is likely similar to many municipal wastewater treatment facilities with cogeneration capabilities. Unless the power purchasing agreements allow for the utility to purchase excess power from the cogeneration units, there are very little incentives for these facilities to participate in demand response programs. 


\subsection{Potential for Demand Response in Wastewater Treatment Facilities}

This research also revealed several opportunities for demand response in municipal wastewater treatment facilities. The equipment with the most demand response potential was the facility's effluent pumps. Wastewater was easily diverted to the facility's effluent storage ponds which have a capacity of 10 to 15 million gallons, more than the facility processes in an entire day. Pumping treated effluent to the ocean was simply shifted to off-peak hours, and reductions up to $300 \mathrm{~kW}$ were experienced throughout the duration of the demand response test. While significant demand response potential was identified in the plant, the facility manager stated that the incentives offered for demand response were not high enough to cover the increased energy usage occurring as a rebound after a demand response test.

The degradation in effluent quality due to the blower shutdowns underscores the potential for installing variable frequency devices (VFD) on key equipment at the San Luis Rey Wastewater Treatment Plant. For example, installing a VFD on the blower motors would allow the facility to lower aeration blower load from 100 percent to a lower fraction, delivering the required amount of oxygen into the aeration basins to maintain effluent quality while reducing facility load. PLCs or the SCADA system could monitor turbidity and control the aeration load to ensure facility operations remain within regulated safety limits. However, the potential for energy efficiency opportunities at the San Luis Rey facility is limited by lack of capital to install VFDs on large motors.

In conclusion, municipal wastewater treatment energy demand in California is high, and energy-intensive equipment offer significant potential for open automated demand response. In particular, large load reductions can be seen by targeting effluent pumps and centrifuges. Limiting factors to participation in demand response programs are the reaction of effluent turbidity to reduced aeration load, along with the cogeneration capabilities of municipal facilities, including existing power purchase agreements and utility receptiveness to purchasing electricity from cogeneration facilities. 


\subsection{References}

California Energy Commission (2005). California's Water-Energy Relationship.

Communication Technologies Inc. (2004). "Supervisory Control and Data Acquisition (SCADA) Systems." NCS Technical Information Bulletin 04-1.

Consortium for Energy Efficiency (2006). National Municipal Water and Wastewater Facility Initiative.

Coughlin, K., Mary Ann Piette, Charles Goldman and Sila Kiliccote (2008). Estimating Demand Response Load Impacts: Evaluation of Baseline Load Models for Non-Residential Buildings in California, Demand Response Research Center. Ernest Orlando Lawrence Berkeley National Laboratory. LBNL - 63728.

Department of Environmental Protection Bureau of Land \& Water Quality (2002). "Energy Conservation in Wastewater Treatment Facilities." Operation \& Maintenance Newsletter.

Energy Conservation Task Force of the Water Environment Federation (1997). Energy Conservation in Wastewater Treatment Facilities. WEF Manual of Practice No. FD-2.

Environmental Protection Agency (2002). Federal Water Pollution Control Act: 108.

Environmental Protection Agency (2004). Technical Development Document for the Final Effluent Limitations Guidelines and Standards for the Meat and Poultry Products Point Source Category (40 CFR 432).

Environmental Protection Agency (2008). Ensuring a Sustainable Future: An Energy Management Guidebook. Office of Wastewater Management.

Flex your Power. (2008). "Demand Response Programs." Retrieved 10/10/2008, from http:/ / www.fypower.org/flexalert/demand resp faq.html.

Fuller, J. (2003). Energy Efficient Alternative for the Fortuna Wastewater Treatment Facility, The Community Clean Water Institute.

Global Energy Partners LLC (2007). Enhancing Digester Operation.

Kogge, P. M. (2008). Central Processing Unit. Microsoft Encarta Online Encyclopedia

LBNL (2008). Load Variability Derivation Tool Berkeley, CA, Demand Response Research Center.

Massachusetts Water Resources Authority (2007). Deer Island Treatment Plant Performance.

Metcalf \& Eddy Inc. (2003). Wastewater Engineering, Treatment and Reuse, McGraw-Hill.

Mines, R. (2009). Virtual Tour of Municipal Wastewater Treatment Plant (WWTP), Mercer University.

Natural Resources Defense Council (2004). Energy Down the Drain: The Hidden Costs of California Energy, Pacific Institute. 
New Mexico Environment Department. (2007). "Chapter 3: Plant Pretreatment." Retrieved 03/04/2010, from http:/ / www.nmenv.state.nm.us/swqb/fot/WastewaterStudyManual/03.pdf.

North Dakota Department of Health. (2005). "Total Suspended Solids." Retrieved July 11, 2008, from http:/ / www.health.state.nd.us/wq/sw/Z6_WQ_Standards/WQ_TSS.htm.

Pacific Gas and Electric Company. (2008). "What is Demand Response?" Retrieved 10/10/2008, from

http://www.pge.com/mybusiness/energysavingsrebates/demandresponse/whatisde mandresponse/.

Piette, M. A., G.Ghatikar, S. Kiliccote, E. Koch, D. Hennage, P. Palensky, and C. McParland, (2009). Open Automated Demand Response Communications Specification (Version 1.0), California Energy Commission, PIER Program CEC-500-2009-063.

Weather Underground Inc. (2010). "Weather Underground." Retrieved 09/01/2010, from http://www.wunderground.com/. 


\subsection{Glossary}

\begin{tabular}{|c|c|}
\hline ADR & Automated Demand Response \\
\hline BOD & Biological Oxygen Demand \\
\hline CEC & California Energy Commission \\
\hline COD & Chemical Oxygen Demand \\
\hline DCS & Distributed Control Systems \\
\hline DO & Dissolved Oxygen \\
\hline DR & Demand Response \\
\hline DRRC & Demand Response Research Center \\
\hline EPA & Environmental Protection Agency \\
\hline GWh & Gigawatt Hour \\
\hline HMI & Human Machine Interface \\
\hline $\mathrm{I} / \mathrm{O}$ & Input/ Output \\
\hline kW & Kilowatt \\
\hline kWh & Kilowatt Hour \\
\hline LBNL & Lawrence Berkeley National Laboratory \\
\hline mg & milligrams \\
\hline MTU & Master Terminal Units \\
\hline MW & Megawatt \\
\hline NPDES & National Pollutant Discharge Elimination System \\
\hline NTU & Nephelometric Turbidity Units \\
\hline OpenADR & Open Automated Demand Response \\
\hline PG\&E & Pacific Gas and Electric \\
\hline PID & Proportional Integral Derivatives \\
\hline PIER & Public Interest Energy Research \\
\hline PLC & Programmable Logic Controllers \\
\hline PPA & Purchase Power Agreement \\
\hline R\&D & Research and Development \\
\hline RTU & Remote Terminal Units \\
\hline SCADA & Supervisory Control and Data Acquisition \\
\hline SDG\&E & San Diego Gas and Electric \\
\hline TOU & Time of use \\
\hline TSS & Total Suspended Solids \\
\hline US & United States \\
\hline VFD & Variable Frequency Drive \\
\hline
\end{tabular}


